\title{
Listado de especies y clave de géneros y subgéneros de escarabajos estercoleros (Coleoptera: Scarabaeidae: Scarabaeinae) presentes y presuntos para Ecuador
}

\author{
Checklist with a key to genera and subgenera of dung beetles (Coleoptera: Scarabaeidae: Scarabaeinae) \\ present and supposed for Ecuador
}

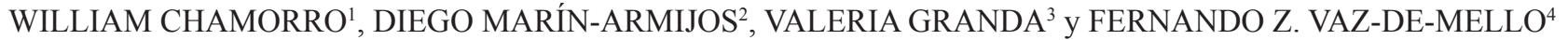

\begin{abstract}
Resumen: Los escarabajos de la subfamilia Scarabaeinae (Coleoptera: Scarabaeidae) son un grupo importante utilizado en estudios de taxonomía, ecología, biodiversidad, conservación e historia natural, por ser buenos indicadores de la calidad del hábitat y ricos en géneros y especies. Su taxonomía es relativamente bien conocida; sin embargo, comúnmente se registran nuevos taxones y cambios nomenclaturales, principalmente por revisiones a nivel de género. Actualmente, en el neotrópico se han registrado 127 taxones (entre géneros y subgéneros), de los cuales 59 taxones pertenecientes a 33 géneros y 220 especies (con 22 nuevos registros) se reconocen en Ecuador y otros nueve géneros podrían llegar a ser registrados. Con el objetivo de fomentar el estudio y el conocimiento de este grupo en Ecuador, en este trabajo se presenta una clave de identificación de géneros y subgéneros presentes y/o presuntos para el país, la cual incluye taxones actuales según nuevas publicaciones para el neotrópico de Scarabaeinae.
\end{abstract}

Palabras clave: Escarabajos copronecrófagos, distribución geográfica, taxonomía y sistemática, región neotropical.

\begin{abstract}
The beetles of the Subfamily Scarabaeinae are a group that have been used in taxonomic, ecological, natural history, biodiversity and conservation studies recently, as they are good indicators of habitat quality and due to their great genera and species richness. Their taxonomy is relatively well known, however new taxa and nomenclatural changes are frequently ocurring, mainly due to taxonomic revisions at the genus level. Currently in the Neotropics, 127 taxa (between genera and subgenera) are recorded, with 59 taxa belonging to 33 genera and 220 species (with 23 new records) present in Ecuador, and nine more genera that allegedly could be registered. With the aim of promoting the study and knowledge of this group in Ecuador, an identification key for the genera and subgenera present and/ or supposed to be present in this country is provided in this work, which includes current taxa from Scarabaeinae (Coleoptera: Scarabaeidae) for the neotropic.
\end{abstract}

Key words: Copro-necrophagous beetles, geographical distribution, taxonomy and systematics, Neotropical region.

\section{Introducción}

Ecuador está ubicado al norte de Sudamérica sobre la línea ecuatorial, con un área de $283.561 \mathrm{~km}^{2}$, dividido geográficamente en cuatro regiones naturales: costa o pacífica, andina o región de la sierra, amazónica o región oriental y región insular o islas Galápagos. Administrativamente, el territorio ecuatoriano está dividido en 24 provincias y con respecto a sus biomas presenta 91 tipos de ecosistemas naturales con formaciones vegetales tales como: bosques de tierras bajas, bosques secos, bosques premontanos, bosques nublados, bosques altoandinos, áreas de páramo, etc. (Ministerio del Ambiente del Ecuador 2013).

Los escarabajos de la subfamilia Scarabaeinae son muy utilizados en el neotrópico, principalmente en estudios de taxonomía (Medina et al. 2001); ecología (Carpio et al. 2009; Domínguez et al. 2015), biodiversidad (Celi et al. 2004), conservación (Celi y Dávalos 2001) e historia natural (Puker et al. 2014). De acuerdo con algunos criterios mencionados por Favila y Halffter (1997) estos insectos presentan las siguientes características: ser un grupo de fácil recolecta, su método de captura representa un bajo costo económico, su identificación taxonómica está bien definida (determinación principalmente de géneros, subgéneros y especies), y se conocen su historia natural y biología, por su amplia distribución geográfica y por mostrar respuestas a cambios antrópicos en la modificación de su hábitat. Por esas características se han denominado específicamente como un buen grupo bioindicador y en el territorio ecuatoriano son muy utilizados principalmente en estudios de impacto ambiental, desarrollando planes y leyes de manejo de conservación especialmente en grandes regiones de bosques a conservar. Un ejemplo exitoso de estos monitoreos ambientales son los propuestos por Celi y Dávalos (2001) en el el Chocó biogeográfico ecuatoriano en la provincia de Esmeraldas, donde por dos años se trabajó conjuntamente en la capacitación de comunidades indigenas $\mathrm{y}$ afrodescendientes.

Según Vaz-de-Mello et al. (2011), en el neotrópico se han registrado 119 taxones, sin embargo, al 2018 este dato se ha incrementado a 127 entre géneros y subgéneros con nuevos cambios nomenclaturales detallados a continuación:

(1) un nuevo género amazónico Lobidion descrito por Génier (2010); (2) un nuevo cambio en la nomenclatura de Deltochilum (Telhyboma) Kolbe, 1893 = Deltochilum (Deltochilum) Eschscholtz, 1822, sinónimo establecido por Génier (2012); (3) un nuevo cambio en la nomenclatura para

\footnotetext{
${ }^{1}$ Investigador Asociado. Universidad Técnica Particular de Loja, Departamento de ecología, San Cayetano Alto s/n C.P. 1101 608, Loja, Ecuador, william. chamorro@gmail.com. ${ }^{2}$ Profesor. Universidad Técnica Particular de Loja, Museo de Colecciones Biológicas, Departamento de Ciencias Naturales, San Cayetano Alto s/n C.P. 1101 608, Loja, Ecuador,dsmarin@utpl.edu.ec. ${ }^{3}$ Bióloga. Investigadora Asociada. Instituto Nacional de Biodiversidad, INABIO, Pasaje Rumipamba N. 341 y Av. de los Shyris (Parque la Carolina) C.P. 17078976. Quito, Ecuador, valegranda@gmail.com. Quito, Ecuador, valegranda@gmail. com. ${ }^{4} \mathrm{Ph}$. D. Universidade Federal de Mato Grosso, Instituto de Biociências, Departamento de Biologia e Zoologia, Av. Fernando Correa da Costa, 2367, Boa Esperança, Cuiabá, Mato Grosso, 78060-900, Brasil, vazdemello@gmail.com. Autor para correspondencia: William Chamorro. Investigador Asociado. Universidad Técnica Particular de Loja, Departamento de ecología, San Cayetano Alto s/n C.P. 1101 608, Loja, Ecuador, william.chamorro@gmail.com.
} 
Tetramereia Klages, 1907, sinonimizado con el género Dendropaemon Perty, 1830, establecido por Génier y Arnaud (2016); (4) tres subgéneros restablecidos por Génier y Arnaud (2016) dentro del género Dendropaemon: D. (Enicotarsus) Laporte, 1831; D. (Eurypodea) Klages, 1906 у D. (Onthoecus) Lacordaire, 1856; (5) seis nuevos subgéneros determinados por Génier y Arnaud (2016) para el género Dendropaemon: D. (Glaphyropaemon), D. (Nigropaemon), D. (Rutilopaemon), D. (Streblopaemon), D. (Sulcopaemon) y D. (Titthopaemon); (6) para el mismo género Dendropaemon, un nuevo subgénero $D$. (Crassipaemon) (citado como nuevo nombre) publicado por Cupello y Génier (2017) en reemplazo de D. (Onthoecus) Lacordaire, 1856; (7) Cupello (2018) determina que el subgénero Eucanthidium Halffter y Martínez, 1986 es sinónimo junior del género Canthidium Erichson, 1847 y finalmente, (8) el cambio de Canthidium (Canthidium) por el nombre revalidado del subgénero Canthidium (Neocanthidium) Martínez, Halffter \& Pereira, 1964, establecido por Cupello (2018). También se conocen varias revisiones a nivel de género en donde se describen algunas especies nuevas con datos de distribución para Ecuador y se proponen algunos cambios nomenclaturales: Arnaud (2002), Canhedo (2006), Cook (1998, 2000, 2002), Cupello y Vaz-de-Mello (2013), Edmonds (1994, 2000), Edmonds y Zidek (2004, 2010, 2012), Génier (1996, 2009, 2010), Génier y Arnaud (2016), Génier y Kohlmann (2003), González et al. (2009), González-Alvarado y Vaz-deMello (2014), Halffter y Martínez (1966), Martínez y Halffter (1986), Ratcliffe y Smith (1999), Silva et al. (2015) y Vaz-deMello (2008). Por lo anteriormente expuesto, en este trabajo se propuso realizar una clave genérica y subgenérica de los escarabajos coprófagos del Ecuador, producto que servirá para paises vecinos como: Colombia, Perú y Venezuela. Además, se actualizó la nomenclatura para los escarabajos Scarabaeinae (Coleoptera: Scarabaeidae) del Nuevo Mundo y, finalmente, se presenta un listado de las especies distribuidas en Ecuador.

Con respecto al número de especies conocidas para Ecuador no se tiene un registro total. Hasta 2011 se presenta un listado de 265 especies y 37 géneros (Carvajal et al. 2011); sin embargo, este trabajo muestra un valor sobrestimado de las especies presentes en el territorio ecuatoriano (incluyendo las Islas Galápagos). En ese estudio se presentan algunos registros de especies dudosas e inválidamente citadas, por ejemplo: Copris lugubris Boheman, 1858 mencionada como registro erróneo por Peck (2005) y Eucranium cyclosoma Burmeister, 1861 especie erróneamente registrada para Ecuador, donde Ocampo (2010) señala que este es un género y especie endémica de Argentina. Si se hace un recuento de la historia a través de publicaciones se presentan los siguientes datos de escarabajos estercoleros citados para Ecuador: Gemminger y Harold (1869) con 11 registros de especies, posteriormente Gillet (1911) presentó un catálogo de distribución donde se incrementa a 30 el número de registros. Luego se destaca el trabajo de Blackwelder (1944), que recopila información de los coleópteros del neotrópico (incluyendo Antillas mayores y menores), este autor registró 82 especies y finalmente Krajcik (2012) en su "checklist" de distribución a nivel mundial sobre la superfamilia Scarabaeoidea reporta 94 especies de escarabajos estercoleros para el país. Por lo anterior, en este trabajo se presenta un listado actualizado de 220 especies pertenecientes a 33 géneros.

Además, se presenta una clave actualizada de los géneros y subgéneros presentes y presuntos para Ecuador con 103 ilustraciones de sus caracteres más relevantes. Algunos géneros como: Anisocanthon Martínez \& Pereira, 1956; Besourenga Vaz-de-Mello, 2008; Canthotrypes Paulian, 1939; Deltorhinum Harold, 1867; Diabroctis Gistel, 1857; Digitonthophagus Balthasar, 1959; Hansreia Halffter \& Martínez, 1977; Lobidion Génier, 2010; Pseudocanthon Bates, 1887 y el subgénero Coprophanaeus (Megaphanaeus) d'Olsoufieff, 1924 se presume pueden estar en las diferentes regiones del territorio ecuatoriano ya que se registran en los países vecinos de Colombia y/o Perú.

\section{Materiales y métodos}

Para la elaboración de la clave se revisaron especímenes de las siguientes colecciones: CEMT (Setor de Entomologia da Coleção Zoológica da Universidade Federal de Mato Grosso Cuiabá, Brasil. Fernando Vaz-de-Mello), MEPN (Colección Entomológica, Museo de la Escuela Politécnica Nacional. Quito, Ecuador. Vladimir Carvajal), MECN (Museo Ecuatoriano de Ciencias Naturales, Quito, Ecuador. Santiago Villamarín), MGO-UCE (Museo Laboratorio Gustavo Orces, Universidad Central del Ecuador. Quito, Ecuador. Fabiola Montenegro), MNHN (Muséum national d'Histoire nature1le. Paris, Francia. Olivier Montreuil y Antoine Mantilleri). MQCAZ. PUCE (Museo de Zoología Pontificia Universidad Católica, Quito, Ecuador. Álvaro Barragán, Carlos Carpio y Fernanda Salazar) y MUTPL (Colección Universidad Técnica Particular de Loja, Ecuador. Diego Marín).

Las distribuciones referidas en esta clave incluyen la región y en algunas ocasiones ecosistemas vegetales definidos por la propuesta del Ministerio del Ambiente del Ecuador (2013).

\section{Resultados y discusión}

De los 127 taxones de escarabajos copronecrófagos (Coleoptera: Scarabaeidae: Scarabaeinae) enlistados en el neotrópico, para Ecuador se registraron 59 taxones divididos en 33 géneros, 26 subgéneros y 220 especies (con 22 nuevos registros para el país), con la posible inclusión de ocho presuntos géneros y un subgénero. En la clave, los taxones que estan entre corchetes [ ] se presentan como taxones presuntos.

Clave para los géneros y subgéneros de Scarabaeinae (Coleoptera: Scarabaeidae) presentes y presuntos para Ecuador

1. Punta del mesoescutelo claramente visible entre la base de los élitros (Figs. 1A-D) .............................. 2

1'. Mesoescutelo completamente cubierto por los élitros .... 4

2. Cuerpo muy aplanado dorsalmente, alargado, con lados paralelos. Cabeza con dos dientes débiles (a veces ausentes) en el clípeo. Mesocoxas paralelas al eje longitudinal del cuerpo, en posición externa con relación al metaesterno (Fig. 1E). Distribución sobre todas las áreas excepto páramo ............................. Eurysternus Dalman, 1824 2'. Cuerpo poco convexo dorsalmente, forma general ovalada. Cabeza con clípeo cuadridentado, con emarginaciones laterales externas a los dientes centrales. Mesocoxas oblicuas al eje longitudinal del cuerpo (Fig. 1F).... Malagoniella Martínez, 1961....3

3. Pronoto con fina quilla basal (Fig. 1G). Distribución sobre los matorrales secos del sur hacia el pacífico

Malagoniella (Megathopomima) Martínez, 1961 
3'. Pronoto sin marginación basal. Distribución en la Amazonía baja ........ Malagoniella (Malagoniella) Martínez, 1961

4. Mesotarsos y metatarsos fuertemente aplanados (Fig. 1H), tarsómero apical con robusto proceso espiniforme sobre la inserción de las uñas (Fig. 2A); pigidio horizontal; cuerpo aplanado y alargado. Distribución en los bosques húmedos

Bdelyrus Harold, 1869

4'. Último tarsómero de los mesotarsos y metatarsos sin proceso espiniforme (Fig. 2B), o pigidio claramente vertical, o ambos

5. Pata anterior con foseta trocanto-femoral anterior situada en el borde del trocánter (no confundir con la articulación trocanto-femoral, la foseta trocanto-femoral está en el borde apical del trocánter, mientras que la articulación es posterior). (Fig. 2C) 6 5'. Pata anterior sin foseta trocanto-femoral anterior (Fig. 2D) .14

6. Último esternito abdominal expandido en su parte media, cubre todo el disco del abdomen. Los demás esternitos visibles sólo lateralmente (Fig. 2E) .......................... 7 6'. Último esternito abdominal no cubre totalmente el disco, los demás esternitos visibles y diferenciados en la parte media del abdomen

7. Pseudoepipleura abruptamente estrecha hacia su parte posterior, angulada a nivel de la metacoxa (Fig. 2F) ............. 8 7'. Pseudoepipleura gradualmente estrecha hacia el ápice, sin ángulo a nivel de la metacoxa (Fig. 2G) ................... 9

8. Élitros con interestrias no aquilladas (Fig. 2H). Sutura clípeo-genal visible y extendida hasta el borde externo de la cabeza; sutura fronto-clipeal visible, al menos a los lados del borde externo de la cabeza. Borde clípeo-genal con una incisión que parece separar en forma redondeada el clípeo y la gena. Distribución sobre la Amazonía baja

Eutrichillum Martínez, 1969 8'. Élitros con interestrias aquilladas (en la única especie conocida que puede estar presente en Ecuador). Suturas clípeogenal y clípeo-frontal no visibles, borde clípeo-genal recto a levemente sinuoso (Figs. 3A-B). Podría estar en el sureste amazónico ecuatoriano

[Besourenga Vaz-de-Mello, 2008]

9. Mesotibia abruptamente expandida hacia el ápice, con un fuerte diente latero-ventral y sedas apicales escasas. (Fig. 3C). Distribución sobre la costa y bosques secos andinos Onoreidium Vaz-de-Mello, 2008 9'. Mesotibia gradualmente expandida hacia el ápice, región ápico-lateral cubierta por cepillo de sedas anchas (Fig. 3D)

10. Cabeza plana o ligera y regularmente convexa, sin concavidades evidentes al lado de los ojos. Borde lateral del clípeo recto o curvado levemente hacia afuera; gena no sobresale más allá del clípeo lateralmente (Fig. 3E). Estrías elitrales con puntos bien separados entre sí. Distribución sobre la costa ...................... Bradypodidium Vaz-de-Mello, 2008 10'. Cabeza regularmente convexa en parte media, con concavidades evidentes en zona anterior a los ojos. Borde lateral del clípeo curvado hacia adentro, con gena saliente (Fig.
3F). Estrías elitrales moniliformes por lo menos apicalmente (puntos dos veces más anchos que las estrías, puntos casi continuos o continuos en la mitad apical). (Fig. 3G). Distribución en la costa

Trichillidium Vaz-de-Mello, 2008

11. Meso y metatibias con quillas o tubérculos transversales en la cara externa (Fig. $3 \mathrm{H})$........................... 12 11'. Meso y metatibias simples, sin quillas ni tubérculos externos (Fig. 4A) ...................................... 13

12. Pronoto a cada lado con surco longitudinal, si el surco está ausente, fosetas pronotales laterales ausentes (Figs. 4BC). Distribución en todas las áreas por arriba de los $100 \mathrm{~m}$

Uroxys Westwood, 1842 (parte)

12'. Lados del pronoto sin surco longitudinal, con foseta lateral (Fig. 4D). Distribución en todas las áreas por arriba de los $100 \mathrm{~m}$

Scatimus Erichson, 1847

13. Cuerpo dorsalmente glabro. Élitros convexos dorsalmente; pseudoepipleura delimitada por quilla incompleta o por convexidad elitral. Pronoto casi siempre a cada lado con surco longitudinal (Figs. 4B-C). Ojos en vista dorsal siempre expuestos ......................... Uroxys Westwood, 1842 (parte) 13'. Cuerpo dorsalmente cubierto de sedas. Pseudoepipleura demarcada por fuerte quilla a lo largo del élitro (Fig. 4E). Pronoto nunca con surco longitudinal a cada lado. Ojos (vista dorsal) no expuestos, o visibles sólo como pequeños triángulos. Distribución en los bosques húmedos y páramos

Cryptocanthon Balthasar, 1942

14. Longitud del primer metatarsómero mayor a la longitud combinada de los tres tarsómeros siguientes (Fig. 2B); si es subigual entonces tibias anteriores con cuatro dientes (Fig. $4 \mathrm{~F}$ ), tibias medias y posteriores con dientes externos, palpos labiales con dos palpómeros (es raro un tercero muy reducido), el segundo más largo que el primero; metatarso con cinco tarsómeros ........................................... 15 14'. Longitud del primer metatarsómero menor a la longitud combinada de los tres metatarsómeros siguientes; si subigual o poco mayor, entonces tibias anteriores con tres dientes, tibias medias sin dientes o quillas externos, palpos labiales con tres palpómeros, el tercero tan largo como la mitad del segundo, y el segundo más corto que el primero; o metatarso con menos de cinco tarsómeros

15. Longitud de 8 a $13 \mathrm{~mm}$, pronoto brillante con reflejos rojos, bronces o verdes, élitros opacos, de color café variegados con manchas grandes, claras y oscuras. Propleura con quilla oblicua que alcanza el borde lateral del ángulo anterior, formando un diente antero-lateral, redondeado en los machos y agudo en las hembras (Fig. 4G); macho con un gran diente apical interno en la protibia, fuertemente curvado hacia abajo en el ápice; macho con dos cuernos en el vértex y una quilla clípeo-frontal, y un par de gibosidades obtusas en la parte anterior del disco del pronto (en especímenes bien desarrollados); hembras con fuertes quillas transversales en la sutura fronto-clipeal en el vértex, y una quilla oblicua a transversal a cada lado de la parte anterior del disco pronotal, reducida a un tubérculo en especímenes pequeños. Posiblemente sobre la Amazonía en áreas abiertas (introducidos

.[Digitonthophagus Balthasar, 1959]

15'. No como se describe arriba. Distribución en todas las áreas .......... Onthophagus (Onthophagus) Latreille, 1807

16. Meso y metatarsos sin uñas (Fig. 4H) ................... 17 
17. Cuerpo por lo general dorsalmente aplanado. Meso y metatarsos con dos, tres o cuatro tarsómeros (Fig. 5A) ........... Dendropaemon Perty, 1830... 18 17'. Cuerpo dorsalmente convexo. Meso y metatarsos con cinco tarsómeros

18. Base del pronoto con marginación largamente interrumpida a cada lado de la línea media (Fig. 5B), marginación nunca pareciendo crenulada o interrumpida por puntos cetosos; fosas pronotales laterales simples, redondeadas, sin borde afilado anteriormente; superficie anterior de las fosas simplemente punteado, puntuaciones nunca confluente o formando rúgulas. Distribución sobre la Amazonía

Dendropaemon (Glaphyropaemon) Génier \& Arnaud, 2016 18 '. Base del pronoto generalmente completamente marginada, si la marginación es más o menos interrumpida a cada lado entonces algunos puntos setosos están presentes (Fig. 5C); segmentos abdominales 3-8 con pubescencia roja oscura larga y erecta; metatibia robusta. Distribución sobre los bosques piemontanos amazónicos

.... Dendropaemon (Crassipaemon) Cupello \& Génier, 2017

19. Tarsómero basal de los meso y metatarsos ensanchado, casi o más ancho que largo. Tarsos posteriores moniliformes (Fig. 5D). Distribución sobre el sur de la Amazonía Megatharsis Waterhouse, 1891 19'. Tarsómero basal de los meso y metatarsos alargado, siempre más largo que ancho. Tarsómeros posteriores de formato triangular o rectangular (Fig. 4H) 20

20. Lamela antenal basal normal, no cóncava apicalmente, recibiendo en la concavidad a las otras lamelas (Figs. 5E-F). Metaepisterno sencillo, sin prolongación .................... 21 20'. Lamela antenal basal grande fuertemente cóncava apicalmente, recibiendo en la concavidad a las otras dos lamelas (Fig. 5G). Metaepisterno con prolongación posterior cubriendo margen lateral del élitro (Fig. $5 \mathrm{H}$ )

22

21. Bordes externos de los élitros (vistos desde arriba) redondeados (Fig. 6A). Estrias elitrales muy débiles. Forma general del cuerpo oval convexa. Distribución sobre la Amazonía Gromphas Brullé, 1834 21'. Borde externo de los élitros (vistos desde arriba) paralelos (Fig. 6B). Forma general del cuerpo alargada, aplanada dorsalmente. Distribución sobre los Páramos

Oruscatus Bates, 1870

22. Margen clipeal con emarginación medial profunda y aguda, formando dos dientes agudos separados del borde lateral adyacente por emarginaciones externas (Fig. 6C)

Coprophanaeus Olsoufieff, 1924 ... 23

22'. Margen clipeal sin emarginación profunda y aguda, a lo sumo con dos conspicuos dientes en medio .................. 24

23. Interestrías elitrales transversamente aquilladas, quillas separadas por fosetas transversales (Fig. 6D). Especímenes muy grandes, de hasta $50 \mathrm{~mm}$ de longitud, raramente con menos de $25 \mathrm{~mm}$. Posiblemente en la Amazonía

. [Coprophanaeus (Megaphanaeus) Olsoufieff, 1924] 23'. Interestrías elitrales microesculpidas, pero sin macroescultura evidente. Especímenes pequeños o medianos, raramente con más de $25 \mathrm{~mm}$. Distribución sobre todas las áreas excepto páramo
24. Cabeza con quilla transversal frontal, además de la quilla fronto-clipeal. Posiblemente en la Amazonía (Fig. 6E) ...... [Diabroctis Gistel, 1857] 24'. Cabeza apenas con un cuerno o quilla fronto-clipeal............................................. 25

25. Metaesterno con fuerte proceso espiniforme curvado dorsalmente, entre el ápice de las procoxas (Fig. 6F). Ángulo medio-posterior del pronoto prolongado entre la base de los élitros (Fig. 6G) ............. Oxysternon Laporte, 1840 ...... 26 $25^{\prime}$. Metaesterno simplemente angulado antero-medialmente, $\sin$ proceso espiniforme ............................. 27

26. Proceso clipeal reducido a un pequeño tubérculo. Quilla clipeal lateral ausente. Metasterno con fila irregular de 5-10 puntos setíferos adyacentes a la mesocoxa. Especímenes pequeños raramente con más de $13 \mathrm{~mm}$ de longitud. Distribución sobre la Amazonía

Oxysternon (Mioxysternon) Edmonds, 1972 26'. Proceso clipeal espiniforme o en forma de quilla transversal (Fig. 6H). Quilla clipeal lateral presente. (Fig. 7A). Especímenes más grandes, raramente con menos de 15 $\mathrm{mm}$ de longitud. Distribución sobre la Amazonía y Costa Oxysternon (Oxysternon) Laporte, 1840

27. Porción anterior de la quilla circumnotal entera, no interrumpida detrás de cada ojo (Fig. 7B). Distribución sobre todas las áreas boscosas

Sulcophanaeus Olsoufieff, 1924 27'. Porción anterior de la quilla circumnotal interrumpida detrás de cada ojo (Figs. 7C-D)

Phanaeus Macleay, 1819 28

28. Pronoto densamente gránulo-rugoso, por lo menos anterolateralmente; puntuación, si presente, sólo en el disco (Fig. 7C). Distribución sobre los bosques húmedos y secos de la costa ............... Phanaeus (Phanaeus) Macleay, 1819 28 '. Pronoto liso, a veces débilmente puntuado; si densamente granulado, granulación confinada al disco del macho; si con escultura densa anterolateralmente, con alguna puntuación mezclada (Fig. 7D). Distribución sobre todas las áreas excepto en páramo

Phanaeus (Notiophanaeus) Edmonds, 1994

29. Cuerpo casi siempre muy alargado, cilíndrico. Uñas tarsales reducidas, casi rectas o poco curvadas (Fig. 7E). Propleura convexa o débilmente cóncava, nunca fuertemente excavada anteriormente (Fig. 7F). Cabeza sin quilla transversal. Distribución sobre todas las áreas excepto páramo

Anomiopus Westwood, 1842 29'. Cuerpo aplanado, hemisférico, redondeado, ovalado, pero no cilíndrico. Uñas tarsales largas, fuertemente curvas, falciformes o angulares (Fig. 7G); si son reducidas, entonces propleura profundamente excavada anteriormente y/o cabeza dorsalmente con quilla transversal ..................... 30

30. Uñas tarsales con fuerte diente basal (Fig. 7H). Longitud inferior a $6 \mathrm{~mm}$. Clípeo bidentado. Distribución sobre la Amazonía ............................ Canthonella Chapin, 1930 30'. Uñas tarsales sin diente basal, a lo máximo en ángulo recto ................................................................... 31 
31. Mesotibias no ensanchadas hacia el ápice, o sólo débil y gradualmente (Fig. 8A) .................................... 32 31'. Mesotibias fuertemente ensanchadas hacia el ápice (Fig. 8B) 48

32. Pronoto con un proceso dentiforme medio-posterior, cubriendo la base de la sutura elitral. Cuerpo alargado, muy aplanado; longitud superior a $15 \mathrm{~mm}$. (Fig. 8C). Distribución sobre los bosques montano bajos de la cordillera amazónica del sur ......................... Streblopus Lansberge, 1874 32'. Pronoto sin proceso medio-posterior .................. 33

33. Ápice de algunas interestrías discales con cortas quillas o tubérculos (Fig. 8D)

Deltochilum Eschscholtz, 1822 ......... 34

33'. Interestrías elitrales sin quillas o tubérculos apicales, a lo máximo con una quilla lateral que puede ser casi completa

34. Cabeza más larga que ancha, estrechada anteriormente (Fig. 8E); tibias posteriores muy bruscamente arqueadas en la mitad. Distribución sobre bosques húmedos Deltochilum (Aganhyboma) Kolbe, 1893 34'. Cabeza claramente más ancha que larga, no triangularmente estrechada anteriormente; tibias posteriores, cuando fuertemente arqueadas, son sinuosas o ampliamente arqueadas, no arqueadas muy bruscamente en la mitad ........... 35

35. Novena interestría elitral (en la pseudopepipleura) sin quilla, o con quilla inconspicua (Fig. 8F). Distribución sobre bosques húmedos.

Deltochilum (Calhyboma) Kolbe, 1893 35'. Novena interestría elitral distintamente aquilla-

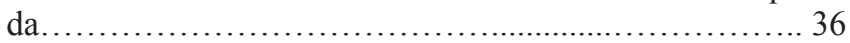

36. Élitros muy aplanados. Quilla de la novena interestría (en la pseudopepipleura) presente por lo menos en los tres cuartos basales de la interestría (Fig. 8G). Distribución sobre bosques húmedos y secos por debajo de los $1000 \mathrm{~m}$....

Deltochilum (Deltochilum) Eschscholtz, 1822 36'. Élitros no aplanados dorsalmente o tamaño casi menor que $20 \mathrm{~mm}$. Quilla de la novena interestría extendiéndose a lo más hasta poco después de la mitad anterior de la pseudoepipleura (Fig. 8H) ....

37. Clípeo bidentado. (Fig. 9A). Disco del metaesterno sin tubérculos en la parte posterior. Distribución sobre áreas boscosas

Deltochilum (Deltohyboma) Lane, 1946

37'. Clípeo cuadridentado (Fig.9B). Disco del metaesterno en la parte posterior bituberculado (Fig. 9C). Distribución sobre áreas boscosas

Deltochilum (Hybomidium) Shipp, 1897

38. Borde posterior de la cabeza no marginado entre los ojos, a lo sumo con corta indicación de marginado entre o cerca de los ojos (Fig. 9D). Mesoesterno relativamente largo, no estrechado medialmente, por completo horizontal ......... 39 $38^{\prime}$. Borde posterior de la cabeza clara y completamente marginado entre los ojos. (Fig. 9E). Mesoesterno más corto en la parte media que a los lados, o en posición vertical y poco visible ventralmente

40

39. Clípeo cuadridentado (Fig. 9F). Cuerpo alargado, aplanado. Uñas tarsales anguladas basalmente. Posiblemente en bosques secos y la Amazonía .. [Pseudocanthon Bates, 1887] 39'. Clípeo bidentado (Fig. 9D). Cuerpo redondeado. Uñas tarsales sencillas, sin ángulo basal. Distribución sobre bosques húmedos amazónicos.

Sylvicanthon Halffter \& Martínez, 1977

40. Pronoto lateralmente aplanado, con un diente agudo en la parte media y denticulado antero-ventralmente; élitros con quilla lateral fuerte y completa (Fig. 9G); color verde metálico en el pronoto, crema o café opaco (coriáceo) en los élitros. Ubicación probable en el sureste amazónico

. [Hansreia Halffter \& Martínez, 1977] 40'. Lados del pronoto no aplanados, no denticulados anteriormente. Quilla elitral lateral frecuentemente presente pero si es así poco marcada anteriormente, y entonces pronoto y élitros similarmente coloreados ......................... 41

41. Meso y metatibias con quillas transversales externas, más visibles en las mesotibias (Fig. 9H). Cabeza de forma triangular alargada (Fig. 10A). Dorso bicolor. Ubicación probable en el sureste amazónico

[Canthotrypes Paulian, 1939]

41'. Meso y metatibias sin quillas transversales, a lo más con tubérculos en las mesotibias (Fig. 10 B) .................. 42

42. Primer metatarsómero corto, con aproximadamente la mitad del largo del segundo, oblicuamente truncado apicalmente (aproximadamente $45^{\circ}$ ). Bordes laterales de los metatarsómeros paralelos, formando un borde continuo para todo el tarso, forma general de los metatarsómeros 2-4 cuadrada a rectangular (Fig. 10B). Distribución en los bosques húmedos amazónicos y de la costa... Scybalocanthon Martínez, 1948 42'. Primer meso y metatarsómeros sólo poco más cortos o poco más largos que el segundo; si mucho más corto, entonces truncado transversal apicalmente. Bordes laterales de los meso y metatarsómeros divergentes apicalmente, forma general de los tarsómeros 1-4 trapezoidal (Fig. 8A) ....... 43

43. Dorso (principalmente pronoto) aplanado, con escultura irregular (mosaico de áreas lisas, seríceas y granulosas con elevaciones y depresiones poco conspicuas (Fig. 10 C). Podría estar en la Amazonía

[Anisocanthon Martínez \& Pereira, 1956] 43'. Pronoto con escultura regular, a lo sumo con depresión media posterior ........ Canthon Hoffmannsegg, 1817 ... 44

44. Cara ventral del metafémur no marginada anteriormente

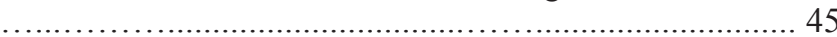
44'. Cara ventral del metafémur con fina quilla anterior (Fig. 10D) ....................................... 47

45. Pigidio giboso (Fig. 10E), muy brillante. Distribución sobre la Amazonía ............................................ Canthon (Goniocanthon) Pereira \& Martínez, 1956 $45^{\prime}$. Pigidio aplanado o poco convexo, opaco o débilmente brillante .............................................. 46

46. Distancia interocular aproximadamente seis veces el ancho del ojo (Fig. 10F), y/o pigidio y propigidio no separados por quilla transversal

Canthon s. lat. (parte) 46'. Distancia interocular aproximadamente diez veces el ancho del ojo (Fig. 10G); pigidio separado del propigidio por una quilla transversal. Distribución en sistemas fores- 
tales y boscosos

Canthon (Glaphyrocanthon) Martínez, 1948

47. Pigidio y propigidio no separados por quilla transversal. Distribución en bosques secos y húmedos ....................................... Canthon s. lat. (parte) 47'. Pigidio y propigidio separados al menos parcialmente por una quilla transversal (Fig. 10H). Distribución en todas las áreas excepto páramo

Canthon (Canthon) Hoffmannsegg, 1817

48. Metatibia curvada, débilmente ensanchada hacia el ápice, ancho apical menor a la quinta parte de la longitud de la metatibia (Fig. 11A). Ángulo interno apical de las meso y metatibias prolongado más allá de la inserción del metatarso, y con espolón insertado en la prolongación. Longitud inferior a $4 \mathrm{~mm}$. Distribución sobre la Amazonía Sinapisoma Boucomont, 1928 48'. Metatibia fuertemente ensanchada hacia el ápice, ancho apical mayor a la quinta parte de la longitud de la metatibia (Fig. 11B); si débilmente ensanchada, metatibia recta o curvada irregular a lo largo de su longitud. Ángulo interno apical de las meso y metatibias no prolongado 49

49. Propleura profundamente excavada en su parte anterior, excavación delimitada por un área vertical posterior, terminada en fuerte quilla transversal. (Fig. 11C). Ángulo interno apical de la protibia $\sim 90^{\circ}$ ó agudo, borde anterior del diente apical continuo ( $\sin$ formar ángulo) con el extremo apical de la protibia (Fig. 11D) .................................... 50 49'. Propleura débilmente excavada en su parte anterior, excavación no delimitada claramente en la parte posterior; quilla propleural transversal casi siempre ausente. Ángulo interno apical de la protibia truncado oblicuo $\left(>90^{\circ}\right)$; sí $\sim 90^{\circ}$ o débilmente agudo, borde anterior del diente apical no continuo (formando ángulo) con el extremo apical de la protibia (Fig. $11 \mathrm{E})$

.. 52

50. Clípeo regularmente arqueado, con dos dientes o ampliamente emarginado. (Fig. 11F). Si meso y metatarsos reducidos, quilla fronto-clipeal ausente o apenas indicada. Distribución sobre todas las áreas y quizás incluso en el páramo Ateuchus Weber, 1801 50'. Clípeo de forma triangular, con o sin dientes, sutura clípeo-frontal con una quilla ampliamente arqueada (Fig. 11G). Tarsos medios y posteriores reducidos, uñas vestigiales .... 51

51. Pronoto con surco longitudinal o transversal o si no con concavidades una detras de cada ojo (Fig. 11H). Último esternito abdominal en las hembras sin quilla dentiforme transversa en el medio. Podría estar en toda la Amazonía

[Deltorhinum Harold, 1867]

51'. Pronoto sencillamente convexo. (Fig. 12A). Último esternito abdominal en las hembras con quilla dentiforme transversa en el medio (Fig. 12B). Podría estar en el sureste de la Amazonía

[Lobidion Génier, 2010]

52. Metaesterno convexo. Ángulo interno apical de la protibia $\sim 90^{\circ}$ ó agudo (Fig. 11E). Mesoesterno muy corto, en posición vertical. Ensanchamiento de mesotibias es resultado solo de la curvatura del borde interno, borde externo recto Canthidium Erichson, 1847 .... 53 52'. Metaesterno aplanado. Ángulo interno apical de la protibia generalmente $>90^{\circ}$. Mesoesterno desarrollado, de posi- ción horizontal. Ensanchamiento de mesotibias resultado de la curvatura de los bordes interno y externo .................. 54

53. Margen posterior del pronoto bordeada por una hilera de puntos más grandes que los puntos adyacentes (Fig. 12C), a veces interrumpida en parte media y/o primera y segunda estrías elitrales apicalmente reunidas a las estrías laterales. Distribución sobre todas las áreas excepto páramo Canthidium (Neocanthidium) Martínez,

Halffter \& Pereira, 1964

53'. Primera y segunda estrías elitrales no reunidas apicalmente a las estrías laterales y margen posterior del pronoto sin hilera basal de puntos (Fig. 12D). Distribución sobre todas las áreas excepto páramo

Canthidium (Canthidium) Erichson, 1847

54. Proceso clipeal ventral casi siempre coniforme y bifurcado en el ápice, a veces insertado en una quilla longitudinal; rara vez de otra forma, pero nunca como quilla transversal sencilla (Fig. 12E). Espolón metatibial generalmente dentado o bifurcado apicalmente ...... Dichotomius Hope, 1838 ... 55 54'. Proceso clipeal transversal, obtusamente triangular o subrectangular (en vista frontal) (Fig. 12F). Espolón metatibial generalmente espatulado o truncado

.57

55. Margen clipeal redondeado o débilmente emarginado; sí clípeo bidentado, dientes pequeños y no marginados (Fig. $12 \mathrm{G})$. Distribución sobre todas las áreas ......................

Dichotomius (Dichotomius) Hope, 1838 55'. Clípeo distintamente bidentado, dientes generalmente marginados .. 56

56. Cabeza con borde lateral anguloso en el punto de unión entre clípeo y gena (Fig. 12H). Pilosidad metaesternal muy escasa o ausente. Distribución sobre la Amazonía y bosques piemontanos amazónicos

Dichotomius (Selenocopris) Burmeister, 1846 56'. Cabeza con borde lateral redondeado, sin ángulo en el punto de unión clípeo-genal (Fig. 13A). Pilosidad metaesternal abundante. Distribución sobre todas las áreas excepto páramo......... Dichotomius (Luederwaldtinia) Martínez, 1951

57. Quilla ventral media de la protibia interrumpida por sedas, por lo menos en toda la mitad apical. (Fig. 13B). Primer y segundo antenómeros de la clava antenal con foseta en la superficie distal ............. Ontherus Erichson, 1847 ....58 57'. Quilla ventral media de la protibia glabra excepto a veces en el ápice (Fig. 13C). Primer y segundo antenómeros de la clava antenal sin foseta en la superficie distal ............. 59

58. Sutura mesometasternal recta o débilmente curvada, nunca angulosa (Fig. 13D). Sutura fronto-clipeal siempre tuberculada. Distribución sobre bosques húmedos, incluso de altura .................. Ontherus (Caelontherus) Génier, 1996 58'. Sutura mesometasternal angulosa medialmente; si recta, sutura fronto-clipeal aquillada (Fig. 13E). Distribución en zonas bajas de Amazonía y costa

Ontherus (Ontherus) Erichson, 1847

59. Metatibia con fuerte quilla transversal lateral (Fig. 13F). Distribución sobre bosques húmedos y secos de la costa Copris (Copris) Geoffroy, 1762 59'. Metatibia sin quilla lateral (Fig. 13G). Distribución sobre áreas de páramo y bosques altoandinos ...............................

Homocopris Burmeister, 1846 
A
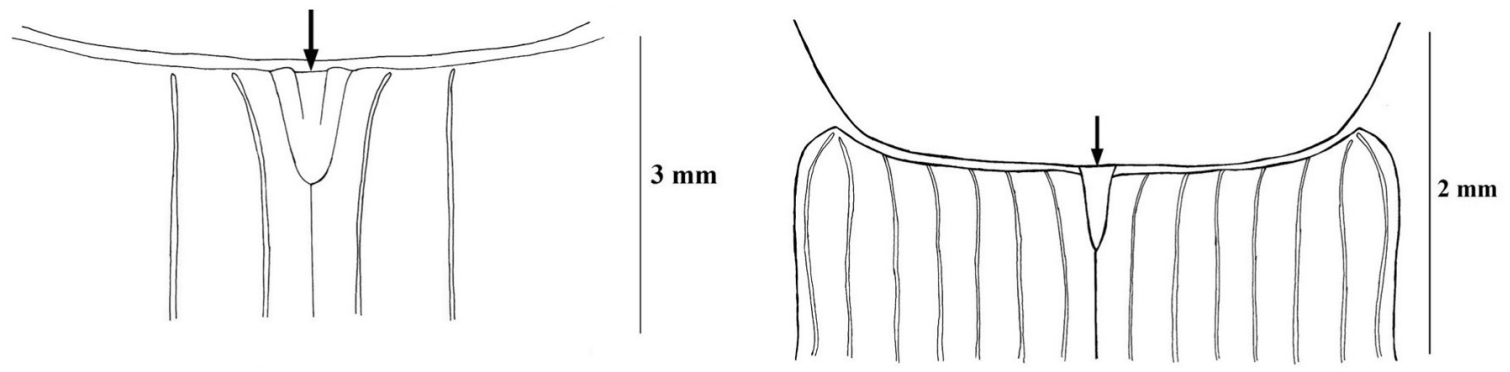

C

D
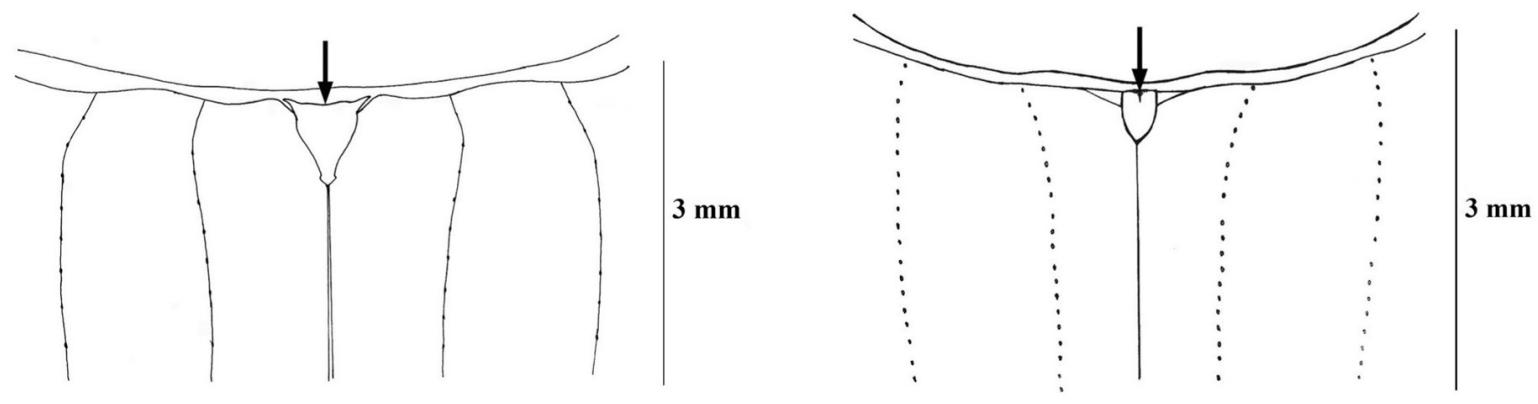

$\mathbf{E}$
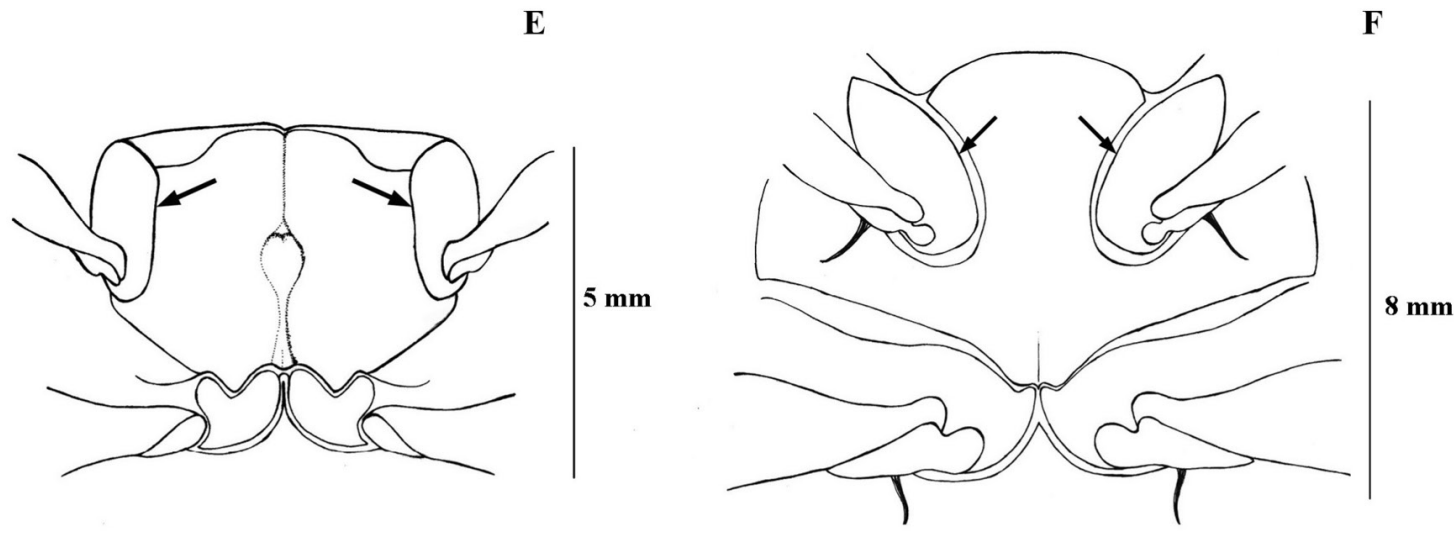

G

H
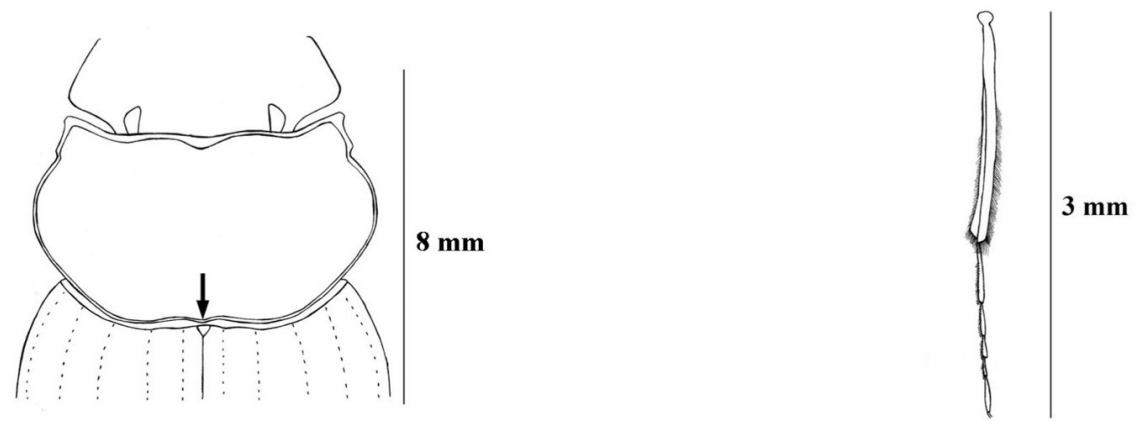

Figura 1. A. Eurysternus marmoreus Castelnau, 1840, escutelo visible. B. Eurysternus wittmerorum Martínez, 1988, escutelo visible. C. Malagoniella (Malagoniella) astyanax polita Halffter, Pereira \& Martínez, 1960, escutelo visible. D. Malagoniella (Megathopomima) cupreicollis (Waterhouse, 1890), escutelo visible. E. Eurysternus marmoreus Castelnau, 1840, mesocoxas. F. Malagoniella (Malagoniella) astyanax polita Halffter, Pereira \& Martínez, 1960, mesocoxas. G. Malagoniella (Megathopomima) cupreicollis (Waterhouse, 1890), pronoto. H. Bdelyrus pecki Cook, 1998, mesotarsos. 


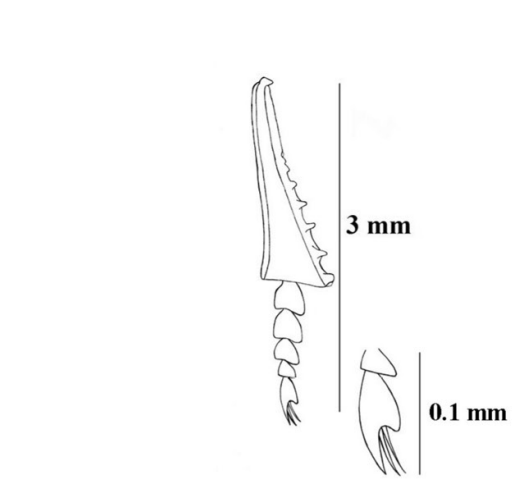

A

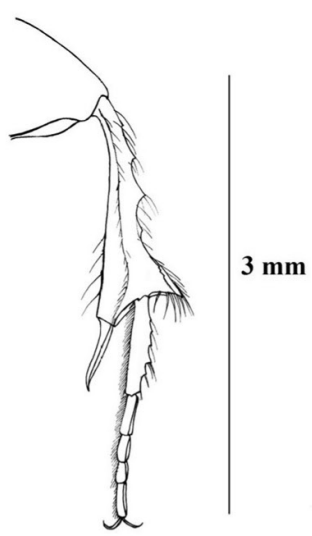

B

D

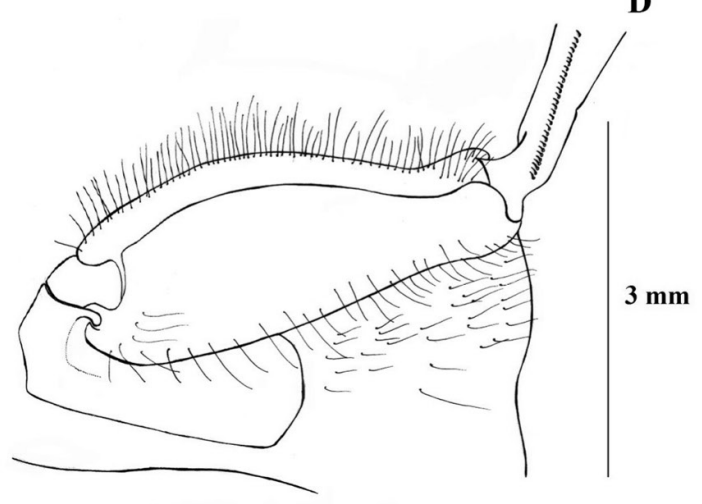

$\mathbf{F}$
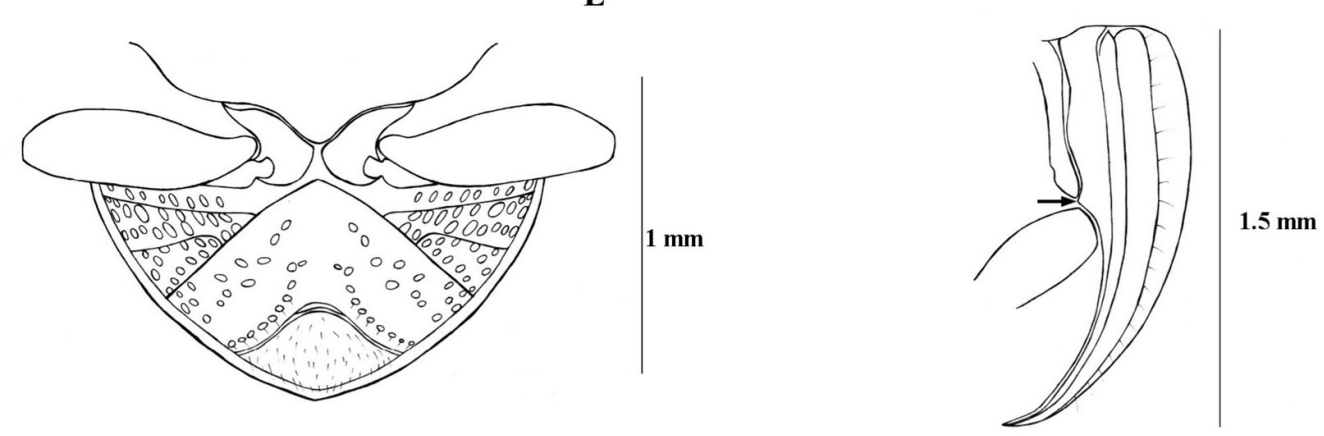

G
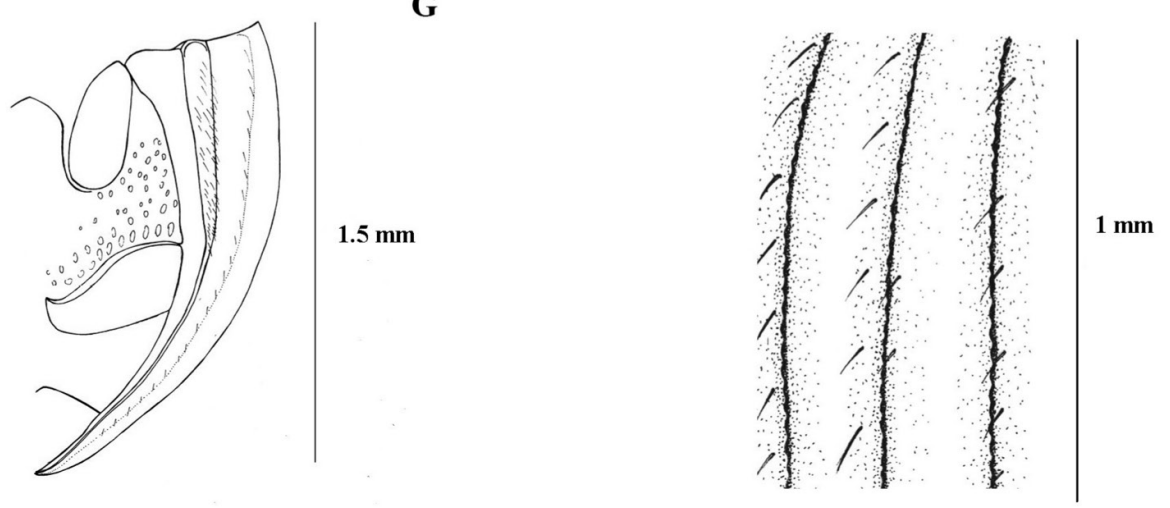

$\mathbf{H}$

Figura 2. A. Bdelyrus pecki Cook, 1998, metatarsomero con proceso espiniforme. B. Onthophagus (Onthophagus) xanthomerus Bates, 1887, metatarsos. C. Uroxys elongatus Harold, 1868, foseta trocanto-femoral visible. D. Dichotomius (Dichotomius) quinquelobatus Felsche, 1901, foseta trocanto-femoral ausente. E. Onoreidium howdeni (Ferreira \& Galileo, 1993), vista del último esternito abdominal. F. Eutrichillum sp., vista lateral de la pseudoepipleura. G. Trichillidium pilosum (Robinson, 1948), vista lateral de la pseudoepipleura. H. Eutrichillum sp., élitros. 


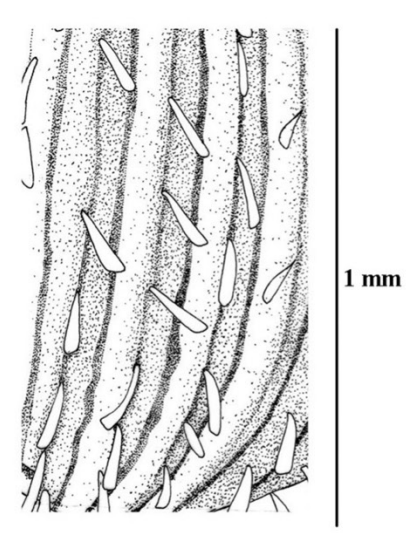

A

B
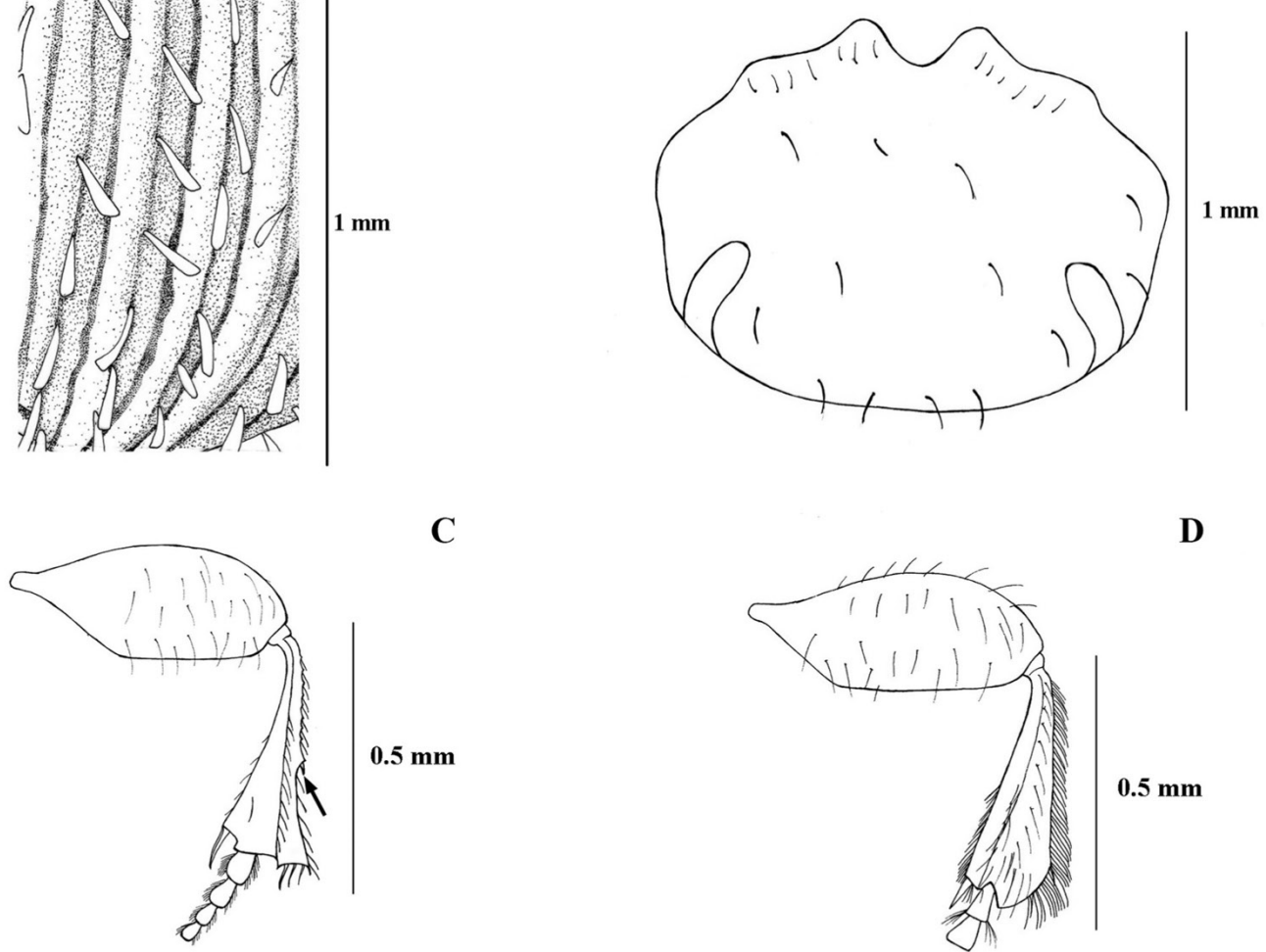

C

D

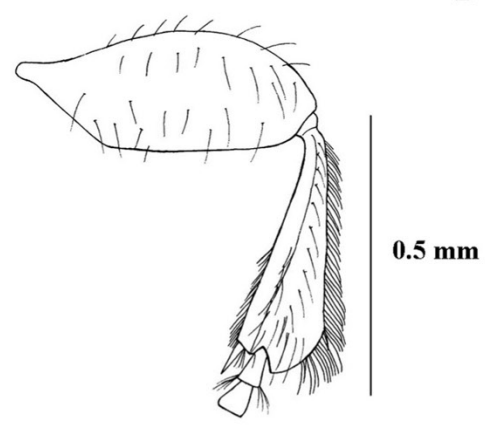

E

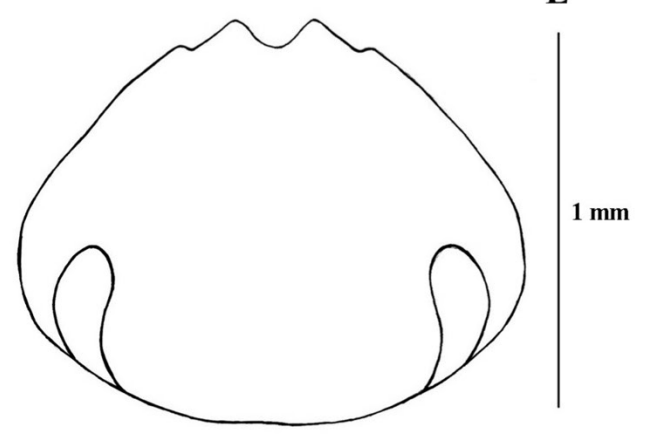

G

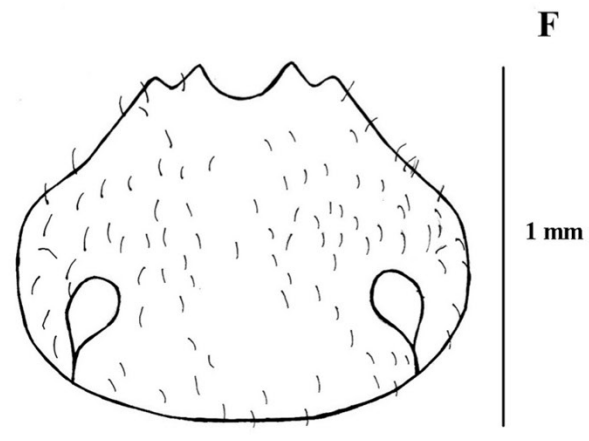

H
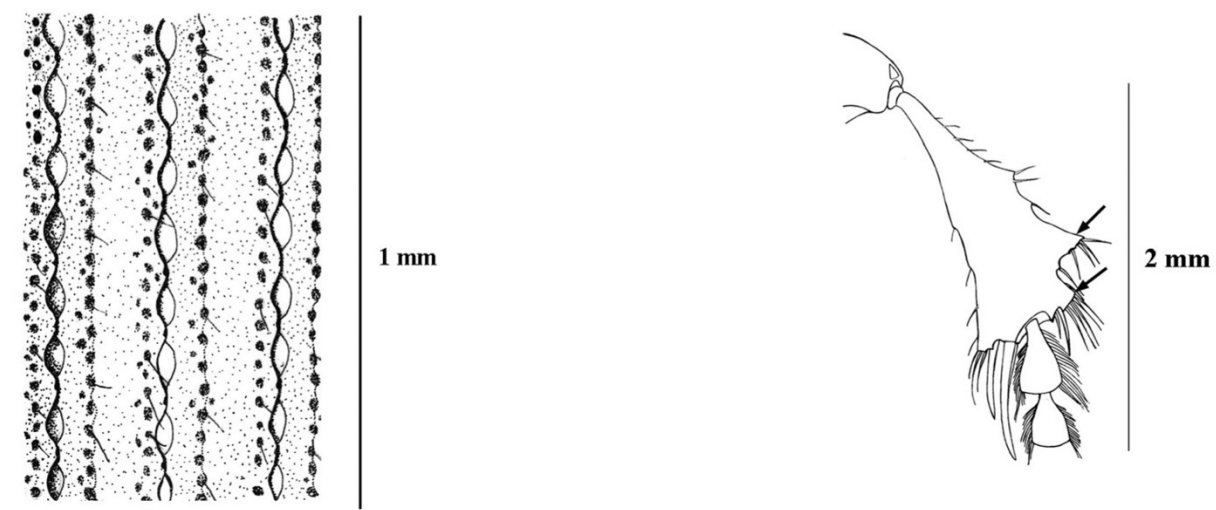

Figura 3. A. Besourenga horacioi (Martínez, 1967), interestrias elitrales. B. Besourenga horacioi (Martínez, 1967), cabeza. C. Onoreidium howdeni (Ferreira \& Galileo, 1993), mesotibia. D. Trichillidium pilosum (Robinson, 1848), mesotibia. E. Bradypodidium bradyporum (Boucomont, 1928), cabeza. F. Trichillidium pilosum (Robinson, 1948), cabeza. G. Trichillidium pilosum (Robinson, 1948), estrías elitrales. H. Scatimus furcatus Balthasar, 1939, mesotibia. 
Clave de escarabajos estercoleros para Ecuador

81

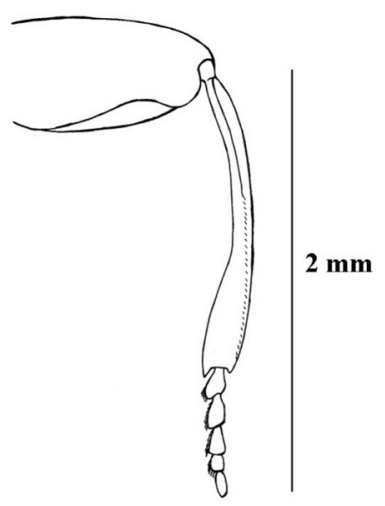

C

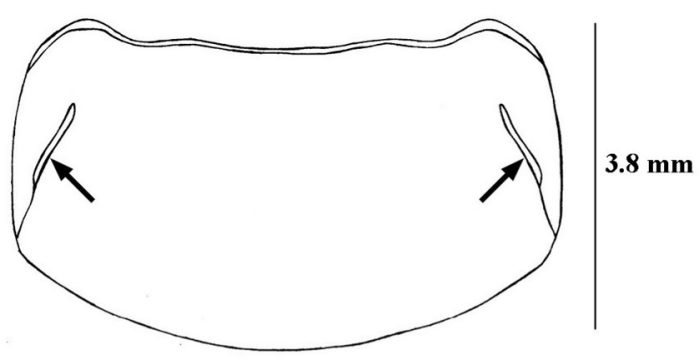

E

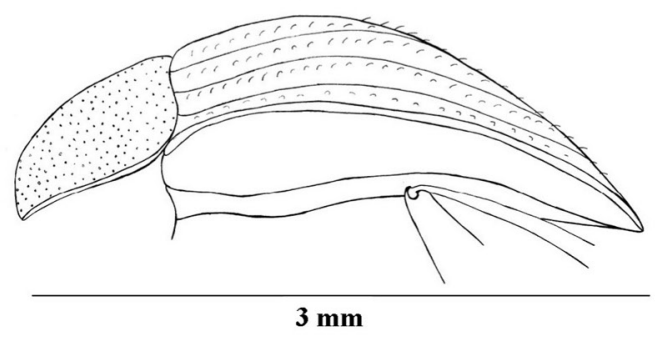

G

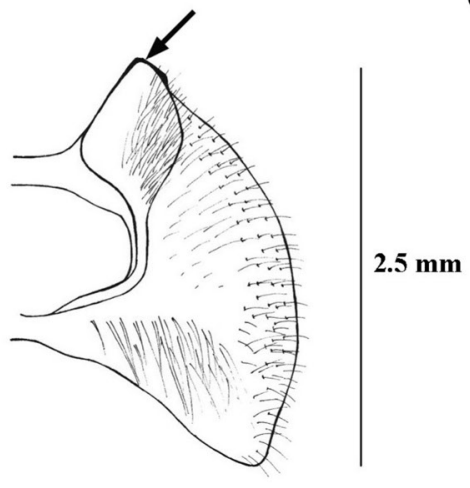

A

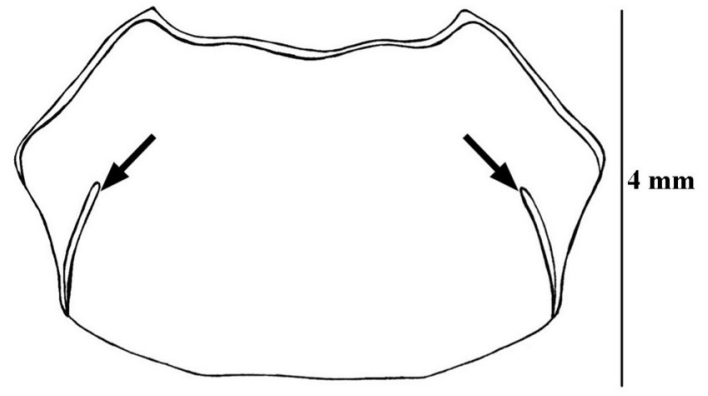

D
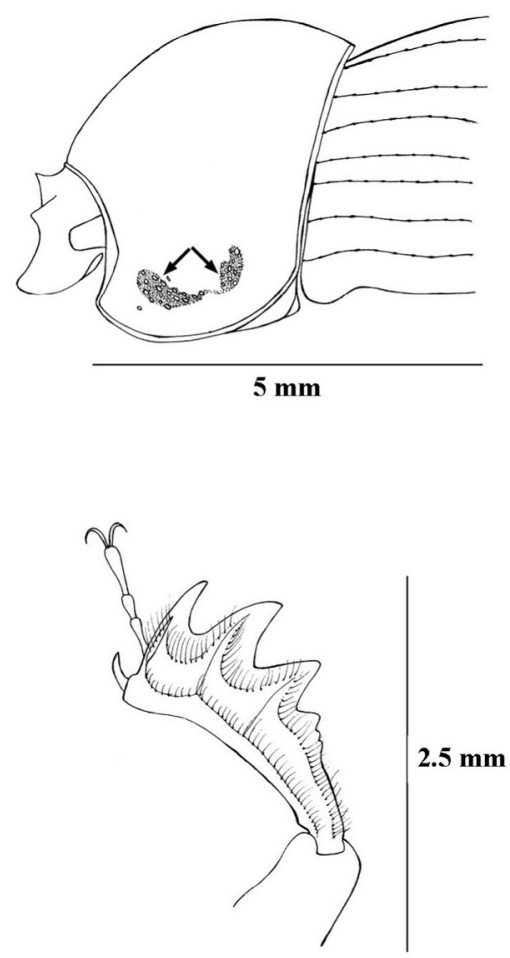

F

H

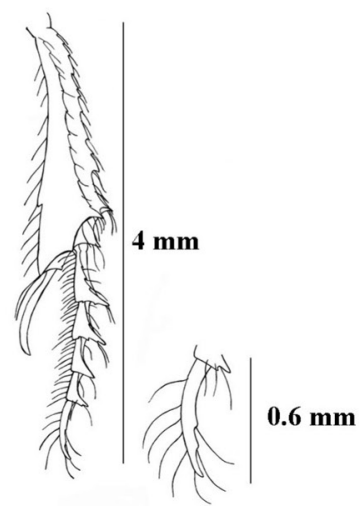

Figura 4. A. Cryptocanthon napoensis Cook, 2002, mesotibia. B. Uroxys sp., surcos pronotales del macho. C. Uroxys sp., surcos pronotales de la hembra. D. Scatimus strandi Balthasar, 1939, fosetas pronotales. E. Cryptocanthon napoensis Cook, 2002, pseudopipleura. F. Digitonthophagus gazella (Fabricius, 1787), protibia. G. Digitonthophagus gazella (Fabricius, 1787), propleura. H. Sulcophanaeus velutinus (Murray, 1856), metatarsos. 
A
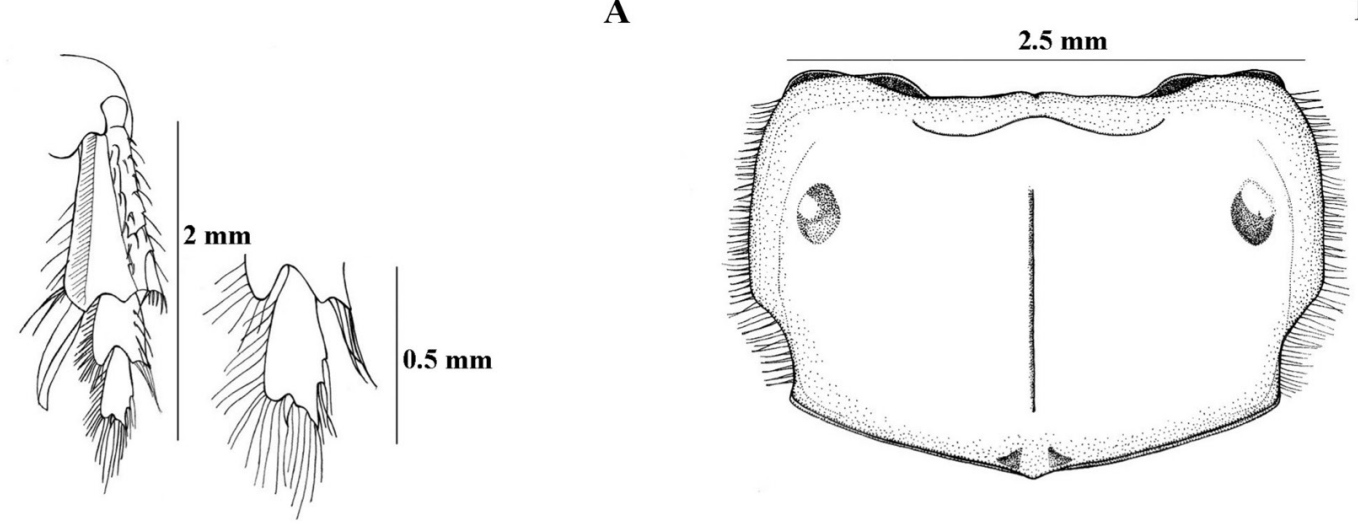

C

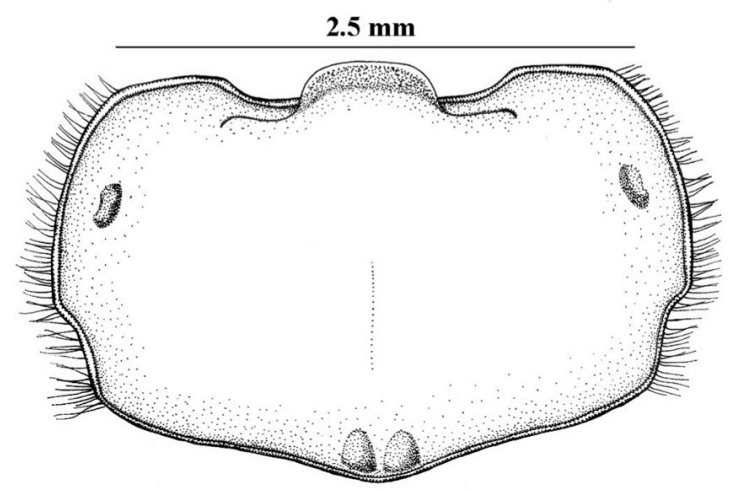

E

F
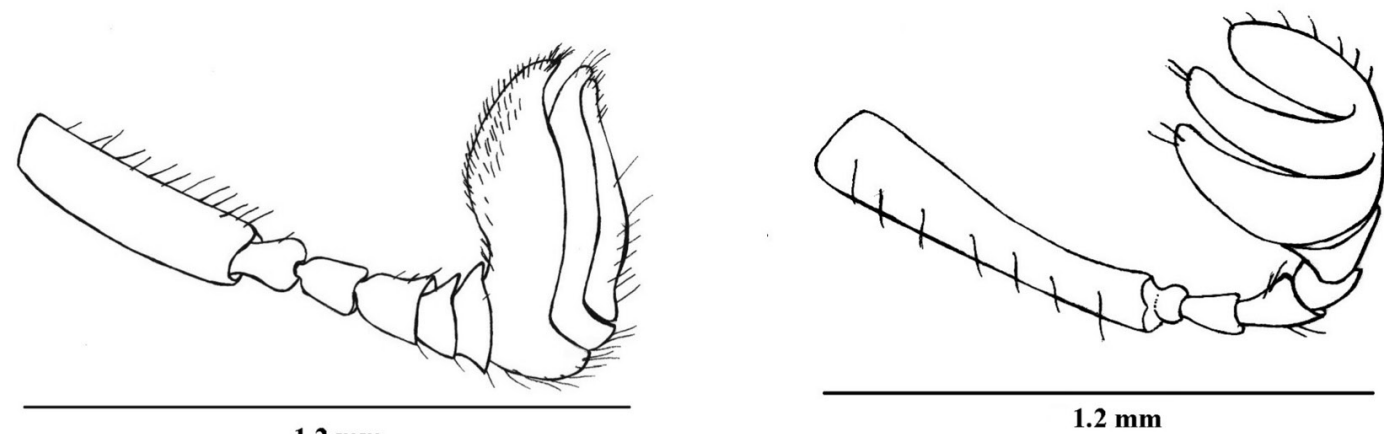

$1.2 \mathrm{~mm}$

G
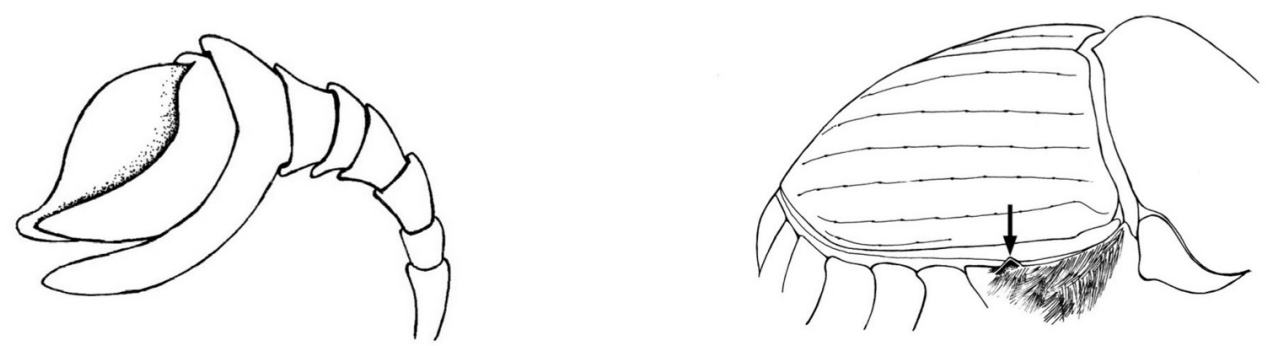

$10 \mathrm{~mm}$

$1.8 \mathrm{~mm}$

Figura 5. A. Dendropaemon (Glaphyropaemon) angustipennis Harold, 1869, metatarsos. B. Dendropaemon (Glaphyropaemon) angustipennis Harold, 1869, pronoto. C. Dendropaemon (Crassipaemon) morettoi Génier \& Arnaud, 2016, pronoto. D. Megatharsis buckleyi Waterhouse, 1891, metatarsos. E. Oruscatus opalescens Bates, 1870, lamela antenal basal. F. Gromphas aeruginosa (Perty, 1830), lamela antenal basal. G. Phanaeus (Notiophanaeus) meleagris Blanchard, 1843, lamela antenal basal. H. Phanaeus (Notiophanaeus) meleagris Blanchard, 1843, vista metaepsiterno. 
A

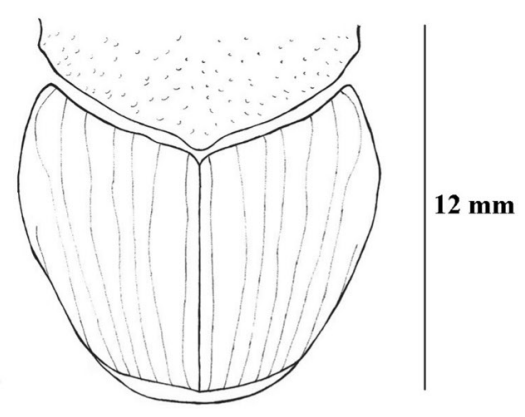

C

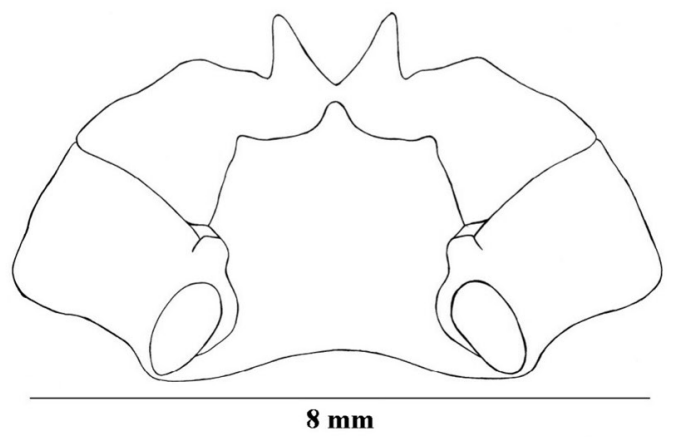

$\mathbf{E}$

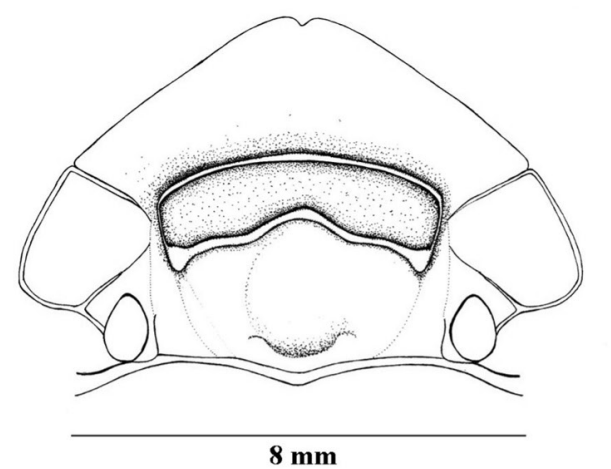

G

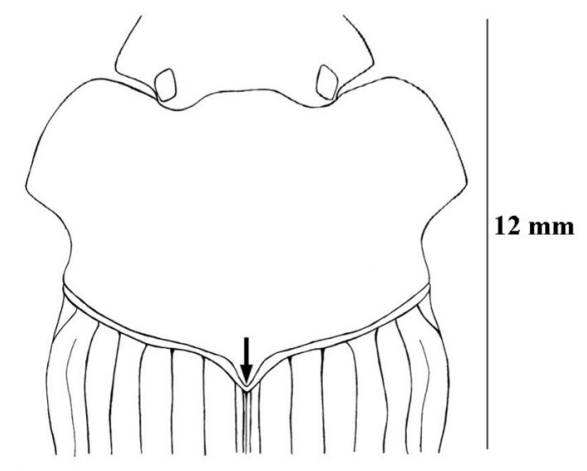

B

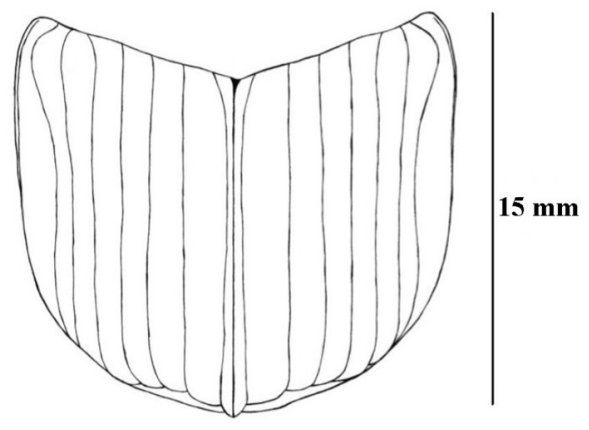

D

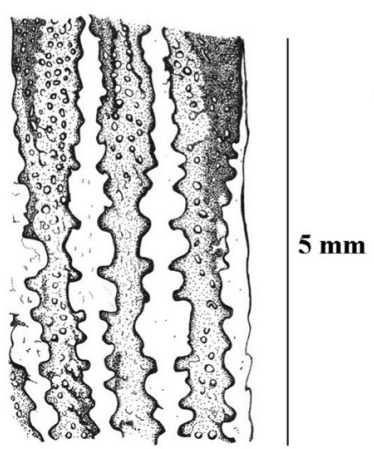

F

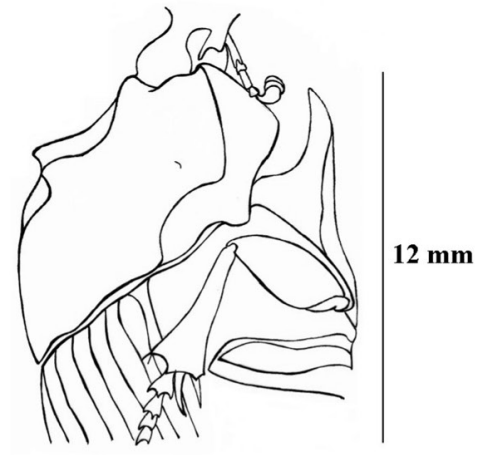

H

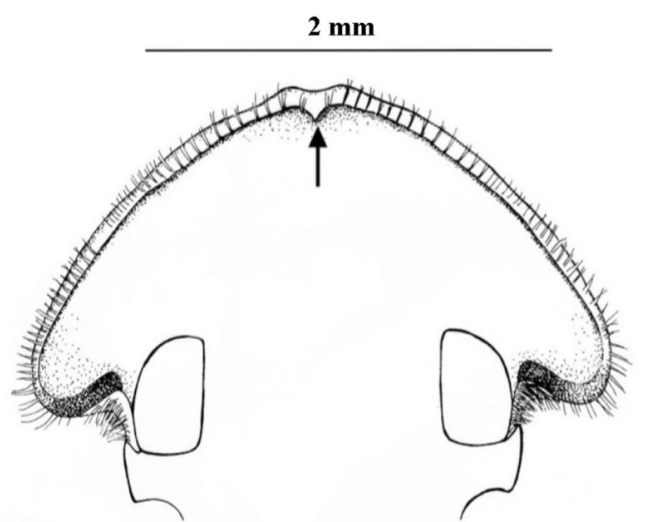

Figura 6. A. Gromphas aeruginosa (Perty, 1830), élitros. B. Oruscatus opalescens Bates, 1870, élitros. C. Coprophanaeus (Coprophanaeus) morenoi Arnaud, 1982, clípeo. D. Coprophanaeus (Megaphanaeus) lancifer (Linnaeus, 1767), interestrias elitrales. E. Diabroctis mimas (Linnaeus, 1758), cabeza. F. Oxysternon (Oxysternon) silenus Castelnau, 1840, espina metaesternal. G. Oxysternon (Oxysternon) silenus Castelnau, 1840, pronoto. H. Oxysternon (Oxysternon) conspicillatum (Weber, 1801), quilla clipeal ventral. 
A

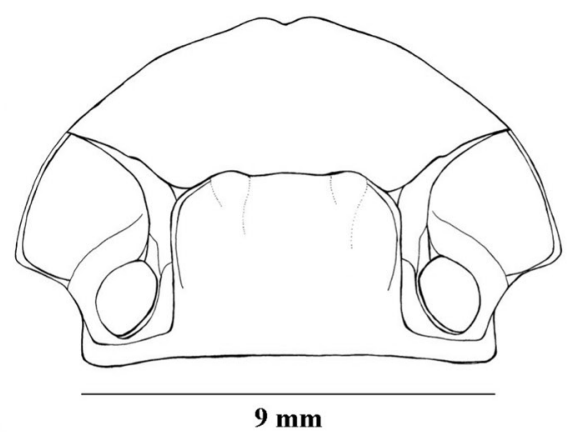

C

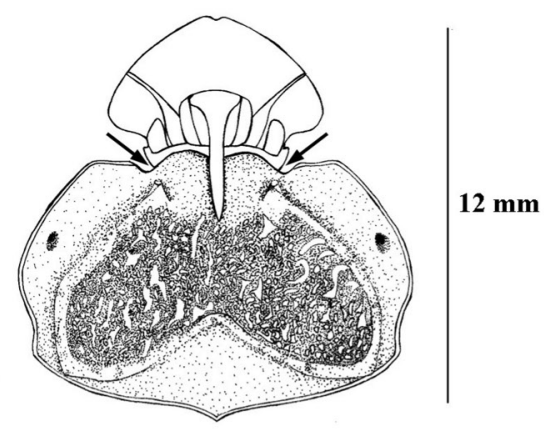

E

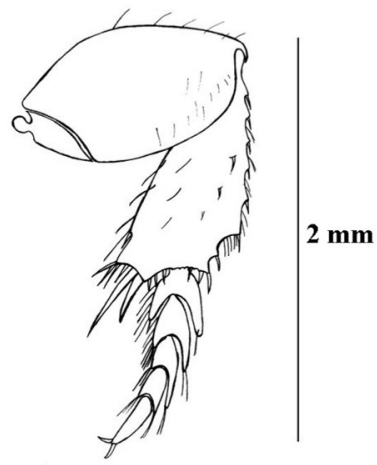

G

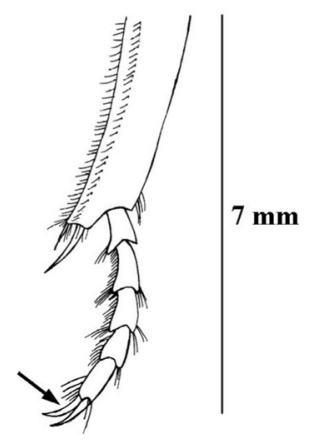

B

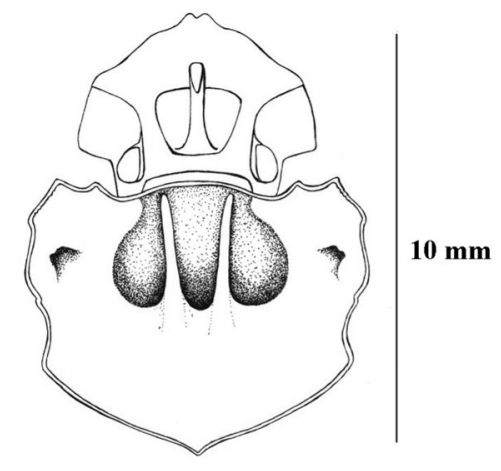

D

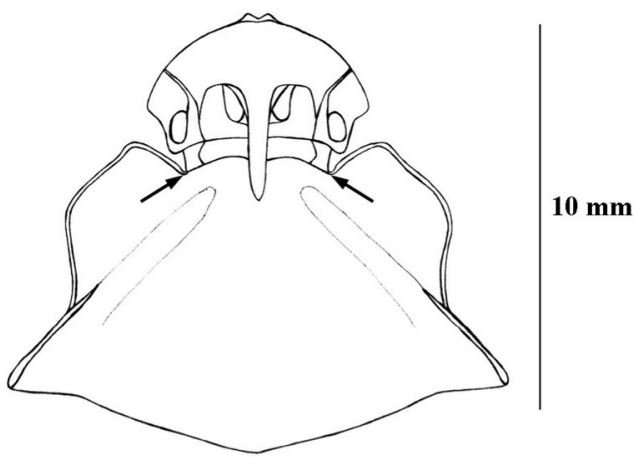

F

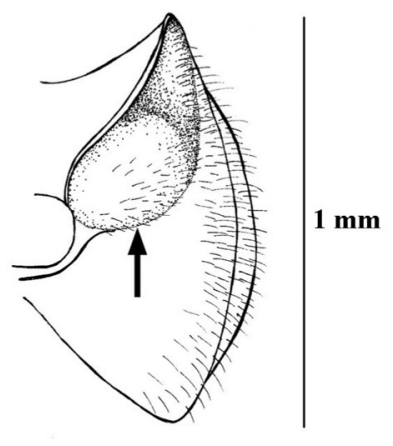

H

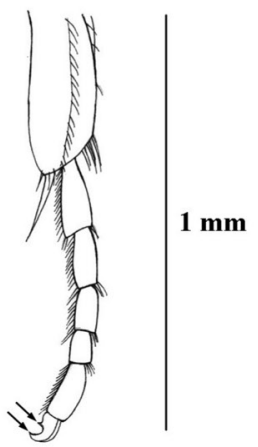

Figura 7. A. Oxysternon (Oxysternon) conspicillatum (Weber, 1801), cabeza. B. Sulcophanaeus velutinus (Murray, 1856), pronoto del macho. C. Phanaeus (Phanaeus) lunaris Taschenberg, 1870, disco pronotal del macho. D. Phanaeus (Notiophanaeus) pyrois Bates, 1887, disco pronotal del macho. E. Anomiopus brevipes (Waterhouse, 1891), uñas metatarsales. F. Anomiopus brevipes (Waterhouse, 1891), propleura. G. Deltochilum (Deltochilum) orbiculare Lansberge, 1874, uñas metatarsales. H. Canthonella sp., uñas mesotarsales. 


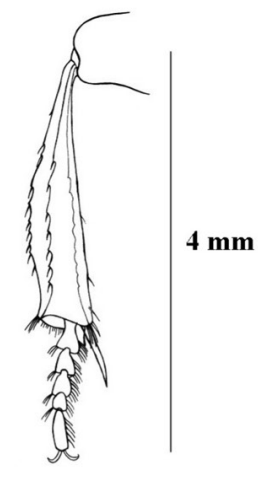

A

B

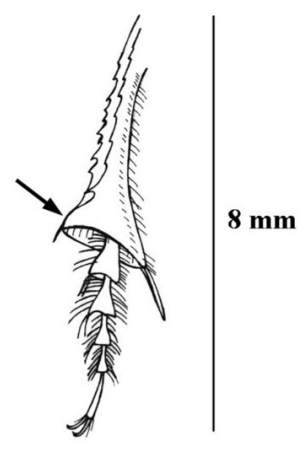

C

D
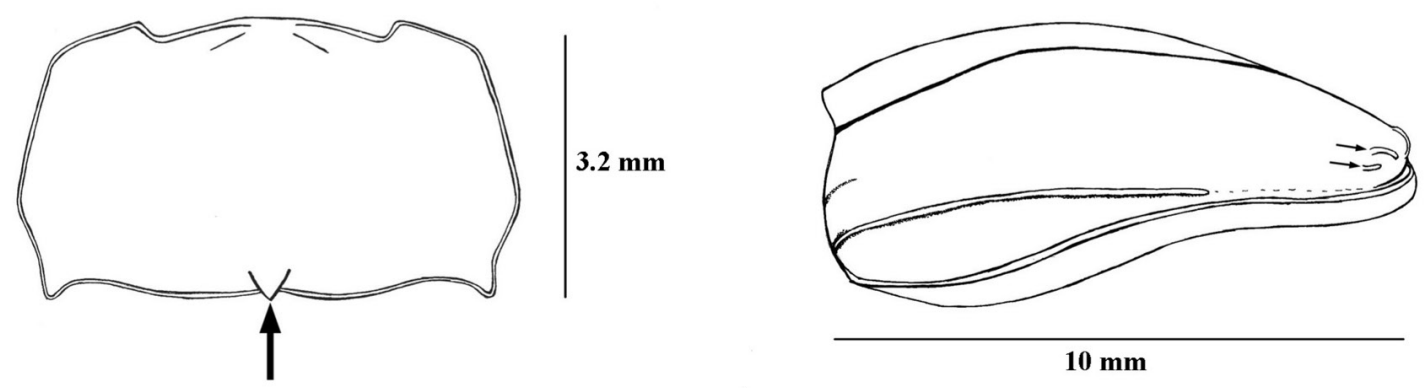

E
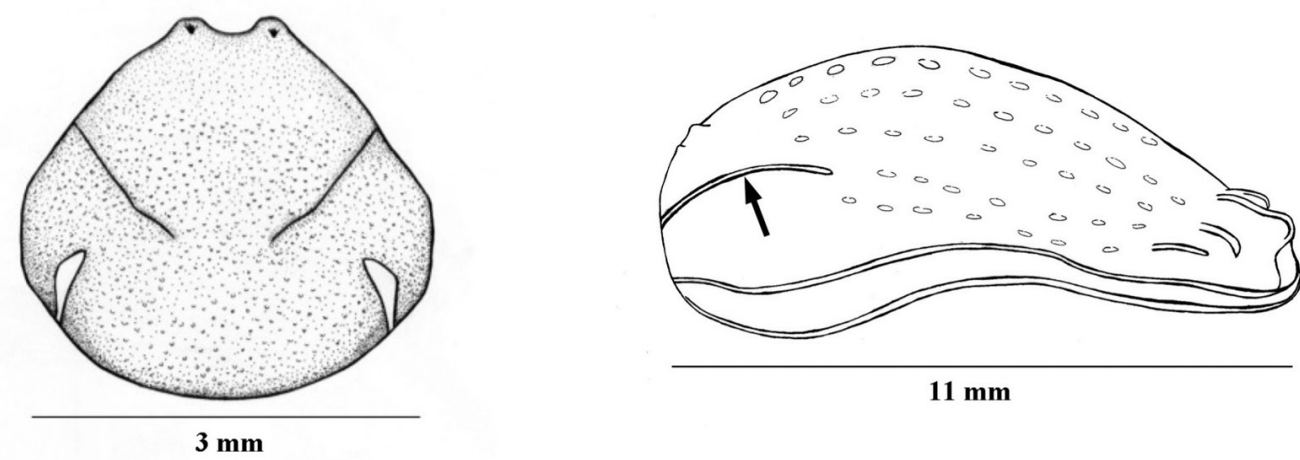

$11 \mathrm{~mm}$

G

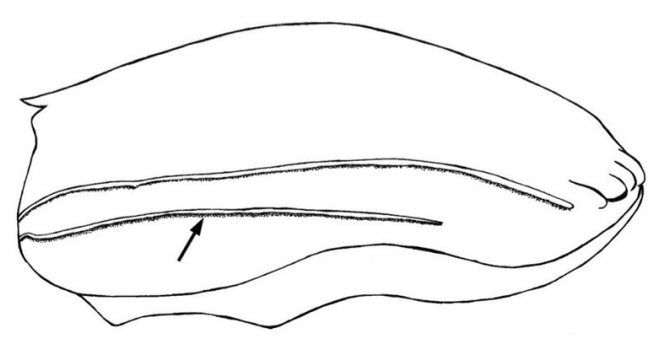

$15 \mathrm{~mm}$

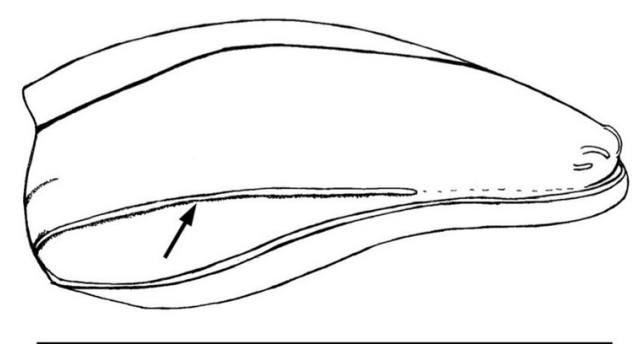

$10 \mathrm{~mm}$

Figura 8. A. Canthon (Canthon) aberrans (Harold, 1868), metatibia. B. Homocorpis buckleyi (Waterhouse, 1891), metatibia. C. Streblopus punctatus (Balthasar, 1938), pronoto. D. Deltochilum (Calhyboma) carinatum (Westwood, 1837), tubérculos elitrales. E. Deltochilum (Aganhyboma) larseni Silva, Louzada \& Vaz-de-Mello 2015, cabeza. F. Deltochilum (Calhyboma) tessellatum Bates, 1870, novena interestría elitral. G. Deltochilum (Deltochilum) rosamariae Martínez, 1991, novena interestría elitral. H. Deltochilum (Deltohyboma) aequinoctiale Buquet, 1844, novena interestría elitral. 
A

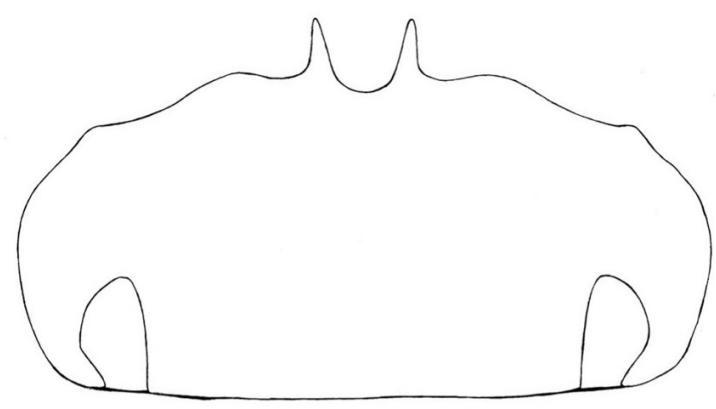

$4.5 \mathrm{~mm}$

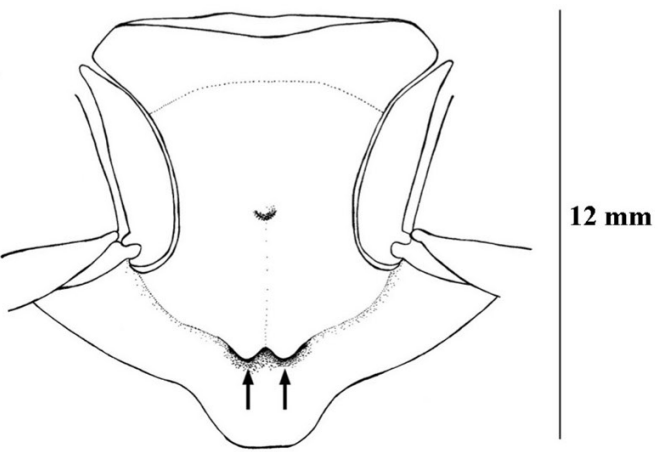

C

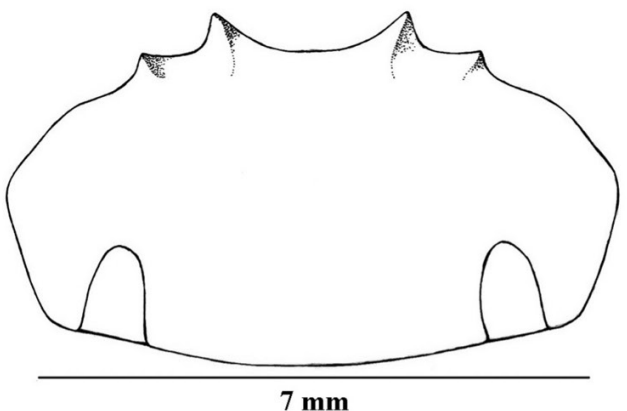

$7 \mathrm{~mm}$

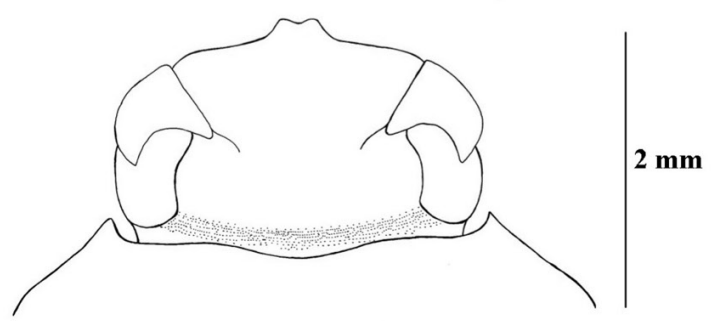

E
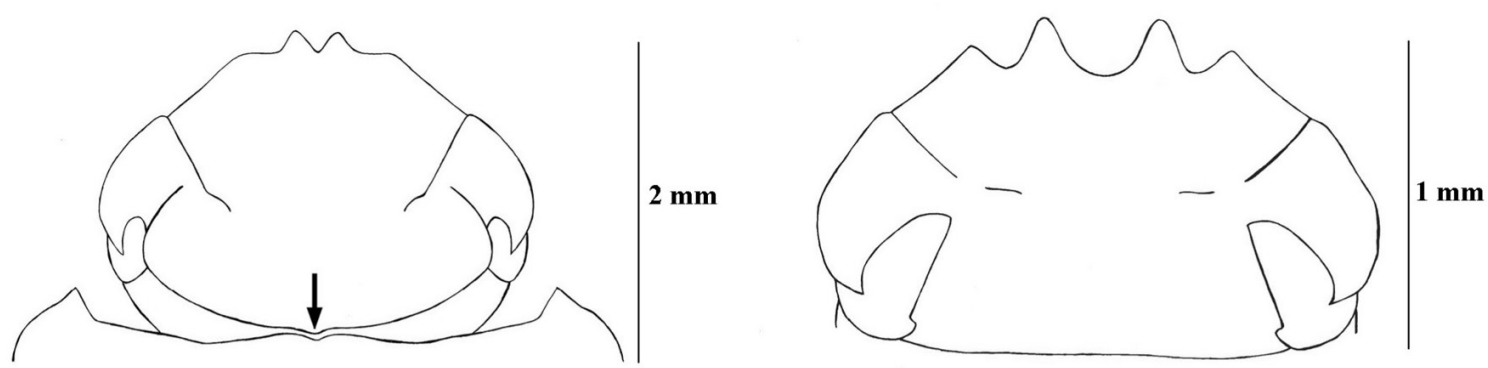

G

H
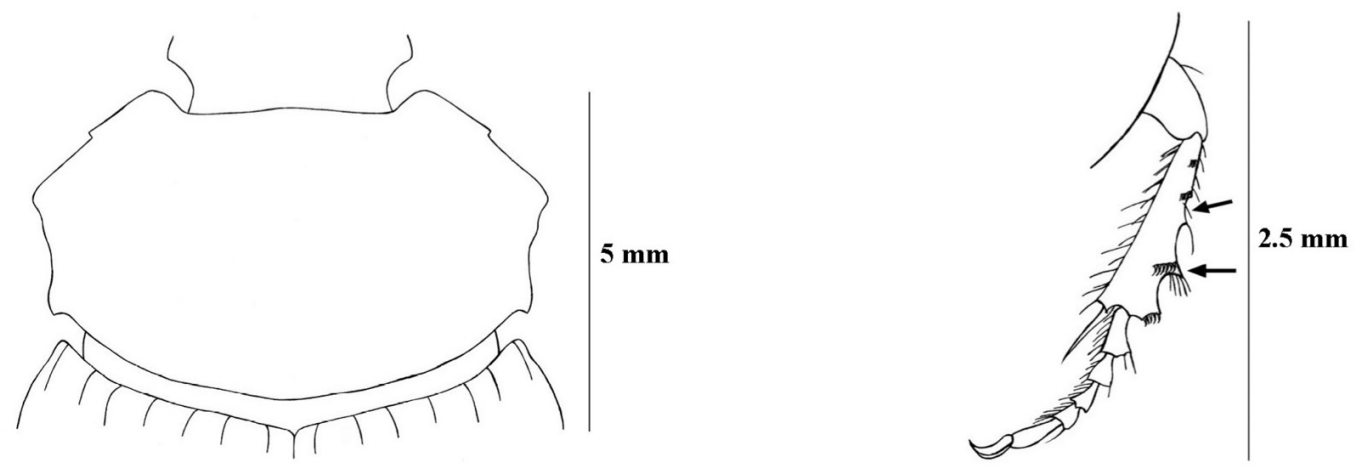

Figura 9. A. Deltochilum (Deltohyboma) aequinoctiale (Buquet, 1844), clípeo bidentado. B. Deltochilum (Hybomidium) orbignyi amazonicum Bates, 1887, clípeo cuadridentado. C. Deltochilum (Hybomidium) orbignyi amazonicum Bates, 1887, tubérculos metaesternales. D. Sylvicanthon bridarolli Martínez, 1948, cabeza. E. Canthon (Glaphyrocanthon) semiopacus Harold, 1868, cabeza. F. Pseudocanthon xanthurus (Blanchard, 1846), clípeo cuadridentado. G. Hansreia affinis (Fabricius, 1801), disco pronotal. H. Canthotrypes oberthuri Paulian, 1939, metatibia. 
A

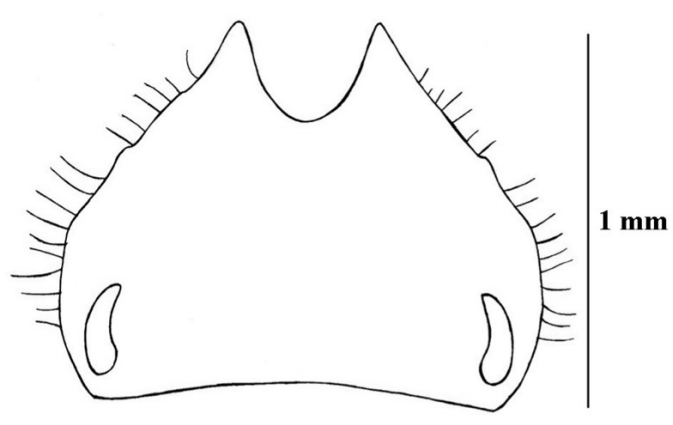

C

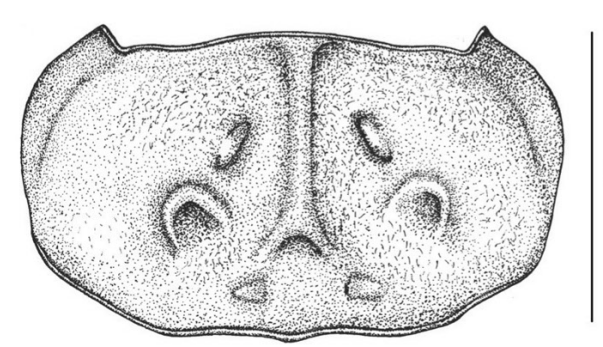

$\mathbf{E}$

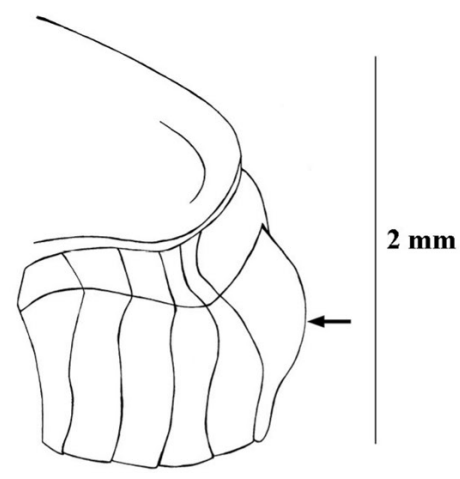

G

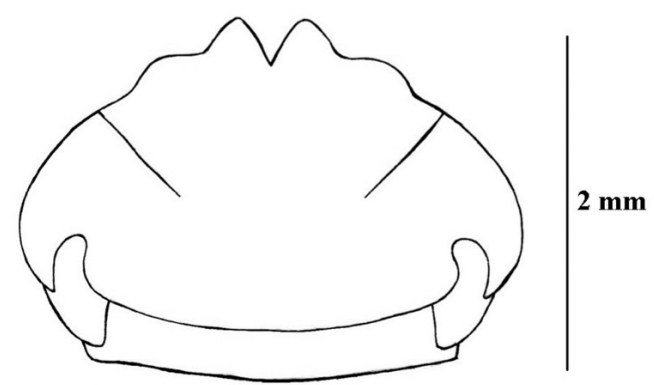

B

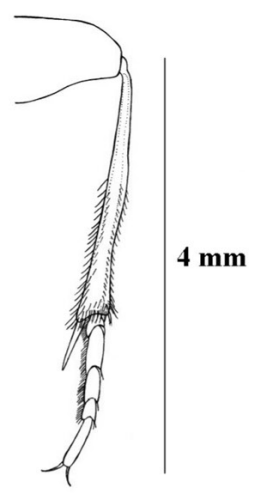

D

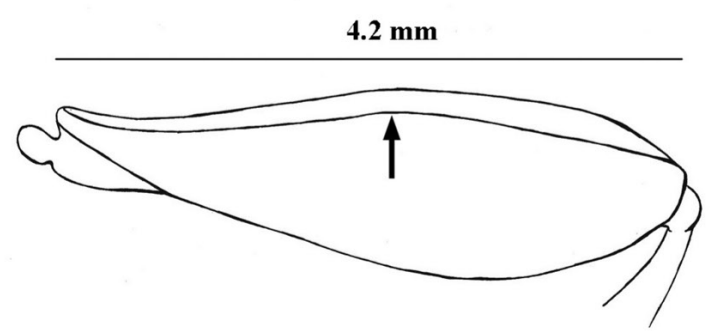

F

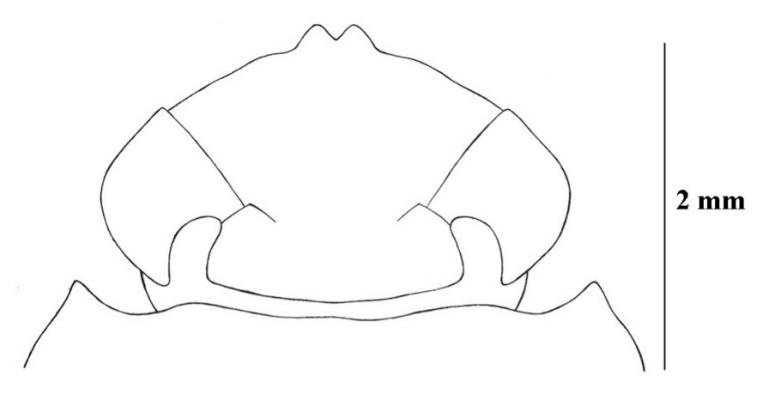

$\mathbf{H}$

Figura 10. A. Canthotrypes oberthuri Paulian, 1939, cabeza. B. Scybalocanthon kaestneri (Balthasar, 1939), metatibia. C. Anisocanthon villosus (Harold, 1868), disco pronotal. D. Canthon (Canthon) proseni Martínez, 1949, metafémur. E. Canthon (Goniacanthon) fulgidus Redtenbacher, 1867, pigidio. F. Canthon (Canthon) proseni Martínez, 1949, cabeza. G. Canthon (Glaphyrocanthon) pallidus Schmidt, 1922, cabeza. H. Canthon (Canthon) aberrans (Harold, 1868), propigidio. 
A
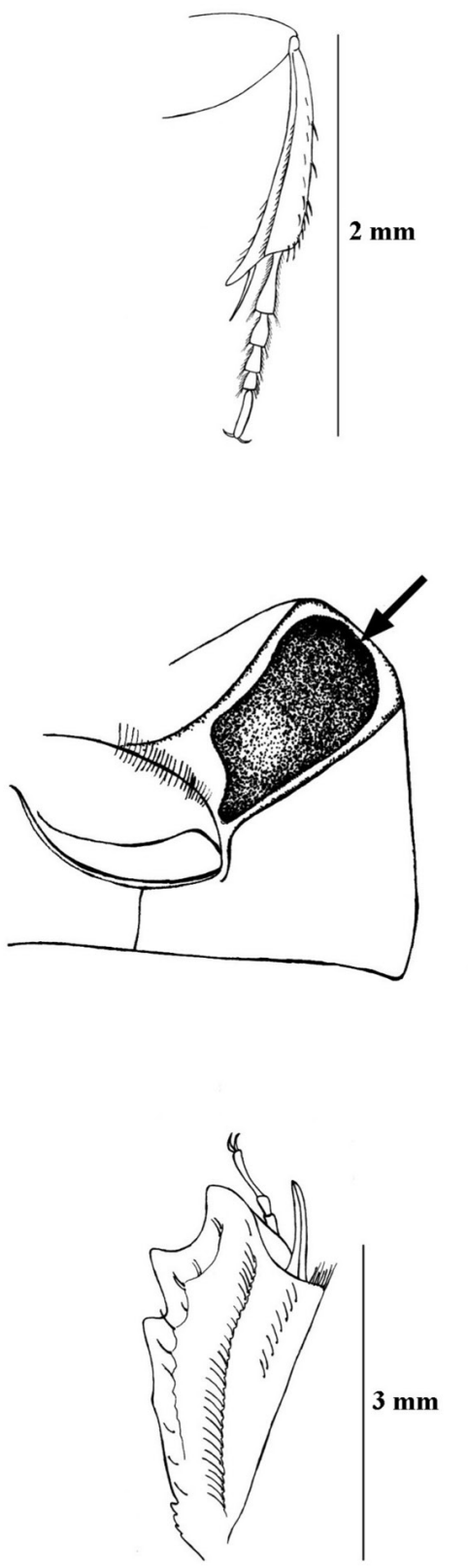

E

G

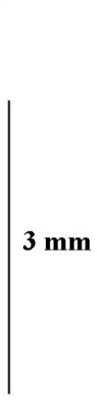

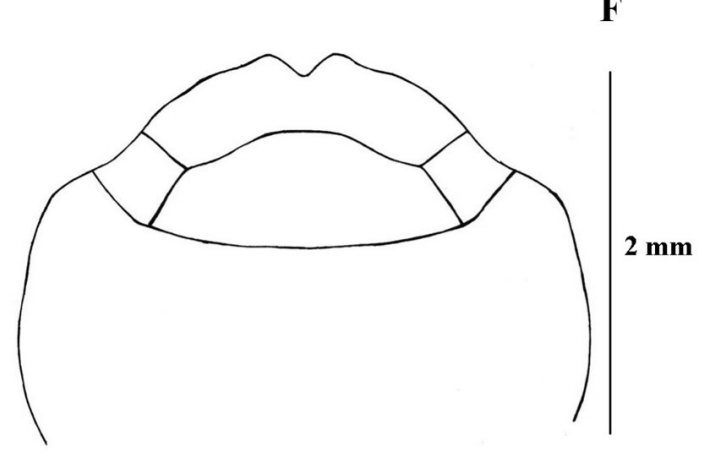

B

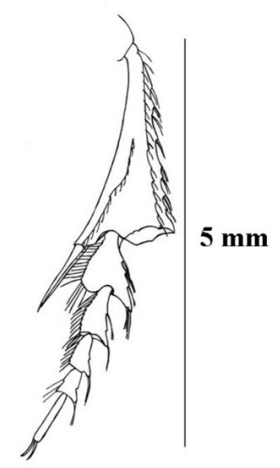

D

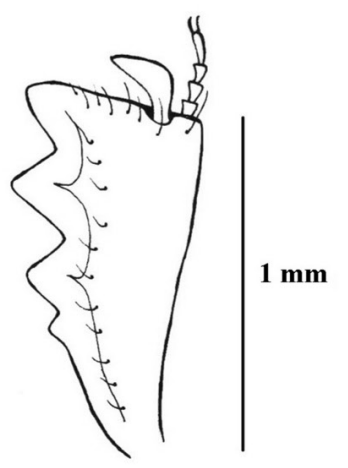

H

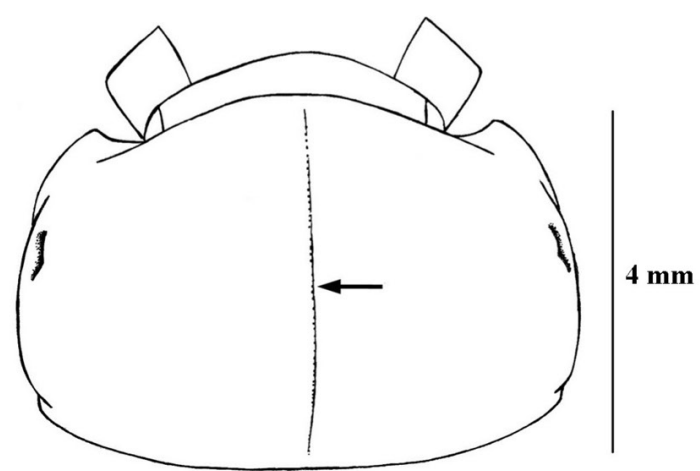

Figura 11. A. Sinapisoma sp., metatibia. B. Ontherus (Caelontherus) compressicornis Luederwaldt, 1931, metatibia. C. Ateuchus sp., propleura. D. Ateuchus sp., protibia. E. Canthidium (Canthidium) onitoides (Perty, 1830), protibia. F. Ateuchus scatimoides (Balthasar, 1939), cabeza. G. Deltorhinum batesi Harold, 1867, cabeza. H. Deltorhinum batesi Harold, 1867, pronoto. 

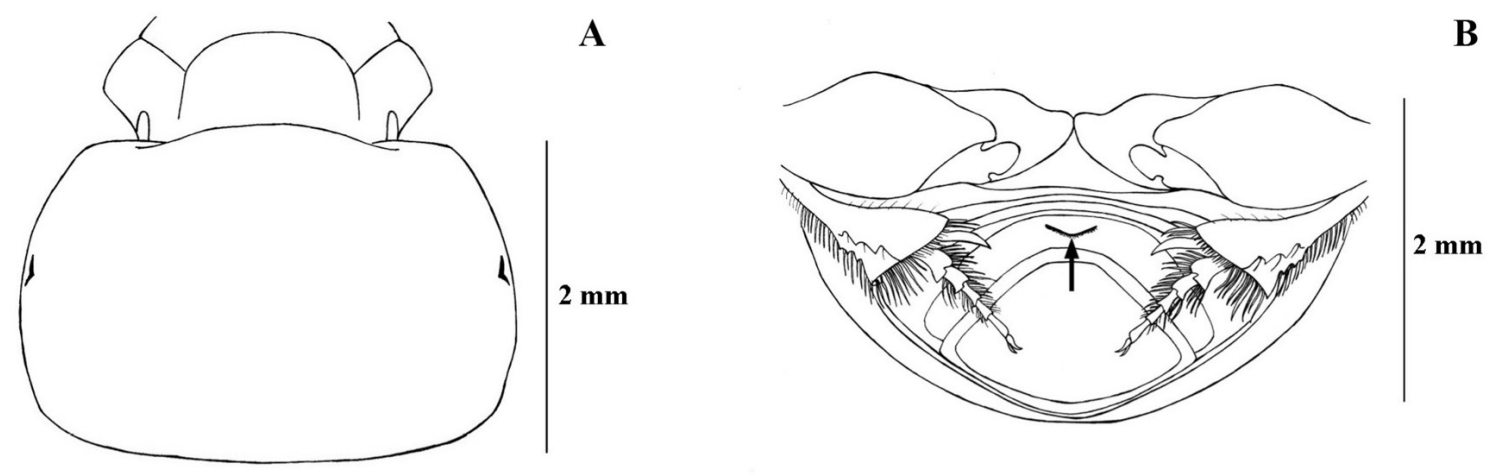

C

D
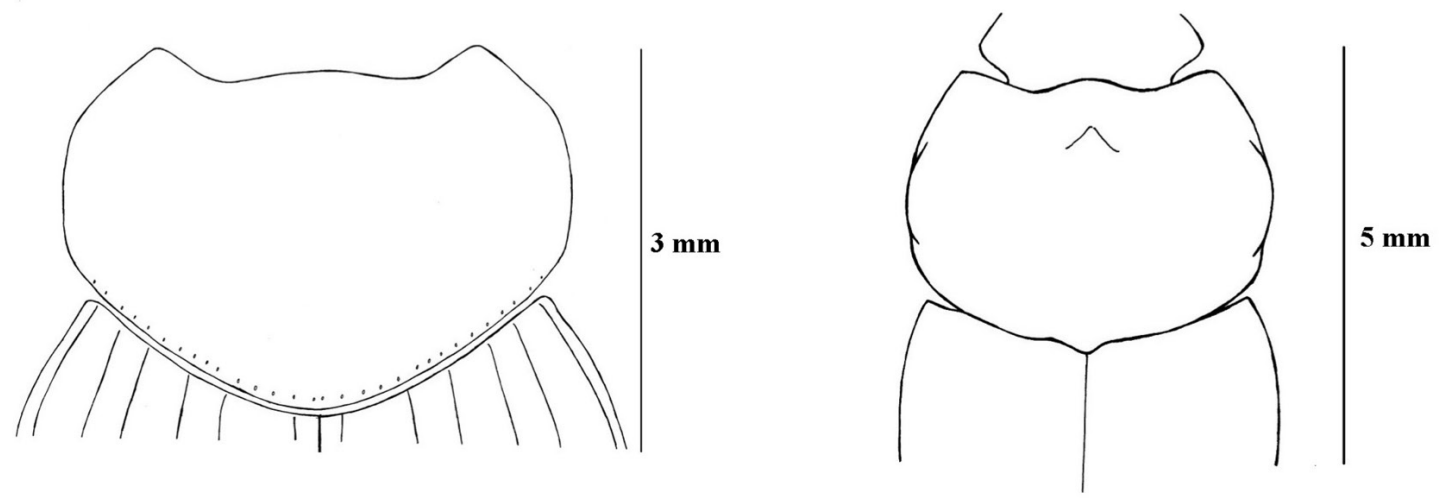

E

F
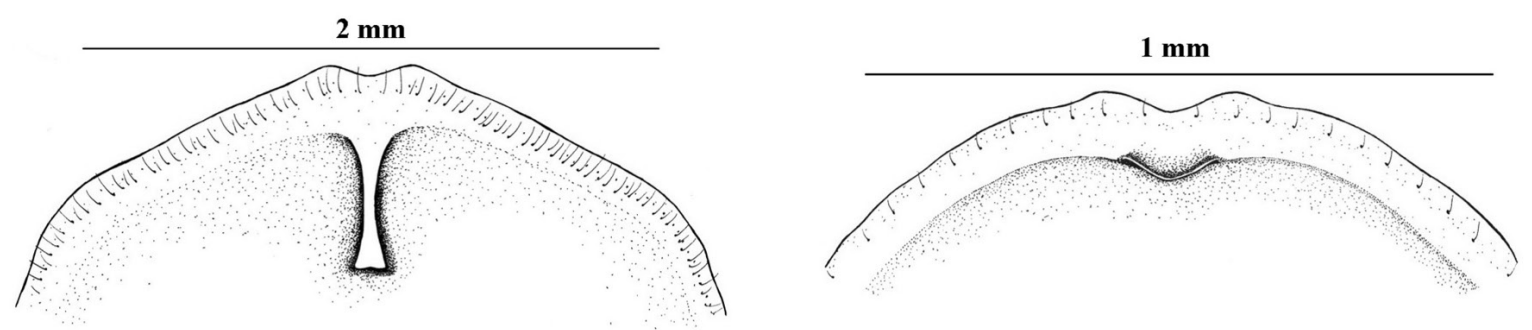

G
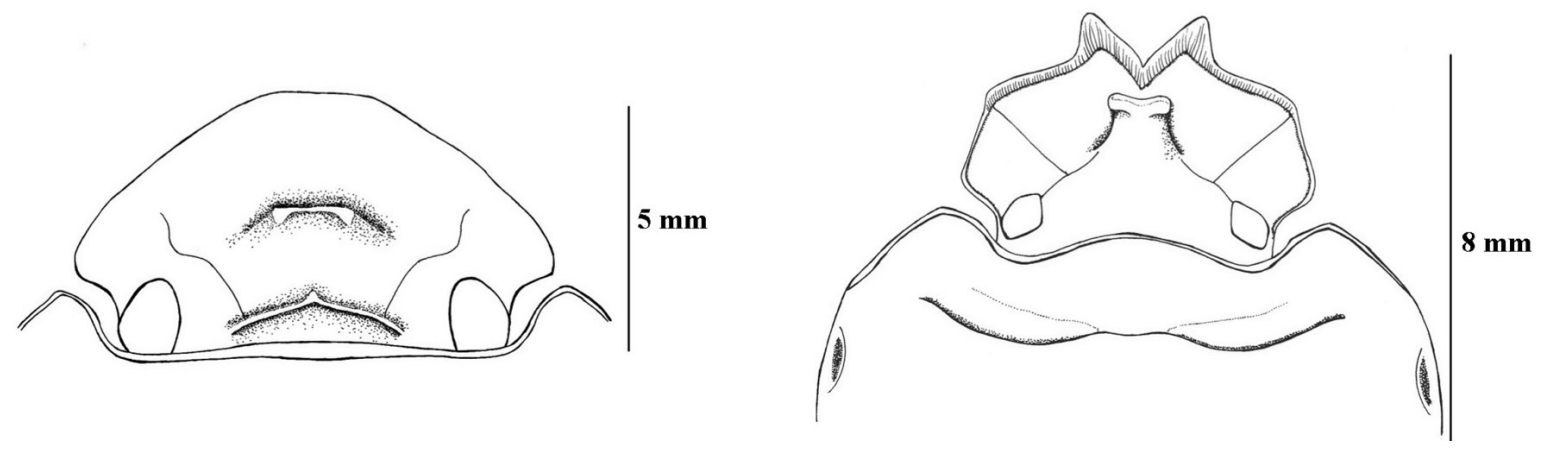

Figura 12. A. Lobidion punctatissimum Génier, 2010, pronoto. B. Lobidion punctatissimum Génier, 2010, esternitos abdominales en la hembra. C. Canthidium (Neocanthidium) coerulescens Balthasar, 1939, pronoto. D. Canthidium (Canthidium) onitoides (Perty, 1830), pronoto. E. Dichotomius (Dichotomius) cotopaxi (Guérin-Méneville, 1855), proceso clipeal ventral. F. Copris (Copris) incertus Say, 1835, proceso clipeal ventral. G. Dichotomius (Dichotomius) podalirius (Felsche, 1901), cabeza. H. Dichotomius (Selenocopris) sp., cabeza. 

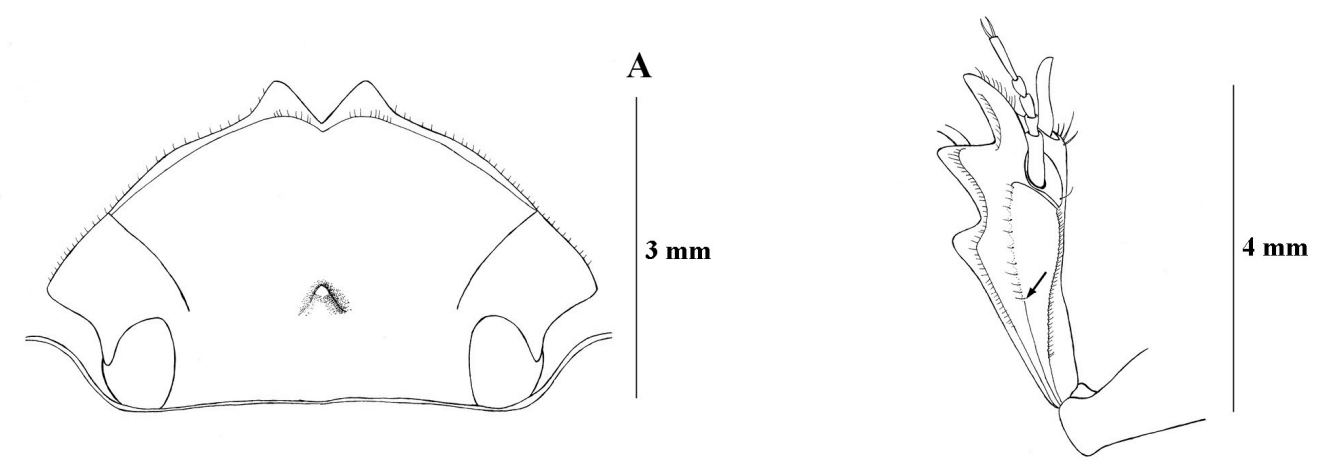

B

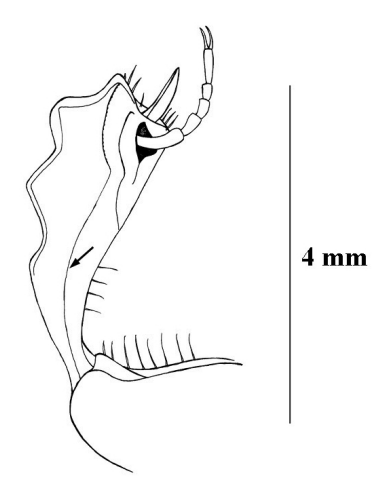

C

D

E
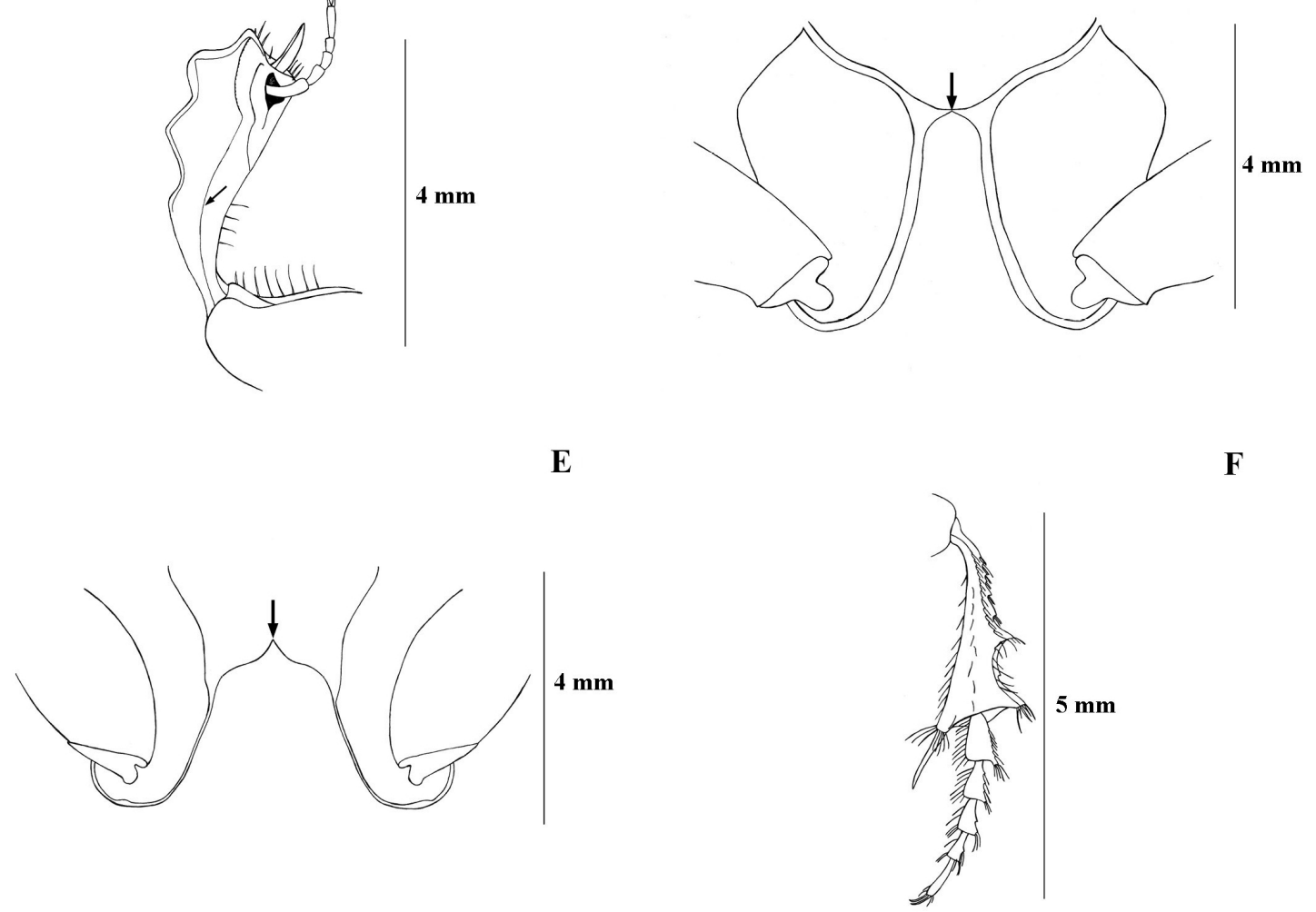

F

G

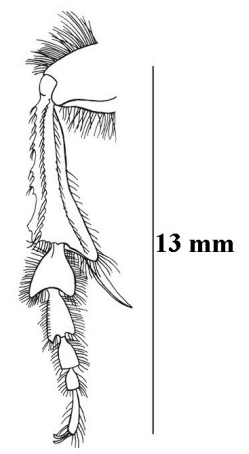

Figura 13. A. Dichotomius (Luederwaldtinia) fortepunctatus Luederwaldt, 1923, cabeza. B. Ontherus (Caelontherus) compressicornis Luederwaldt, 1931, protibia. C. Copris (Copris) incertus Say, 1835, protibia. D. Ontherus (Caelontherus) compressicornis Luederwaldt, 1931, mesoesterno. E. Ontherus (Ontherus) pubens Génier, 1996, mesoesterno. F. Copris (Copris) incertus Say, 1835, metatibia. G. Homocorpis achamas (Harold, 1867), metatibia. 
A continuación se presenta un listado actualizado (Tabla 1) con 220 especies para Ecuador, detallando la distribución en las provincias, su colección de referencia y/o en algunos casos su fuente bibliográfica. Al revisar las colecciones de referencia se determinó 19 nuevos registros de especies de Scarabaeinae para el país: Anomiopus pictus (Harold, 1862); Ateuchus aeneomicans (Harold, 1868); Ateuchus connexus (Harold, 1868); Bdelyrus lobatus Cook, 1998; Canthidium (Canthidium) funebre Balthasar, 1939; Canthidium muticum (Boheman, 1858); Canthidium (Canthidium) rufinum Harold, 1867; Canthon (Canthon) obscuriellus Schmidt, 1922; Canthon (Glaphyrocanthon) brunnipennis Schmidt, 1922; Canthon (Glaphyrocanthon) quadriguttatus (Olivier, 1789); Canthon (Glaphyrocanthon) semiopacus Harold, 1868; Canthon sericatus Schmidt, 1922; Dichotomius (Dichotomius) robustus (Luederwaldt, 1935); Dichotomius (Luderwaldtinia) simplicicornis (Luederwaldt, 1935); Eurysternus strigilatus Génier, 2009; Ontherus (Caelontherus) laminifer Balthasar, 1938; Ontherus (Caelontherus) tenustriatus Génier, 1996; Onthophagus (Onthophagus) digitifer Boucomont, 1932; Scybalocanthon moniliatus (Bates, 1887) y Uroxys pauliani Balthasar, 1940.

Esta lista fue ordenada alfabéticamente por géneros, subgéneros y finalmente por especies y no se incluyen nombres de tribus simplemente porque no existe un arreglo taxonómico o filogenético final. Los géneros: Canthonella, Eutrichillum y Sinapisoma son registrados pero aún no se han descrito sus respectivas especies.

En este trabajo reiteramos en mencionar taxones que probablemente se puedan encontrar en el territorio ecuatoriano.
Tal es el caso de algunos géneros, subgéneros y especies como: Digitonthophagus gazella (Fabricius, 1787) que ha sido introducida desde África y se encuentra en todo el territorio sudamericano exceptuando Ecuador (Vaz-De-Mello et al. 2011); Diabroctis mimas (Linnaeus, 1758) registrados en los llanos orientales de Colombia y la Amazonía norte del Perú (Medina et al. 2001; Figueroa et al. 2014) y por último la especie de amplio rango de distribución Coprophanaeus (Megaphanaeus) lancifer (Linnaeus, 1767) citada para casi toda la Amazonia sudamericana en países como: Bolivia, Brasil, Colombia, Guyana Francesa, Perú y Venezuela (Medina et al. 2001; Edmonds y Zidek 2004; Figueroa et al. 2014). Por lo tanto, es importante reportar a futuro sus registros por vez primera, sus métodos de colecta, estacionalidad, datos relevantes ecológicos y de historia natural que se puedan obtener.

El territorio ecuatoriano con su pequeña extensión de $283.561 \mathrm{~km}^{2}$ presenta hasta el momento 220 especies, una riqueza menor comparada con otros países sudamericanos como Brasil que enlistó 618 especies (Vaz-de-Mello 2000) y Colombia con 283 especies (Medina et al. 2001), sin embargo, presenta una riqueza mayor que Bolivia que registró 216 especies (Hamel-Leigue et al. 2006), Costa Rica que presenta 182 especies (Solís y Kohlmann 2012) y Panamá con 113 especies (Ratcliffe 2002). Con futuros estudios principalmente de revisiones de géneros y descripciones de especies, el número total de registros para Ecuador seguramente será incrementado.

Tabla 1. Listado de géneros, subgéneros y especies (Coleoptera: Scarabaeidae: Scarabaeinae) presentes en Ecuador.

\begin{tabular}{|c|c|c|c|}
\hline Género-Subgénero & Especie & Distribución & $\begin{array}{l}\text { Colección de referencia } \\
\text { y/o fuente bibliográfica }\end{array}$ \\
\hline \multirow{3}{*}{$\begin{array}{c}\text { Anomiopus } \\
\text { Westwood, } 1842\end{array}$} & $\begin{array}{l}\text { Anomiopus brevipes } \\
\text { (Waterhouse, 1891) }\end{array}$ & Orellana & Canhedo (2006) \\
\hline & $\begin{array}{l}\text { Anomiopus intermedius } \\
\text { (Waterhouse, 1891) }\end{array}$ & Orellana, Pastaza, Sucumbios & Canhedo (2006) \\
\hline & $\begin{array}{l}\text { Anomiopus pictus } \\
\text { (Harold, 1862) }\end{array}$ & Orellana & CEMT \\
\hline \multirow{5}{*}{$\begin{array}{l}\text { Ateuchus } \\
\text { Weber, } 1801\end{array}$} & $\begin{array}{l}\text { Ateuchus aeneomicans } \\
\text { (Harold, 1868) }\end{array}$ & Orellana, Pastaza & CEMT \\
\hline & $\begin{array}{l}\text { Ateuchus connexus } \\
\text { (Harold, 1868) }\end{array}$ & Orellana & CEMT \\
\hline & $\begin{array}{l}\text { Ateuchus ecuadorensis } \\
\text { (Boucomont, 1928) }\end{array}$ & $\begin{array}{l}\text { Bolívar, El Oro, Los Ríos, Manabí, Santa } \\
\text { Elena, Santo Domingo de los Tsáchilas }\end{array}$ & CEMT \\
\hline & $\begin{array}{l}\text { Ateuchus parvus } \\
\text { (Balthasar, 1939) }\end{array}$ & Los Ríos & CEMT \\
\hline & $\begin{array}{l}\text { Ateuchus scatimoides } \\
\text { (Balthasar, 1939) }\end{array}$ & $\begin{array}{c}\text { Orellana, Pastaza, Sucumbios, Zamora } \\
\text { Chinchipe }\end{array}$ & $\begin{array}{l}\text { CEMT, MEPN, MGO.UC, } \\
\text { MECN, MQCAZ, MUTPL }\end{array}$ \\
\hline \multirow{9}{*}{$\begin{array}{l}\text { Bdelyrus } \\
\text { Harold, } 1869\end{array}$} & Bdelyrus ecuadorae Cook, 2000 & Provincia sin determinar & Cook (2000) \\
\hline & Bdelyrus genieri Cook, 1998 & Napo, Orellana, Pastaza, Sucumbios & CEMT, MUTPL \\
\hline & Bdelyrus grandis Cook, 1998 & Sucumbios & CEMT, MQCAZ \\
\hline & Bdelyrus howdeni Cook, 1998 & Orellana, Pastaza, Sucumbios & CEMT, MUTPL \\
\hline & Bdelyrus lobatus Cook, 1998 & Pastaza & CEMT \\
\hline & Bdelyrus parvoculus Cook, 1998 & Napo & MQCAZ \\
\hline & Bdelyrus pecki Cook, 1998 & Napo, Sucumbios, Zamora Chinchipe & CEMT, MUTPL \\
\hline & Bdelyrus seminudus Bates, 1887 & Pichincha & CEMT, MUTPL \\
\hline & Bdelyrus triangulus Cook, 1998 & Napo & MQCAZ \\
\hline
\end{tabular}




\begin{tabular}{|c|c|c|c|c|}
\hline \multicolumn{2}{|c|}{ Género-Subgénero } & Especie & Distribución & $\begin{array}{l}\text { Colección de referencia } \\
\text { y/o fuente bibliográfica }\end{array}$ \\
\hline \multicolumn{2}{|c|}{$\begin{array}{c}\text { Bradypodidium } \\
\text { Vaz-de-Mello, } 2008\end{array}$} & $\begin{array}{l}\text { Bradypodidium bradyporum } \\
\text { (Boucomont, 1928) }\end{array}$ & Esmeraldas & CEMT \\
\hline \multirow{8}{*}{\multicolumn{2}{|c|}{$\begin{array}{l}\text { (Canthidium) } \\
\text { Erichson, } 1847\end{array}$}} & $\begin{array}{l}\text { Canthidium (Canthidium) } \\
\text { aurifex Bates, } 1887\end{array}$ & Los Ríos & Howden y Young (1981) \\
\hline & & $\begin{array}{c}\text { Canthidium (Canthidium) funebre } \\
\text { Balthasar, } 1939\end{array}$ & Sucumbios & MUTPL \\
\hline & & $\begin{array}{c}\text { Canthidium (Canthidium) hespenheidei } \\
\text { Howden \& Young, } 1981\end{array}$ & Pichincha & Howden y Young (1981) \\
\hline & & $\begin{array}{c}\text { Canthidium (Canthidium) macroculare } \\
\text { Howden \& Gill, } 1987\end{array}$ & Los Ríos & MQCAZ \\
\hline & & $\begin{array}{c}\text { Canthidium (Canthidium) onitoides } \\
\text { (Perty, 1830) }\end{array}$ & Orellana, Pastaza, Sucumbios & MUTPL \\
\hline & & $\begin{array}{c}\text { Canthidium (Canthidium) opacum } \\
\text { Balthasar, } 1939\end{array}$ & Loja & Bezdek y Hajek (2012) \\
\hline & & $\begin{array}{c}\text { Canthidium (Canthidium) orbiculatum } \\
\text { (Lucas, 1859) }\end{array}$ & Orellana, Sucumbios & CEMT \\
\hline & & $\begin{array}{c}\text { Canthidium (Canthidium) rufinum } \\
\text { Harold, } 1867\end{array}$ & Orellana, Sucumbios & CEMT \\
\hline \multirow{9}{*}{$\begin{array}{c}\text { Canthidium } \\
\text { Erichson, } 1847\end{array}$} & \multirow{6}{*}{$\begin{array}{l}\text { (Neocanthidium) } \\
\text { Martínez, Halffter, } \\
\text { \& Pereira, } 1986\end{array}$} & $\begin{array}{c}\text { Canthidium (Neocanthidium) centrale } \\
\text { Boucomont, } 1928\end{array}$ & Esmeraldas, Los Ríos & CEMT \\
\hline & & $\begin{array}{c}\text { Canthidium (Neocanthidium) coerulescens } \\
\text { Balthasar, } 1939\end{array}$ & $\begin{array}{l}\text { Sucumbios, Tungurahua, } \\
\text { Zamora Chinchipe }\end{array}$ & CEMT, MUTPL \\
\hline & & $\begin{array}{c}\text { Canthidium (Neocanthidium) escalerai } \\
\text { Balthasar, } 1939\end{array}$ & Guayas & Bezdek y Hajek (2012) \\
\hline & & $\begin{array}{c}\text { Canthidium (Neocanthidium) inoptatum } \\
\text { Balthasar, } 1939\end{array}$ & Chimborazo & Bezdek y Hajek (2012) \\
\hline & & $\begin{array}{c}\text { Canthidium (Neocanthidium) lentum } \\
\text { Erichson, } 1847\end{array}$ & Provincia sin determinar & Martínez y Halffter (1986) \\
\hline & & $\begin{array}{c}\text { Canthidium (Neocanthidium) luteum } \\
\text { Balthasar, } 1939\end{array}$ & Loja & Balthasar (1939a) \\
\hline & \multirow{3}{*}{ Incertae sedis } & Canthidium flavum Balthasar, 1939 & Loja & Balthasar (1939a) \\
\hline & & Canthidium muticum (Boheman, 1858) & El Oro & CEMT \\
\hline & & $\begin{array}{c}\text { Canthidium pseudaurifex } \\
\text { Balthasar, } 1939\end{array}$ & $\begin{array}{c}\text { Esmeraldas, Imbabura, Los Ríos, } \\
\text { Santa Elena }\end{array}$ & CEMT \\
\hline \multirow{11}{*}{$\begin{array}{c}\text { Canthon } \\
\text { Hoffmannsegg, } \\
1817\end{array}$} & \multirow{5}{*}{$\begin{array}{c}\text { (Canthon) } \\
\text { Hoffmannsegg, } \\
1817\end{array}$} & $\begin{array}{c}\text { Canthon (Canthon) aberrans } \\
\text { (Harold, 1868) }\end{array}$ & $\begin{array}{c}\text { Cotopaxi, El Oro, Esmeraldas, } \\
\text { Imbabura, Manabí, Morona Santia- } \\
\text { go, Napo, Orellana, Pichincha, Santo } \\
\text { Domingo de los Tsáchilas, Sucumbios, } \\
\text { Tungurahua, Zamora Chinchipe }\end{array}$ & $\begin{array}{l}\text { CEMT, MECN, MQCAZ, } \\
\text { MUTPL }\end{array}$ \\
\hline & & $\begin{array}{c}\text { Canthon (Canthon) delicatulus } \\
\text { Balthasar, } 1939\end{array}$ & $\begin{array}{c}\text { Azuay, El Oro, Esmeraldas, Guayas, } \\
\text { Los Ríos, Loja, Manabí, Pichincha, Santo } \\
\text { Domingo de los Tsáchilas }\end{array}$ & CEMT, MQCAZ, MUTPL \\
\hline & & $\begin{array}{c}\text { Canthon (Canthon) gemellatus } \\
\text { Erichson, } 1847\end{array}$ & Provincia sin determinar & Balthasar (1939b) \\
\hline & & $\begin{array}{c}\text { Canthon (Canthon) obscuriellus } \\
\text { Schmidt, } 1922\end{array}$ & Imbabura & CEMT, MQCAZ \\
\hline & & $\begin{array}{l}\text { Canthon (Canthon) proseni } \\
\text { (Martínez, 1948) }\end{array}$ & $\begin{array}{c}\text { Morona Santiago, Napo, Orellana, } \\
\text { Pastaza, Sucumbios, Zamora Chinchipe }\end{array}$ & $\begin{array}{l}\text { CEMT, MEPN, MGO.UC, } \\
\text { MQCAZ, MUTPL }\end{array}$ \\
\hline & \multirow{6}{*}{$\begin{array}{l}\text { (Glaphyrocanthon) } \\
\text { Martínez, } 1948\end{array}$} & $\begin{array}{c}\text { Canthon (Glaphyrocanthon) angustatus } \\
\text { Harold, } 1867\end{array}$ & Esmeraldas, Los Ríos, Manabí & CEMT, MECN, MQCAZ \\
\hline & & $\begin{array}{c}\text { Canthon (Glaphyrocanthon) angustatus } \\
\text { ohausi Balthasar, } 1939\end{array}$ & Pastaza & Bezdek y Hajek (2011) \\
\hline & & $\begin{array}{c}\text { Canthon (Glaphyrocanthon) bimaculatus } \\
\text { Schmidt, } 1922\end{array}$ & Orellana, Sucumbios & MQCAZ, MUTPL \\
\hline & & $\begin{array}{l}\text { Canthon (Glaphyrocanthon) } \\
\text { brunnipennis Schmidt, } 1922\end{array}$ & Sucumbios & CEMT \\
\hline & & $\begin{array}{c}\text { Canthon (Glaphyrocanthon) luteicollis } \\
\text { Erichson, } 1847\end{array}$ & $\begin{array}{c}\text { Morona Santiago, Napo, Orellana, } \\
\text { Pastaza, Sucumbios, Tungurahua, Zamora } \\
\text { Chinchipe }\end{array}$ & $\begin{array}{l}\text { CEMT, MECN, MGO.UC, } \\
\text { MQCAZ, MUTPL }\end{array}$ \\
\hline & & $\begin{array}{c}\text { Canthon (Glaphyrocanthon) pallidus } \\
\text { Schmidt, } 1922\end{array}$ & $\begin{array}{c}\text { Napo, Sucumbios, Tungurahua, Zamora } \\
\text { Chinchipe }\end{array}$ & CEMT, MQCAZ, MUTPL \\
\hline
\end{tabular}




\begin{tabular}{|c|c|c|c|c|}
\hline Género- & Subgénero & Especie & Distribución & $\begin{array}{l}\text { Colección de referencia } \\
\text { y/o fuente bibliográfica }\end{array}$ \\
\hline \multirow{11}{*}{$\begin{array}{c}\text { Canthon } \\
\text { Hoffmannsegg, } \\
1817\end{array}$} & \multirow[t]{6}{*}{$\begin{array}{l}\text { (Glaphyrocanthon) } \\
\text { Martinez, } 1948\end{array}$} & $\begin{array}{l}\text { Canthon (Glaphyrocanthon) plagiatus } \\
\text { Harold, } 1880\end{array}$ & Provincia sin determinar & MNHN \\
\hline & & $\begin{array}{l}\text { Canthon (Glaphyrocanthon) politus } \\
\text { Harold, } 1868\end{array}$ & Napo, Zamora Chinchipe & CEMT \\
\hline & & $\begin{array}{l}\text { Canthon (Glaphyrocanthon) } \\
\text { quadriguttatus (Olivier, 1789) }\end{array}$ & $\begin{array}{l}\text { Orellana, Pastaza, Sucumbios, Tungu- } \\
\text { rahua, Zamora Chinchipe }\end{array}$ & CEMT, MUTPL \\
\hline & & $\begin{array}{c}\text { Canthon (Glaphyrocanthon) semiopacus } \\
\text { Harold, } 1868\end{array}$ & Napo, Sucumbios & MQCAZ, MUTPL \\
\hline & & $\begin{array}{c}\text { Canthon (Glaphyrocanthon) subhyalinus } \\
\text { Harold, } 1867\end{array}$ & Provincia sin determinar & Schmidt (1922) \\
\hline & & $\begin{array}{c}\text { Canthon (Glaphyrocanthon) subhyalinoides } \\
\text { Balthasar, } 1939\end{array}$ & $\begin{array}{l}\text { El Oro, Esmeraldas, Guayas, Los Ríos, } \\
\text { Manabí, Santa Elena }\end{array}$ & CEMT, MGO.UC, MUTPL \\
\hline & $\begin{array}{l}\text { (Goniacanthon) } \\
\text { Pereira \& } \\
\text { Martínez, } 1956\end{array}$ & $\begin{array}{l}\text { Canthon (Goniacanthon) fulgidus } \\
\text { Redtenbacher, } 1867\end{array}$ & Napo, Orellana, Pastaza, Sucumbios & $\begin{array}{l}\text { CEMT, MECN, MGO.UC, } \\
\text { MQCAZ, MUTPL }\end{array}$ \\
\hline & \multirow{4}{*}{ Incertae sedis } & Cathon balteatus Boheman, 1858 & $\begin{array}{l}\text { Azuay, El Oro, Guayas, Manabí, Los } \\
\text { Ríos, Santa Elena }\end{array}$ & CEMT, MQCAZ, MUTPL \\
\hline & & Canthon balteatus lojanus Balthasar, 1939 & Loja & MUTPL \\
\hline & & Canthon fuscipes Erichson, 1847 & Provincia sin determinar & Schmidt (1922) \\
\hline & & Canthon sericatus Schmidt, 1922 & Pastaza & CEMT \\
\hline \multicolumn{2}{|c|}{ Canthonella Chapin, 1930} & Canthonella sp. & Pastaza & CEMT, MUTPL \\
\hline $\begin{array}{c}\text { Copris } \\
\text { Geoffroy, } 1762 \\
\end{array}$ & $\begin{array}{c}\text { (Copris) } \\
\text { Geoffroy, } 1762\end{array}$ & Copris (Copris) incertus Say, 1835 & $\begin{array}{l}\text { Bolívar, Cotopaxi, Imbabura, El Oro, } \\
\text { Esmeraldas, Los Ríos, Santa Elena }\end{array}$ & CEMT \\
\hline \multirow{7}{*}{$\begin{array}{l}\text { Coprophanaeus } \\
\text { d'Olsoufieff, } \\
1924\end{array}$} & \multirow{7}{*}{$\begin{array}{l}\text { (Coprophanaeus) } \\
\text { d'Olsoufieff, } 1924\end{array}$} & $\begin{array}{l}\text { Coprophanaeus (Coprophanaeus) } \\
\text { callegarii Arnaud, } 2002\end{array}$ & Sucumbios & Arnaud (2002) \\
\hline & & $\begin{array}{l}\text { Coprophanaeus (Coprophanaeus) } \\
\text { conocephalus (d'Olsoufieff, 1924) }\end{array}$ & $\begin{array}{c}\text { Bolívar, Cañar, Carchi, Guayas, Loja, } \\
\text { Manabí, Pichincha }\end{array}$ & $\begin{array}{l}\text { CEMT, MECN, MQCAZ, } \\
\text { MUTPL }\end{array}$ \\
\hline & & $\begin{array}{c}\text { Coprophanaeus (Coprophanaeus) jasius } \\
\text { (Olivier, 1789) }\end{array}$ & Napo & Arnaud (2002) \\
\hline & & $\begin{array}{c}\text { Coprophanaeus (Coprophanaeus) } \\
\text { morenoi Arnaud, } 1982\end{array}$ & $\begin{array}{l}\text { Carchi, Cotopaxi, Esmeraldas, Pichincha, } \\
\text { Santo Domingo de los Tsáchilas }\end{array}$ & $\begin{array}{l}\text { CEMT, MECN, MGO.UC, } \\
\text { MQCAZ, MUTPL }\end{array}$ \\
\hline & & $\begin{array}{c}\text { Coprophanaeus (Coprophanaeus) } \\
\text { ohausi (Felsche, 1911) }\end{array}$ & $\begin{array}{l}\text { Loja, Morona Santiago, Napo, Orellana, } \\
\text { Pastaza, Sucumbios, Tungurahua, Zamora } \\
\text { Chinchipe }\end{array}$ & $\begin{array}{l}\text { CEMT, MECN, MEPN, } \\
\text { MUTPL }\end{array}$ \\
\hline & & $\begin{array}{l}\text { Coprophanaeus (Coprophanaeus) } \\
\text { suredai Arnaud, } 1996\end{array}$ & Sucumbios & Arnaud (1996) \\
\hline & & $\begin{array}{l}\text { Coprophanaeus (Coprophanaeus) } \\
\text { telamon (Erichson, 1847) }\end{array}$ & $\begin{array}{l}\text { Morona Santiago, Napo, Orellana, Pasta- } \\
\text { za, Sucumbios, Zamora Chinchipe }\end{array}$ & $\begin{array}{l}\text { CEMT, MEPN, MGO.UC, } \\
\text { MQCAZ, MUTPL }\end{array}$ \\
\hline \multirow{6}{*}{\multicolumn{2}{|c|}{$\begin{array}{l}\text { Cryptocanthon } \\
\text { Balthasar, } 1942\end{array}$}} & $\begin{array}{l}\text { Cryptocanthon curticrinis } \\
\text { Cook, } 2002\end{array}$ & Napo & Cook (2002) \\
\hline & & $\begin{array}{l}\text { Cryptocanthon genieri } \\
\text { Cook, } 2002\end{array}$ & Napo, Pastaza & Cook (2002) \\
\hline & & $\begin{array}{l}\text { Cryptocanthon napoensis } \\
\text { Cook, } 2002 \\
\end{array}$ & Napo & CEMT, MUTPL \\
\hline & & $\begin{array}{l}\text { Cryptocanthon otonga } \\
\text { Cook, } 2002\end{array}$ & Cotopaxi & CEMT, MQCAZ \\
\hline & & $\begin{array}{l}\text { Cryptocanthon paradoxus } \\
\text { Balthasar, } 1942 \\
\end{array}$ & Loja & Bezdek y Hajek (2011) \\
\hline & & $\begin{array}{l}\text { Cryptocanthon urguensis } \\
\text { Cook, } 2002\end{array}$ & Napo & Cook (2002) \\
\hline \multirow{5}{*}{$\begin{array}{l}\text { Deltochilum } \\
\text { Eschscholtz, }\end{array}$} & \multirow{2}{*}{$\begin{array}{l}\text { (Aganhyboma) } \\
\text { Kolbe, } 1893\end{array}$} & $\begin{array}{l}\text { Deltochilum (Aganhyboma) arturoi } \\
\text { Silva, Louzada \& Vaz-de-Mello, } 2015\end{array}$ & $\begin{array}{l}\text { Pichincha, Santo Domingo } \\
\text { de los Tsáchilas }\end{array}$ & CEMT \\
\hline & & $\begin{array}{l}\text { Deltochilum (Aganhyboma) larseni Silva, } \\
\text { Louzada \& Vaz-de-Mello, } 2015\end{array}$ & Pastaza, Sucumbios & CEMT \\
\hline & \multirow[b]{3}{*}{$\begin{array}{l}(\text { Calhyboma }) \\
\text { Kolbe, } 1893\end{array}$} & $\begin{array}{c}\text { Deltochilum (Calhyboma) carinatum } \\
\text { (Westwood, 1837) }\end{array}$ & $\begin{array}{l}\text { Morona Santiago, Napo, Orellana, } \\
\text { Pastaza, Sucumbios, Zamora Chinchipe }\end{array}$ & $\begin{array}{l}\text { CEMT, MECN, MEPN, } \\
\text { MGO.UC, MQCAZ, MUTPL }\end{array}$ \\
\hline & & $\begin{array}{l}\text { Deltochilum (Calhyboma) hypponum } \\
\text { (Buquet, 1844) }\end{array}$ & Sucumbios & MECN, MUTPL \\
\hline & & $\begin{array}{l}\text { Deltochilum (Calhyboma) luederwaldti } \\
\text { Pereira \& D'Andretta, } 1955\end{array}$ & Pichincha & González et al. (2009) \\
\hline
\end{tabular}




\begin{tabular}{|c|c|c|c|c|}
\hline \multicolumn{2}{|c|}{ Género-Subgénero } & Especie & Distribución & $\begin{array}{l}\text { Colección de referencia } \\
\text { y/o fuente bibliográfica }\end{array}$ \\
\hline \multirow{4}{*}{\multicolumn{2}{|c|}{$\begin{array}{l}\text { (Calhyboma) } \\
\text { Kolbe, } 1893\end{array}$}} & $\begin{array}{c}\text { Deltochilum (Calhyboma) mexicanum } \\
\text { Burmeister, } 1848\end{array}$ & Guayas, Pichincha & $\begin{array}{c}\text { Pereira y D'Andretta (1955); } \\
\text { Paulian (1939) }\end{array}$ \\
\hline & & $\begin{array}{l}\text { Deltochilum (Calhyboma) robustus } \\
\text { Molano \& González, } 2009\end{array}$ & $\begin{array}{l}\text { Loja, Morona Santiago, Napo, Pastaza, } \\
\text { Zamora Chinchipe }\end{array}$ & $\begin{array}{l}\text { CEMT, MEPN, MQCAZ, } \\
\text { MUTPL }\end{array}$ \\
\hline & & $\begin{array}{c}\text { Deltochilum (Calhyboma) tessellatum } \\
\text { Bates, } 1870\end{array}$ & $\begin{array}{l}\text { Carchi, Morona Santiago, Napo, Tungu- } \\
\text { rahua, Zamora Chinchipe }\end{array}$ & $\begin{array}{l}\text { CEMT, MECN, MEPN, } \\
\text { MQCAZ, MUTPL }\end{array}$ \\
\hline & & $\begin{array}{l}\text { Deltochilum tessellatum arrowi } \\
\text { Paulian, } 1939\end{array}$ & Cañar, Cotopaxi, Pichincha & CEMT \\
\hline \multirow{11}{*}{$\begin{array}{l}\text { Deltochilum } \\
\text { Eschscholtz, } \\
1822\end{array}$} & \multirow{2}{*}{$\begin{array}{c}\text { (Deltochilum) } \\
\text { Eschscholtz, } 1822\end{array}$} & $\begin{array}{c}\text { Deltochilum (Deltochilum) orbiculare } \\
\text { Lansberge, } 1874\end{array}$ & $\begin{array}{c}\text { Morona Santiago, Napo, Orellana, Pasta- } \\
\text { za, Sucumbios }\end{array}$ & MQCAZ, MUTPL \\
\hline & & $\begin{array}{c}\text { Deltochilum (Deltochilum) rosamariae } \\
\text { Martínez, } 1991\end{array}$ & $\begin{array}{c}\text { Esmeraldas, Guayas, Los Ríos, Manabí, } \\
\text { Santa Elena, Santo Domingo de los } \\
\text { Tsáchilas }\end{array}$ & CEMT, MQCAZ, MUTPL \\
\hline & \multirow{6}{*}{$\begin{array}{l}\text { (Deltohyboma) } \\
\text { Lane, } 1946\end{array}$} & $\begin{array}{c}\text { Deltochilum (Deltohyboma) aequinotiale } \\
\text { (Buquet, 1844) }\end{array}$ & Cotopaxi, Pichincha & CEMT, MQCAZ, MUTPL \\
\hline & & $\begin{array}{c}\text { Deltochilum (Deltohyboma) barbipes } \\
\text { Bates, } 1870\end{array}$ & Morona Santiago, Pastaza & CEMT, MUTPL \\
\hline & & $\begin{array}{c}\text { Deltochilum (Deltohyboma) batesi } \\
\text { Paulian, } 1938\end{array}$ & Orellana & CEMT \\
\hline & & $\begin{array}{c}\text { Deltochilum (Deltohyboma) crenulipes } \\
\text { Paulian, } 1938\end{array}$ & $\begin{array}{l}\text { Morona Santiago, Napo, Orellana, Pasta- } \\
\text { za, Sucumbios, Zamora Chinchipe }\end{array}$ & $\begin{array}{l}\text { CEMT, MECN, MGO.UC, } \\
\text { MQCAZ, MUTPL }\end{array}$ \\
\hline & & $\begin{array}{c}\text { Deltochilum (Deltohyboma) peruanum } \\
\text { Paulian, } 1938\end{array}$ & Morona Santiago, Pastaza & $\begin{array}{c}\text { Paulian (1939); } \\
\text { Bezdek y Hajek (2011) }\end{array}$ \\
\hline & & $\begin{array}{c}\text { Deltochilum (Deltohyboma) } \\
\text { speciosissimum Balthasar, } 1939\end{array}$ & Provincia sin determinar & Bezdek y Hajek (2011) \\
\hline & \multirow{3}{*}{$\begin{array}{l}\text { (Hybomidium) } \\
\text { Shipp, } 1897\end{array}$} & $\begin{array}{l}\text { Deltochilum (Hybomidium) loperae } \\
\text { González \& Molano, } 2009\end{array}$ & Carchi, Cotopaxi, Esmeraldas & CEMT, MECN \\
\hline & & $\begin{array}{c}\text { Deltochilum (Hybomidium) orbignyi } \\
\text { amazonicum Bates, } 1887\end{array}$ & $\begin{array}{c}\text { Morona Santiago, Napo, Orellana, } \\
\text { Pastaza, Sucumbios, Tungurahua, Zamora } \\
\text { Chinchipe }\end{array}$ & $\begin{array}{l}\text { CEMT, MGO.UC, MQCAZ, } \\
\text { MUTPL }\end{array}$ \\
\hline & & $\begin{array}{c}\text { Deltochilum (Hybomidium) panamensis } \\
\text { Howden, } 1966\end{array}$ & $\begin{array}{l}\text { Bolívar, Esmeraldas, El Oro, Imbabura, } \\
\text { Manabí, Pichincha, Santa Elena, Santo } \\
\text { Domingo de los Tsáchilas }\end{array}$ & $\begin{array}{l}\text { CEMT, MECN, MGO.UC, } \\
\text { MQCAZ, MUTPL }\end{array}$ \\
\hline \multirow{2}{*}{$\begin{array}{l}\text { Dendropaemon } \\
\text { Perty, } 1830\end{array}$} & $\begin{array}{l}\text { (Crassipaemon) } \\
\text { Cupello \& Génier, } \\
2017\end{array}$ & $\begin{array}{c}\text { Dendropaemon (Crassipaemon) morettoi } \\
\text { Génier \& Arnaud, } 2016\end{array}$ & Morona Santiago & Génier y Arnaud (2016) \\
\hline & $\begin{array}{l}\text { (Glaphyropaemon) } \\
\text { Génier \& } \\
\text { Arnaud, } 2016\end{array}$ & $\begin{array}{l}\text { Dendropaemon (Glaphyropaemon) } \\
\text { angustipennis Harold, } 1869\end{array}$ & Orellana & MQCAZ \\
\hline \multirow{10}{*}{$\begin{array}{l}\text { Dichotomius } \\
\text { Hope, } 1838\end{array}$} & \multirow{10}{*}{$\begin{array}{l}\text { (Dichotomius) } \\
\text { Hope, } 1838\end{array}$} & $\begin{array}{c}\text { Dichotomius (Dichotomius) } \\
\text { compressicollis (Luederwaldt, 1929) }\end{array}$ & Napo, Orellana, Pastaza, Sucumbios & CEMT, MUTPL \\
\hline & & $\begin{array}{l}\text { Dichotomius (Dichotomius) cotopaxi } \\
\text { (Guerin- Meneville, 1855) }\end{array}$ & $\begin{array}{l}\text { Azuay, Bolívar, Cañar, Cotopaxi, } \\
\text { Chimborazo, Loja, Tungurahua }\end{array}$ & CEMT, MQCAZ, MUTPL \\
\hline & & $\begin{array}{l}\text { Dichotomius (Dichotomius) divergens } \\
\text { (Luederwaldt, 1923) }\end{array}$ & $\begin{array}{l}\text { Bolívar, Carchi, Cotopaxi, Esmeraldas, } \\
\text { Guayas, Imbabura, Los Ríos, Pichincha, } \\
\text { Santo Domingo de los Tsáchilas }\end{array}$ & $\begin{array}{l}\text { CEMT, MECN, MGO.UC, } \\
\text { MQCAZ, MUTPL }\end{array}$ \\
\hline & & $\begin{array}{c}\text { Dichotomius (Dichotomius) mamillatus } \\
\text { (Felsche, 1901) }\end{array}$ & $\begin{array}{l}\text { Morona Santiago, Napo, Orellana, } \\
\text { Pastaza, Sucumbios, Zamora Chinchipe }\end{array}$ & $\begin{array}{c}\text { CEMT, MECN, MEPN, } \\
\text { MGO.UC, MQCAZ, MUTPL }\end{array}$ \\
\hline & & $\begin{array}{c}\text { Dichotomius (Dichotomius) monstrosus } \\
\text { (Harold, 1875) }\end{array}$ & Carchi, Napo, Sucumbios & $\begin{array}{l}\text { CEMT, MEPN, MQCAZ, } \\
\text { MUTPL }\end{array}$ \\
\hline & & $\begin{array}{l}\text { Dichotomius (Dichotomius) ohausi } \\
\text { (Luederwaldt, 1923) }\end{array}$ & $\begin{array}{c}\text { Morona Santiago, Napo, Orellana, } \\
\text { Pastaza, Sucumbios, Zamora Chinchipe }\end{array}$ & $\begin{array}{l}\text { CEMT, MECN, MQCAZ, } \\
\text { MUTPL }\end{array}$ \\
\hline & & $\begin{array}{c}\text { Dichotomius (Dichotomius) podalirius } \\
\text { (Felsche, 1901) }\end{array}$ & $\begin{array}{l}\text { Napo, Orellana, Pastaza, Sucumbios, } \\
\text { Zamora Chinchipe }\end{array}$ & $\begin{array}{l}\text { CEMT, MECN, MGO.UC, } \\
\text { MQCAZ, MUTPL }\end{array}$ \\
\hline & & $\begin{array}{c}\text { Dichotomius (Dichotomius) prietoi } \\
\text { Martínez \& Martínez, } 1982\end{array}$ & Morona Santiago, Zamora Chinchipe & MEPN, MQCAZ, MUTPL \\
\hline & & $\begin{array}{c}\text { Dichotomius (Dichotomius) protectus } \\
\text { (Harold, 1867) }\end{array}$ & $\begin{array}{l}\text { Morona Santiago, Napo, Pastaza, } \\
\text { Sucumbios, Tungurahua, Zamora } \\
\text { Chinchipe }\end{array}$ & $\begin{array}{l}\text { CEMT, MECN, MEPN, } \\
\text { MQCAZ, MUTPL }\end{array}$ \\
\hline & & $\begin{array}{c}\text { Dichotomius (Dichotomius) provisorius } \\
\text { (Luederwaldt, 1925) }\end{array}$ & Provincia sin determinar & Luederwaldt (1925) \\
\hline
\end{tabular}




\begin{tabular}{|c|c|c|c|c|}
\hline Géner & Subgénero & Especie & Distribución & $\begin{array}{l}\text { Colección de referencia } \\
\text { y/o fuente bibliográfica }\end{array}$ \\
\hline \multirow{9}{*}{\multicolumn{2}{|c|}{$\begin{array}{l}\text { Dichotomius } \\
\text { Hope, } 1838\end{array}$}} & $\begin{array}{c}\text { Dichotomius (Dichotomius) quinquedens } \\
\text { (Felsche, 1910) }\end{array}$ & $\begin{array}{c}\text { Bolívar, Carchi, Cotopaxi, El Oro, } \\
\text { Esmeraldas, Imbabura, Manabí, } \\
\text { Pichincha, Santo Domingo de los } \\
\text { Tsáchilas }\end{array}$ & $\begin{array}{l}\text { CEMT, MEPN, MQCAZ, } \\
\text { MUTPL }\end{array}$ \\
\hline & & $\begin{array}{c}\text { Dichotomius (Dichotomius) quiquelobatus } \\
\text { (Felsche, 1901) }\end{array}$ & $\begin{array}{l}\text { Morona Santiago, Napo, Pastaza, } \\
\text { Sucumbios, Zamora Chinchipe }\end{array}$ & $\begin{array}{l}\text { CEMT, MECN, MEPN, } \\
\text { MQCAZ, MUTPL }\end{array}$ \\
\hline & & $\begin{array}{c}\text { Dichotomius (Dichotomius) reclinatus } \\
\text { (Felsche, 1901) }\end{array}$ & $\begin{array}{l}\text { Esmeraldas, Cotopaxi, Guayas, Imbabura, } \\
\text { Los Ríos, Santo Domingo de los Tsáchilas }\end{array}$ & CEMT, MQCAZ, MUTPL \\
\hline & & $\begin{array}{l}\text { Dichotomius (Dichotomius) robustus } \\
\text { (Luederwaldt, 1935) }\end{array}$ & Orellana, Sucumbios & CEMT, MUTPL \\
\hline & & $\begin{array}{l}\text { Dichotomius (Dichotomius) satanas } \\
\text { angustus Luederwaldt, } 1923\end{array}$ & $\begin{array}{l}\text { Napo, Pastaza, Tungurahua, Sucumbios, } \\
\text { Zamora Chinchipe }\end{array}$ & CEMT, MECN, MUTPL \\
\hline & & $\begin{array}{c}\text { Dichotomius (Luederwaldtinia) } \\
\text { fortepunctatus (Luederwaldt, 1923) }\end{array}$ & $\begin{array}{c}\text { Carchi, Cotopaxi, Esmeraldas, Guayas, } \\
\text { Imbabura, Los Ríos, Pichincha, Santo } \\
\text { Domingo de los Tsáchilas }\end{array}$ & $\begin{array}{c}\text { CEMT, MECN, MQCAZ, } \\
\text { MUTPL }\end{array}$ \\
\hline & & $\begin{array}{c}\text { Dichotomius (Luederwaldtinia) hempeli } \\
\text { Pereira, } 1942\end{array}$ & Loja & Pereira (1942) \\
\hline & & $\begin{array}{c}\text { Dichotomius (Luederwaldtinia) } \\
\text { problematicus (Luederwaldt, 1923) }\end{array}$ & $\begin{array}{c}\text { Loja, Morona Santiago, Napo, } \\
\text { Pastaza, Sucumbios, Tungurahua, Zamora } \\
\text { Chinchipe }\end{array}$ & CEMT, MECN, MQCAZ \\
\hline & & $\begin{array}{l}\text { Dichotomius (Luederwaldtinia) } \\
\text { simplicicornis (Luederwaldt, 1935) }\end{array}$ & $\begin{array}{c}\text { Loja, Morona Santiago, Napo, Zamora } \\
\text { Chinchipe }\end{array}$ & $\begin{array}{l}\text { CEMT, MEPN, MGO.UC, } \\
\text { MQCAZ, MUTPL }\end{array}$ \\
\hline & $\begin{array}{l}\text { (Selenocopris) } \\
\text { Burmeister, } 1846\end{array}$ & $\begin{array}{c}\text { Dichotomius (Selenocopris) fonsecae } \\
\text { (Luederwaldt, 1926) }\end{array}$ & Morona Santiago, Zamora Chinchipe & CEMT, MEPN, MUTPL \\
\hline \multirow{15}{*}{\multicolumn{2}{|c|}{$\begin{array}{l}\text { Eurysternus } \\
\text { Dalman, } 1824\end{array}$}} & $\begin{array}{l}\text { Eurysternus atrosericus } \\
\text { Génier, } 2009\end{array}$ & Chimborazo, Pichincha & Génier, 2009 \\
\hline & & $\begin{array}{l}\text { Eurysternus caribaeus } \\
\quad \text { (Herbst, 1789) }\end{array}$ & $\begin{array}{c}\text { Bolívar, Carchi, Esmeraldas, } \\
\text { Imbabura, Manabí, Morona Santiago, } \\
\text { Napo, Orellana, Pastaza, Pichincha, Santa } \\
\text { Elena, Sucumbios, Tungurahua, Zamora } \\
\text { Chinchipe }\end{array}$ & $\begin{array}{c}\text { CEMT, MECN, MEPN, } \\
\text { MGO.UC, MQCAZ, MUTPL }\end{array}$ \\
\hline & & $\begin{array}{l}\text { Eurysternus cayennensis } \\
\text { Castelnau, } 1840\end{array}$ & $\begin{array}{l}\text { Morona Santiago, Napo, Orellana, } \\
\text { Pastaza, Sucumbios }\end{array}$ & CEMT, MECN, MQCAZ \\
\hline & & $\begin{array}{l}\text { Eurysternus contractus } \\
\text { Génier, } 2009\end{array}$ & $\begin{array}{l}\text { Loja, Morona Santiago, Napo, } \\
\text { Tungurahua, Zamora Chinchipe }\end{array}$ & $\begin{array}{l}\text { CEMT, MECN, MEPN, } \\
\text { MUTPL }\end{array}$ \\
\hline & & $\begin{array}{l}\text { Eurysternus foedus } \\
\text { Guérin-Méneville, } 1830\end{array}$ & $\begin{array}{c}\text { Esmeraldas, Los Ríos, Manabí, Morona } \\
\text { Santiago, Napo, Orellana, Pastaza, } \\
\text { Pichincha, Santa Elena, Santo Domingo } \\
\text { de los Tsáchilas, Sucumbios }\end{array}$ & $\begin{array}{l}\text { CEMT, MECN, MGO.UC, } \\
\text { MQCAZ, MUTPL }\end{array}$ \\
\hline & & Eurysternus hamaticollis Balthasar, 1939 & Orellana, Pastaza, Sucumbios & CEMT, MQCAZ, MUTPL \\
\hline & & $\begin{array}{l}\text { Eurysternus hypocrita } \\
\text { Balthasar, } 1939\end{array}$ & $\begin{array}{c}\text { Morona Santiago, Napo, Orellana, } \\
\text { Pastaza, Sucumbios, Zamora Chinchipe }\end{array}$ & $\begin{array}{c}\text { CEMT, MECN, MEPN, } \\
\text { MGO.UC, MQCAZ, MUTPL }\end{array}$ \\
\hline & & $\begin{array}{l}\text { Eurysternus lanuginosus } \\
\text { Génier, } 2009\end{array}$ & $\begin{array}{c}\text { Morona Santiago, Napo, Orellana, } \\
\text { Pastaza, Sucumbios, Zamora Chinchipe }\end{array}$ & $\begin{array}{l}\text { CEMT, MECN, MEPN, } \\
\text { MGO.UC, MUTPL }\end{array}$ \\
\hline & & $\begin{array}{l}\text { Eurysternus marmoreus } \\
\quad \text { Castelnau, } 1840\end{array}$ & $\begin{array}{l}\text { Cotopaxi, Napo, Pichincha, Sucumbios, } \\
\text { Tungurahua, Zamora Chinchipe }\end{array}$ & $\begin{array}{l}\text { CEMT, MECN, MQCAZ, } \\
\text { MUTPL }\end{array}$ \\
\hline & & Eurysternus plebejus Harold, 1880 & $\begin{array}{l}\text { El Oro, Esmeraldas, Imbabura, Los Ríos, } \\
\text { Manabí, Morona Santiago, Orellana, } \\
\text { Pastaza, Pichincha, Santa Elena, Santo } \\
\text { Domingo de los Tsáchilas, Sucumbios }\end{array}$ & $\begin{array}{l}\text { CEMT, MECN, MGO.UC, } \\
\text { MQCAZ, MUTPL }\end{array}$ \\
\hline & & $\begin{array}{l}\text { Eurysternus squamosus } \\
\text { Génier, } 2009\end{array}$ & Sucumbios & Génier (2009) \\
\hline & & Eurysternus streblus Génier, 2009 & Carchi, Esmeraldas & $\begin{array}{l}\text { CEMT, MECN, MQCAZ, } \\
\text { MUTPL }\end{array}$ \\
\hline & & $\begin{array}{l}\text { Eurysternus strigilatus } \\
\text { Génier, } 2009\end{array}$ & Pastaza & CEMT \\
\hline & & $\begin{array}{l}\text { Eurysternus vastiorum } \\
\text { Martínez, } 1988\end{array}$ & $\begin{array}{c}\text { Morona Santiago, Napo, Orellana, } \\
\text { Pastaza, Sucumbios }\end{array}$ & CEMT, MQCAZ, MUTPL \\
\hline & & Eurysternus wittmerorum Martínez, 1988 & Orellana, Pastaza, Sucumbios & $\begin{array}{l}\text { CEMT, MECN, MGO.UC, } \\
\text { MQCAZ, MUTPL }\end{array}$ \\
\hline \multicolumn{2}{|c|}{$\begin{array}{l}\text { Eutrichillum } \\
\text { Martínez, } 1968\end{array}$} & Eutrichillum sp. & Sucumbios & MUTPL \\
\hline
\end{tabular}




\begin{tabular}{|c|c|c|c|c|}
\hline \multicolumn{2}{|c|}{ Género-Subgénero } & Especie & Distribución & $\begin{array}{l}\text { Colección de referencia } \\
\text { y/o fuente bibliográfica }\end{array}$ \\
\hline \multicolumn{2}{|c|}{$\begin{array}{c}\text { Gromphas } \\
\text { Brullé, } 1837\end{array}$} & $\begin{array}{l}\text { Gromphas aeruginosa } \\
\quad \text { (Perty, 1830) }\end{array}$ & Orellana & MQCAZ \\
\hline \multirow{2}{*}{\multicolumn{2}{|c|}{$\begin{array}{c}\text { Homocopris } \\
\text { Burmeister, } 1846\end{array}$}} & $\begin{array}{l}\text { Homocopris achamas } \\
\text { (Harold, 1867) }\end{array}$ & Carchi, Chimborazo & CEMT, MEPN, MQCAZ \\
\hline & & Homocopris buckleyi (Waterhouse, 1891) & Loja & CEMT, MUTPL \\
\hline \multirow{2}{*}{$\begin{array}{l}\text { Malagoniella } \\
\text { Martínez, } 1961\end{array}$} & $\begin{array}{l}\text { (Malagoniella) } \\
\text { Martínez, } 1961\end{array}$ & $\begin{array}{c}\text { Malagoniella (Malagoniella) astyanax } \\
\text { polita Halffter, Pereira \& Martínez, } 1960\end{array}$ & Orellana, Sucumbios & CEMT, MQCAZ, MUTPL \\
\hline & $\begin{array}{l}\text { (Megatophomina) } \\
\text { Martínez, } 1961\end{array}$ & $\begin{array}{l}\text { Malagoniella (Megatophomina) } \\
\text { cupreicollis (Waterhouse, 1890) }\end{array}$ & Loja & CEMT, MUTPL \\
\hline \multicolumn{2}{|c|}{$\begin{array}{c}\text { Megatharsis } \\
\text { Waterhouse, } 1891\end{array}$} & Megatharsis buckleyi Waterhouse, 1891 & Morona Santiago, Napo, Orellana & CEMT, MECN, MEPN \\
\hline \multirow{3}{*}{\multicolumn{2}{|c|}{$\begin{array}{c}\text { Onoreidium } \\
\text { Vaz-de-Mello, } 2008\end{array}$}} & Onoreidium cristatum (Arrow, 1931) & Guayas, Loja & CEMT \\
\hline & & $\begin{array}{c}\text { Onoreidium howdeni } \\
\text { (Ferreira \& Galileo, 1993) }\end{array}$ & Guayas, El Oro, Santa Elena & CEMT \\
\hline & & Onoreidium ohausi (Arrow, 1931) & Loja & CEMT \\
\hline \multirow{19}{*}{$\begin{array}{c}\text { Ontherus } \\
\text { Erichson, } 1847\end{array}$} & \multirow{14}{*}{$\begin{array}{l}\text { (Caelontherus) } \\
\text { Génier, } 1996\end{array}$} & $\begin{array}{l}\text { Ontherus (Caelontherus) aequatorius } \\
\text { Bates, } 1891\end{array}$ & $\begin{array}{c}\text { Azuay, Cañar, Chimborazo, Napo, } \\
\text { Pichincha, Sucumbios, Loja, Tungurahua }\end{array}$ & Génier (1996) \\
\hline & & $\begin{array}{l}\text { Ontherus (Caelontherus) brevicollis } \\
\text { Kirsch, } 1871\end{array}$ & Provincia sin determinar & Génier (1996) \\
\hline & & $\begin{array}{c}\text { Ontherus (Caelontherus) compressicornis } \\
\text { Luederwaldt, } 1931\end{array}$ & Cañar, Carchi, Imbabura, Loja, Pichincha & CEMT, MQCAZ, MUTPL \\
\hline & & $\begin{array}{l}\text { Ontherus (Caelontherus) diabolicus } \\
\text { Génier, } 1996\end{array}$ & $\begin{array}{c}\text { Morona Santiago, Napo, Orellana, Pasta- } \\
\text { za, Sucumbios, Zamora Chinchipe }\end{array}$ & $\begin{array}{c}\text { CEMT, MECN, MEPN, } \\
\text { MGO.UC, MQCAZ, MUTPL }\end{array}$ \\
\hline & & $\begin{array}{c}\text { Ontherus (Caelontherus) hadros } \\
\text { Génier, } 1996\end{array}$ & Napo & CEMT, MUTPL \\
\hline & & $\begin{array}{c}\text { Ontherus (Caelontherus) howdeni } \\
\text { Génier, } 1996\end{array}$ & Sucumbios & CEMT \\
\hline & & $\begin{array}{c}\text { Ontherus (Caelontherus) incisus } \\
\text { (Kirsch, 1871) }\end{array}$ & Napo, Zamora Chinchipe & CEMT, MQCAZ, MUTPL \\
\hline & & $\begin{array}{c}\text { Ontherus (Caelontherus) laminifer } \\
\text { Balthasar, } 1938\end{array}$ & Orellana & MQCAZ \\
\hline & & $\begin{array}{c}\text { Ontherus (Caelontherus) magnus } \\
\text { Génier, } 1996\end{array}$ & Pichincha & Génier (1996) \\
\hline & & $\begin{array}{c}\text { Ontherus (Caelontherus) obliquus } \\
\text { Génier, } 1996\end{array}$ & Provincia sin determinar & Génier (1996) \\
\hline & & $\begin{array}{c}\text { Ontherus (Caelontherus) pilatus } \\
\text { Génier, } 1996\end{array}$ & El Oro & MUTPL \\
\hline & & $\begin{array}{c}\text { Ontherus (Caelontherus) politus } \\
\text { Génier, } 1996\end{array}$ & $\begin{array}{l}\text { Carchi, Napo, Sucumbios, Tungurahua, } \\
\text { Zamora Chinchipe }\end{array}$ & $\begin{array}{l}\text { CEMT, MECN, MQCAZ, } \\
\text { MUTPL }\end{array}$ \\
\hline & & $\begin{array}{l}\text { Ontherus (Caelontherus) tenustriatus } \\
\text { Génier, } 1996\end{array}$ & Orellana & CEMT \\
\hline & & $\begin{array}{l}\text { Ontherus (Caelontherus) trituberculatus } \\
\text { Balthasar, } 1938\end{array}$ & $\begin{array}{c}\text { Carchi, El Oro, Esmeraldas, Imbabura, } \\
\text { Pichincha }\end{array}$ & $\begin{array}{c}\text { CEMT, MECN, MQCAZ, } \\
\text { MUTPL }\end{array}$ \\
\hline & \multirow{5}{*}{$\begin{array}{c}\text { (Ontherus) } \\
\text { Erichson, } 1847\end{array}$} & $\begin{array}{c}\text { Ontherus (Ontherus) appendiculatus } \\
\text { (Mannerheim, 1829) }\end{array}$ & Provincia sin determinar & Génier (1996) \\
\hline & & Ontherus (Ontherus) azteca Harold, 1869 & Orellana & MUTPL \\
\hline & & $\begin{array}{c}\text { Ontherus (Ontherus) edentulus } \\
\text { Génier, } 1996\end{array}$ & Napo, Orellana & CEMT, MQCAZ \\
\hline & & $\begin{array}{l}\text { Ontherus (Ontherus) pubens } \\
\text { Génier, } 1996\end{array}$ & $\begin{array}{l}\text { Morona Santiago, Napo, Orellana, Pasta- } \\
\text { za, Sucumbios, Zamora Chinchipe }\end{array}$ & $\begin{array}{l}\text { CEMT, MECN, MGO.UC, } \\
\text { MUTPL }\end{array}$ \\
\hline & & $\begin{array}{l}\text { Ontherus (Ontherus) sulcator } \\
\text { (Fabricius, 1775) }\end{array}$ & Provincia sin determinar & Génier (1996) \\
\hline \multirow{3}{*}{$\begin{array}{l}\text { Onthophagus } \\
\text { Latreille, } 1802\end{array}$} & \multirow{3}{*}{$\begin{array}{l}\text { (Onthophagus) } \\
\text { Latreille, } 1802\end{array}$} & $\begin{array}{c}\text { Onthophagus (Onthophagus) acuminatus } \\
\text { Harold, } 1880\end{array}$ & $\begin{array}{l}\text { Bolívar, Carchi, Cotopaxi, El Oro, } \\
\text { Esmeraldas, Imbabura, Los Ríos, Manabí, } \\
\text { Pichincha, Santa Elena, Santo Domingo } \\
\text { de los Tsáchilas }\end{array}$ & $\begin{array}{l}\text { CEMT, MECN, MQCAZ, } \\
\text { MUTPL }\end{array}$ \\
\hline & & $\begin{array}{c}\text { Onthophagus (Onthophagus) bidentatus } \\
\text { Drapiez, } 1819\end{array}$ & Napo, Zamora Chinchipe & CEMT \\
\hline & & $\begin{array}{c}\text { Onthophagus (Onthophagus) coscineus } \\
\text { Bates, } 1887\end{array}$ & $\begin{array}{l}\text { Carchi, Esmeraldas, Santo Domingo } \\
\text { de los Tsáchilas }\end{array}$ & CEMT, MECN \\
\hline
\end{tabular}




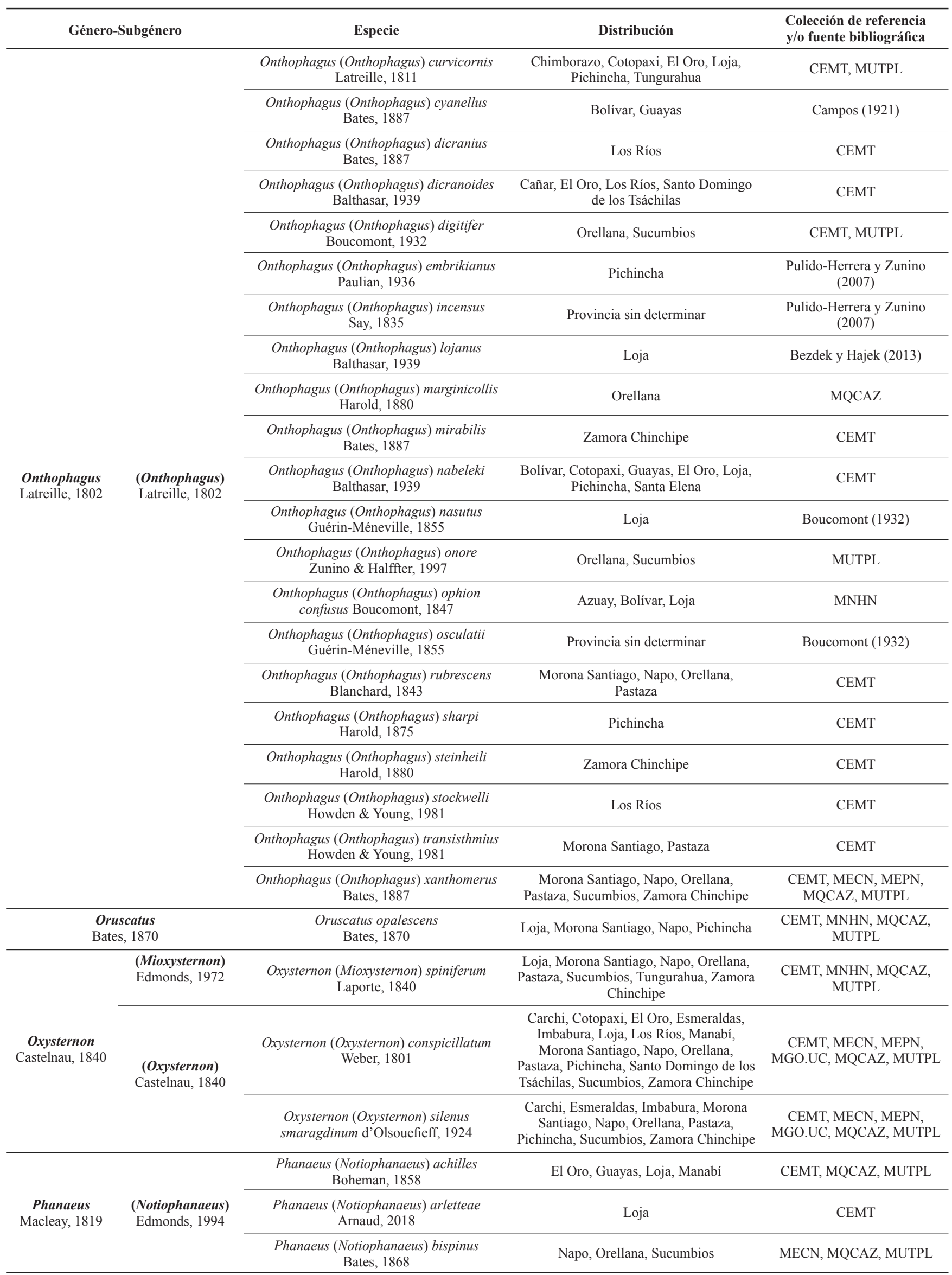




\begin{tabular}{|c|c|c|c|}
\hline Género-Subgénero & Especie & Distribución & $\begin{array}{l}\text { Colección de referencia } \\
\text { y/o fuente bibliográfica }\end{array}$ \\
\hline \multirow{5}{*}{$\begin{array}{c}\text { Phanaeus } \\
\text { Macleay, } 1819\end{array}$} & $\begin{array}{l}\text { Phanaeus (Notiophanaeus) cambeforti } \\
\text { Arnaud, } 1982\end{array}$ & Orellana, Pastaza, Sucumbios & CEMT, MQCAZ, MUTPL \\
\hline & $\begin{array}{l}\text { Phanaeus (Notiophanaeus) chalcomelas } \\
\text { (Perty, 1830) }\end{array}$ & $\begin{array}{c}\text { Morona Santiago, Napo, Orellana, } \\
\text { Pastaza, Sucumbios, Zamora Chinchipe }\end{array}$ & MECN, MQCAZ, MUTPL \\
\hline & $\begin{array}{c}\text { Phanaeus (Notiophanaeus) haroldi } \\
\text { Kirsch, } 1871\end{array}$ & $\begin{array}{c}\text { Morona Santiago, Napo, Orellana, } \\
\text { Pastaza, Sucumbios, Zamora Chinchipe }\end{array}$ & $\begin{array}{l}\text { CEMT, MECN, MGO.UC, } \\
\text { MQCAZ, MUTPL }\end{array}$ \\
\hline & $\begin{array}{c}\text { Phanaeus (Notiophanaeus) meleagris } \\
\text { Blanchard, } 1843\end{array}$ & $\begin{array}{c}\text { Loja, Morona Santiago, Napo, } \\
\text { Pastaza, Sucumbios, Tungurahua, Zamora } \\
\text { Chinchipe }\end{array}$ & MECN, MQCAZ, MUTPL \\
\hline & $\begin{array}{c}\text { Phanaeus (Notiophanaeus) pyrois } \\
\text { Bates, } 1887\end{array}$ & $\begin{array}{l}\text { Bolívar, Carchi, Esmeraldas, Guayas, } \\
\text { Imbabura, Loja, Los Ríos, Manabí, } \\
\text { Pichincha, Santa Elena, Santo Domingo } \\
\text { de los Tsáchilas }\end{array}$ & $\begin{array}{c}\text { CEMT, MECN, MQCAZ, } \\
\text { MUTPL }\end{array}$ \\
\hline $\begin{array}{c}\text { (Phanaeus) } \\
\text { Macleay, } 1819 \\
\end{array}$ & $\begin{array}{c}\text { Phanaeus (Phanaeus) lunaris } \\
\text { Taschenberg, } 1870\end{array}$ & $\begin{array}{l}\text { Azuay, Cañar, Loja, Los Ríos, Santa } \\
\text { Elena, Santo Domingo de los Tsáchilas }\end{array}$ & CEMT, MQCAZ \\
\hline \multirow{7}{*}{$\begin{array}{c}\text { Scatimus } \\
\text { Erichson, } 1847\end{array}$} & $\begin{array}{c}\text { Scatimus cribrosus } \\
\text { Génier \& Kohlmann, } 2003\end{array}$ & $\begin{array}{l}\text { Carchi, Los Ríos, Santo Domingo de los } \\
\text { Tsáchilas }\end{array}$ & CEMT \\
\hline & Scatimus fernandezi Martínez, 1988 & Orellana, Sucumbios & CEMT, MUTPL \\
\hline & Scatimus furcatus Balthasar, 1939 & Pichincha & CEMT, MQCAZ \\
\hline & Scatimus monstrosus Balthasar, 1939 & Loja & MECN, MQCAZ, MUTPL \\
\hline & $\begin{array}{c}\text { Scatimus onorei } \\
\text { Génier \& Kohlmann, } 2003\end{array}$ & El Oro, Loja & CEMT, MUTPL \\
\hline & $\begin{array}{c}\text { Scatimus pacificus } \\
\text { Génier \& Kohlmann, } 2003\end{array}$ & Guayas, Manabí & Génier y Kohlmann (2003) \\
\hline & Scatimus strandi Balthasar, 1939 & $\begin{array}{l}\text { Morona Santiago, Napo, Pastaza, } \\
\text { Tungurahua, Zamora Chinchipe }\end{array}$ & MECN, MQCAZ, MUTPL \\
\hline \multirow{4}{*}{$\begin{array}{l}\text { Scybalocanthon } \\
\text { Martínez, } 1948\end{array}$} & $\begin{array}{l}\text { Scybalocanthon kaestneri } \\
\text { (Balthasar, 1939) }\end{array}$ & Morona Santiago, Napo, Pastaza & $\begin{array}{l}\text { CEMT, MECN, MQCAZ, } \\
\text { MUTPL }\end{array}$ \\
\hline & $\begin{array}{l}\text { Scybalocanthon maculatus } \\
\text { (Schmidt, 1920) }\end{array}$ & $\begin{array}{l}\text { Napo, Pastaza, Tungurahua, Sucumbios, } \\
\text { Zamora Chinchipe }\end{array}$ & CEMT, MQCAZ, MUTPL \\
\hline & $\begin{array}{l}\text { Scybalocanthon moniliatus } \\
\text { (Bates, 1887) }\end{array}$ & Cotopaxi & MQCAZ \\
\hline & $\begin{array}{l}\text { Scybalocanthon trimaculatus } \\
\text { (Schmidt, 1922) }\end{array}$ & $\begin{array}{c}\text { Cañar, Carchi, Cotopaxi, Esmeraldas, } \\
\text { Imbabura, Los Ríos, Pichincha, Santo } \\
\text { Domingo de los Tsáchilas }\end{array}$ & $\begin{array}{l}\text { CEMT, MECN, MGO.UC, } \\
\text { MQCAZ, MUTPL }\end{array}$ \\
\hline $\begin{array}{c}\text { Sinapisoma } \\
\text { Boucomont, } 1928\end{array}$ & Sinapisoma sp. & Orellana & MUTPL \\
\hline $\begin{array}{c}\text { Streblopus } \\
\text { Lansberge, } 1874\end{array}$ & Streblopus punctatus Balthasar, 1938 & Zamora Chinchipe & CEMT, MEPN, MUTPL \\
\hline \multirow{3}{*}{$\begin{array}{l}\text { Sulcophanaeus } \\
\text { d'Olsoufieff, } 1924\end{array}$} & $\begin{array}{l}\text { Sulcophanaeus faunus } \\
\quad \text { (Fabricius, 1775) }\end{array}$ & Provincia sin determinar & $\mathrm{MECN}$ \\
\hline & $\begin{array}{l}\text { Sulcophanaeus miyashitai } \\
\text { Arnaud, } 2002\end{array}$ & Carchi, Esmeraldas, Imbabura, Los Ríos & $\begin{array}{c}\text { CEMT, MECN, MGO.UC, } \\
\text { MQCAZ }\end{array}$ \\
\hline & $\begin{array}{l}\text { Sulcophanaeus velutinus } \\
\text { (Murray, 1856) }\end{array}$ & Imbabura, Pichincha & CEMT, MQCAZ, MUTPL \\
\hline $\begin{array}{c}\text { Sylvicanthon } \\
\text { Halffter \& Martínez, } 1977\end{array}$ & $\begin{array}{l}\text { Silvicanthon bridarollii } \\
\text { Martínez, } 1948\end{array}$ & Pastaza & MGO.UC \\
\hline $\begin{array}{c}\text { Trichillidium } \\
\text { Vaz-de-Mello, } 2008\end{array}$ & $\begin{array}{l}\text { Trichillidium pilosum } \\
\quad \text { (Robinson, 1948) }\end{array}$ & $\begin{array}{l}\text { Esmeraldas, Los Ríos, Pichincha, Santo } \\
\text { Domingo de los Tsáchilas }\end{array}$ & CEMT, MEPN, MUTPL \\
\hline \multirow{9}{*}{$\begin{array}{c}\text { Uroxys } \\
\text { Westwood, } 1842\end{array}$} & Uroxys elongatus Harold, 1868 & Carchi, Imbabura, Pichincha & CEMT, MNHN, MUTPL \\
\hline & Uroxys frankenbergeri Balthasar, 1940 & Loja & Bezdek y Hajek (2011) \\
\hline & Uroxys gorgon Arrow, 1933 & Manabí & MQCAZ \\
\hline & Uroxys latesulcatus Bates, 1891 & Bolívar, Cotopaxi, Imbabura, Pichincha & CEMT, MQCAZ, MUTPL \\
\hline & Uroxys lojanus Arrow, 1933 & Loja & Bacchus (1978) \\
\hline & Uroxys magnus Balthasar, 1940 & Provincia sin determinar & Bezdek y Hajek (2011) \\
\hline & Uroxys monstruosus Balthasar, 1940 & Bolívar, Cañar & CEMT, MQCAZ \\
\hline & Uroxys monstruosus Balthasar, 1940 & Bolívar, Cañar & CEMT, MQCAZ \\
\hline & Uroxys ohausi (Balthasar, 1938) & Loja & CEMT \\
\hline
\end{tabular}




\begin{tabular}{|c|c|c|c|}
\hline Género-Subgénero & Especie & Distribución & $\begin{array}{l}\text { Colección de referencia } \\
\text { y/o fuente bibliográfica }\end{array}$ \\
\hline \multirow{5}{*}{$\begin{array}{c}\text { Uroxys } \\
\text { Westwood, } 1842\end{array}$} & Uroxys pauliani Balthasar, 1940 & Cotopaxi, Imbabura & CEMT \\
\hline & Uroxys rugatus Boucumont, 1928 & Loja, Zamora Chinchipe & CEMT, MQCAZ, MUTPL \\
\hline & Uroxys spaethi Balthasar, 1940 & Tungurahua & CEMT \\
\hline & Uroxys sulcicollis Harold, 1880 & Cañar & CEMT, MQCAZ \\
\hline & Uroxys sulai Balthasar, 1940 & Guayas & Bezdek y Hajek (2011) \\
\hline
\end{tabular}

\section{Agradecimientos}

El primer autor agradece a la beca de maestría OEA-GCUB en la Universidade Federal de Mato Grosso. También se agradece de manera especial a los revisores de este trabajo. En Ecuador a la Universidad Técnica Particular de Loja UTPL especialmente a Carlos Naranjo, Augusta Cueva y a Carlos Iván Espinosa por la realización del curso Identificación de Scarabaoidea Neotropicales en 2012. A CNPq 306745/20160 en Brasil y la Corporación Senderos de Ecuador con sus directivos Cecilia Ortega, Isabel Ortega y Cesar Moreno por el apoyo y financiación. A Santiago Villamarín (MECN), Vladimir Carvajal (MEPN), Fabiola Montenegro (MGO-UCE), Olivier Montreuil y Antoine Mantilleri (MNHN), María Fernanda Salazar, Carlos Carpio y Álvaro Barragán (MQCAZ) por facilitar algunos especímenes revisados en este trabajo. A Ferley Chamorro por la diagramación de las figuras y finalmente a Daniel Holm y Juan Vieira por la revisión del abstract.

\section{Literatura citada}

ARNAUD, P. 1996. Description d'une nouvelle espèce de Coprophanaeus du Brèsil. Besoiro 2: 6-7.

ARNAUD, P. 2002. Les Coléoptères du Monde, Vol. 28. Phanaeini. Dendropaemon, Tetramereia, Homalotarsus, Megatharsis, Diabroctis, Coprophanaeus, Oxysternon, Phanaeus, Sulcophanaeus. Hillside Books, Canterbury, Inglaterra. $151 \mathrm{p}$.

BACCHUS, M. E. 1978. A catalogue of the type-specimens of the Scarabaeinae (Scarabaeidae) and the smaller Lamellicorn families (Coleoptera) described by G. J. Arrow. Bulletin of the British Museum 37 (3): 97-115.

BALTHASAR, V. 1939a. Neue Canthidium arten Entomologische Nachrichten. Berlin 13 (3-4): 111-140.

BALTHASAR, V. 1939b. Eine Vorstudie zur Monographie der Gattung Canthon Hffsg. Folia Zoologica et Hydrobiologica, Riga 9 (2): 179-238.

BEZDEK, A.; HAJEK, J. 2011. Catalogue of type specimens of beetles (Coleoptera) deposited in the National Museum, Prague, Czech Republic. Acta Entomologica Musei Nationalis Pragae 51 (1): 349-378.

BEZDEK, A.; HAJEK, J. 2012. Catalogue of type specimens of beetles deposited in the National Museum, Prague, Czech Republic. Scarabaeidae: Scarabaeinae: Coprini, Eurysternini, Gymnopleurini and Oniticellini. Acta Entomologica Musei Nationalis Pragae 52 (1): 297-334.

BEZDEK, A.; HAJEK, J. 2013. Catalogue of type specimens of beetles deposited in the National Museum, Prague, Czech Republic. Scarabaeidae: Scarabaeinae: Onitini, Onthophagini, Phanaeini, Scarabaeini and Sisyphini. Acta Entomologica Musei Nationalis Pragae 53 (1): 387-442.

BLACKWELDER, R. E. 1944. Checklist of the coleopterous insects of Mexico, Central America, the West Indies, and South America. Part 2. United States National Museum Bulletin 185: 189-341.

BOUCOMONT, A. 1932. Synopsis des Onthophagus d'Amérique du Sud (Col. Scarab.). Annales de la Société Entomologique de France 101: 293-332.
CAMPOS, F. 1921. Estudios sobre la fauna entomológica del Ecuador. Revista del Colegio Nacional Vicente Rocafuerte 6: 26-100.

CANHEDO, V. L. 2006. Revisão taxonômica do gênero Anomiopus Westwood, 1842 (Coleoptera, Scarabaeidae, Scarabaeinae). Archivos de Zoologia 37: 349-502.

CARPIO, C.; DONOSO, D.; RAMÓN, G.; DANGLES, O. 2009. Short term response of dung beetles communities to disturbance by road construction in the Ecuadorian Amazon. Annales de la Société Entomologique de France 4: 455-469.

CARVAJAL, V.; VILLAMARÍN, S.; ORTEGA, A. M. 2011. Escarabajos del Ecuador. Principales Géneros. Instituto de Ciencias Biológicas. Escuela Politécnica Nacional. Serie Entomología, Nro. 1. Quito, Ecuador. 350 p.

CELI, J.; DÁVALOS, A. 2001. Manual de monitoreo. Los escarabajos peloteros como indicadores de la calidad ambiental. EcoCiencia, Quito, Ecuador. 71 p.

CELI, J.; TERNEUS, L.; TORRES, J.; ORTEGA, M. 2004. Dung beetles (Coleoptera: Scarabaeinae) diversity in an altitudinal gradient in the Kutukú Range, Morona Santiago, Ecuadorian Amazon. Lyonia 7 (2): 37-52.

COOK, J. 1998. A revision of the Neotropical genus Bdelyrus Harold (Coleoptera: Scarabaeidae). Canadian Entomologist 130: 631-689.

COOK, J. 2000. Four new species of Bdelyrus (Coleoptera, Scarabaeidae, Scarabaeinae) and a redescription of Bdelyrus lagopus. Canadian Entomologist 132: 551-565.

COOK, J. 2002. A revision of the Neotropical genus Cryptocanthon Balthasar (Coleoptera: Scarabaeidae: Scarabaeinae). Coleopterists Society Monographs, Patricia Vaurie Series 1: 1-96.

CUPELLO, M. 2018. On the types species of the New World dung beetle genus Canthidium Erichson, 1847 (Coleoptera: Scarabaeidae: Scarabaeinae), with an annotated checklist of species. Zootaxa 4388 (4): 451-486. http://dx.doi.org/10.11646/zootaxa.4388.4.1.

CUPELLO, M.; GÉNIER, F. 2017. Dendropaemon Perty, 1830 nomenclature revisited: on the unavailability of "Onthoecus Lacordaire, 1856" (Coleoptera: Scarabaeidae: Scarabaeinae: Phanaeini). The Coleopterists Bulletin 71 (4): 821-824. https://doi. org/10.1649/0010-065X-71.4.821.

CUPELLO, M.; VAZ-DE-MELLO, F. Z. 2013. Taxonomic revision of the South American dung beetle genus Gromphas Brullé, 1837 (Coleoptera: Scarabaeidae: Scarabaeinae: Phanaeini: Gromphadina). Zootaxa 3722 (4): 439-482. http://dx.doi. org/10.11646/zootaxa.3722.4.2.

DOMINGUEZ, D.; MARÍN-ARMIJOS, D.; RUÍZ, C. 2015. Structure of dung beetle communities in an altitudinal gradient of Neotropical dry forest. Neotropical Entomology 44 (1): 40-46. http://dx.doi.org/10.1007/s13744-014-0261-6.

EDMONDS, W. D. 1994. Revision of Phanaeus Macleay, a New World genus of scarabaeine dung beetles (Coleoptera: Scarabaeidae, Scarabaeinae). Natural History Museum of Los Angeles County Contributions in Science 443: 1-105.

EDMONDS, W. D. 2000. Revision of the Neotropical dung beetle genus Sulcophanaeus (Coleoptera-Scarabaeidae, Scarabaeinae). Folia Heyrovskyana. Supplementum 6: 1-60.

EDMONDS, W. D.; ZIDEK, J. 2004. Revision of the Neotropical dung beetle genus Oxysternon (Scarabaeidae: Scarabaeinae: Phanaeini). Folia Heyrovskyana. Supplementum 11: 1-58. 
EDMONDS, W. D.; ZIDEK, J. 2010. A taxonomic review of the Neotropical genus Coprophanaeus Olsoufieef, 1924 (Scarabaeidae: Scarabaeidae: Scarabaeinae). Insecta Mundi 0129: 1-111.

EDMONDS, W. D.; ZÍDEK, J. 2012. Taxonomy of Phanaeus revisited: Revised keys to and comments on species of the New World dung beetle genus Phanaeus MacLeay, 1819 (Coleoptera: Scarabaeidae: Scarabaeinae: Phanaeini). Insecta Mundi 0274: 1-108.

FAVILA, M. E.; HALFFTER, G. 1997. The use of indicador groups for measuring biodiveristy as related to community structure and function. Acta Zoologica Mexicana 72: 1-25.

FIGUEROA, L.; EDMONDS, W. D.; MARTÍNEZ, N. 2014. La tribu Phanaeini (Coleoptera, Scarabaeidae, Scarabaeinae) en el Perú. Revista Peruana de Biología 21 (2): 125-138. http:// dx.doi.org/10.15381/rpb.v21i2.9815.

GEMMINGER, M.; HAROLD, E. V. 1869. Catalogous Scarabaeidae. Catalogous Coleopterorum hucusque descriptorum synonymicus et systematicus. Sumptu E. H. Gummi, Munich. Tom IV: 979-1346.

GÉNIER, F. 1996. A revision of the Neotropical genus Ontherus Erichson (Coleoptera: Scarabaeidae, Scarabaeinae). Memoirs of the Entomological Society of Canada 170: 1-169.

GÉNIER, F. 2009. Le genre Eurysternus Dalman, 1824 (Scarabaeidae: Scarabaeinae: Oniticellini), révision taxonomique et clés de détermination illustrées. Pensoft Publishers, Sofia. 430 p.

GÉNIER, F. 2010. A review of the neotropical dung beetle genera Deltorhinum Harold, 1869, and Lobidion gen. nov. Zootaxa 2693: 35-48.

GÉNIER, F. 2012. A new species and notes on the subgenus Deltochilum (Deltochilum) Eschscholtz, 1822 (Coleoptera: Scarabaeidae: Scarabaeinae: Deltochilini). Zootaxa 3357: 25-36.

GÉNIER, F.; ARNAUD, P. 2016. Dendropaemon Perty, 1830: taxonomy, systematics and phylogeny of the morphologically most derived phanaeine genus (Coleoptera: Scarabaeidae, Scarabaeinae, Phanaeini). Zootaxa 4099 (1): 001-125. http://dx.doi. org/10.11646/zootaxa.4099.1.1.

GÉNIER, F.; KOHLMANN, B. 2003. Revision of the Neotropical dung beetle genera Scatimus Erichson and Scatrichus gen. nov. (Coleoptera: Scarabaeidae: Scarabaeinae). Fabreries 28 (2): 57-111.

GILLET, J. J. E. 1911. Coleopterorum Catalogus. Pars 38: Scarabaeidae: Coprinae I. W. Junk, Berlin, Alemania. 100 p.

GONZÁLEZ A., F. A.; MOLANO R., F.; MEDINA U., C. A. 2009. Los subgéneros Calhyboma, Hybomidium y Telhyboma (Coleoptera: Scarabaeidae: Scarabaeinae: Deltochilum) en Colombia. Revista Colombiana de Entomología 35 (2): 253-274.

GONZÁLEZ-ALVARADO, A.; VAZ-DE-MELLO, F. Z. 2014. Taxonomic review of the subgenus Hybomidium Shipp, 1897 (Coleoptera: Scarabaeidae: Scarabaeinae: Deltochilum). Annales de la Société Entomologique de France (N. S.). International Journal of Entomology 50 (3-4): 431-476. http://dx.doi.org/10.1 080/00379271.2014.989178.

HALFFTER, G.; MARTÍNEZ, A. 1966. Revisión monográfica de los Canthonina americanos (Coleoptera, Scarabaeidae) (Ia parte). Revista de la Sociedad Mexicana de Historia Natural 2: 89-177.

HAMEL-LEIGUE, A.; MANN, D. J.; VAZ-DE-MELLO, F. Z.; HERZOG, S. K. 2006. Hacia un inventario de los escarabajos peloteros (Coleoptera: Scarabaeinae) de Bolivia: primera compilación de los géneros y especies registrados para el país. Revista Boliviana de Ecología y Conservación Ambiental 20: 1-18.

HOWDEN, H. F.; YOUNG, O. P. 1981. Panamanian Scarabaeinae: taxonomy, distribution and habits (Coleoptera, Scarabaeidae). Contributions of the American Entomological Institute 18 (1): 1-204.

KRAJCIK, M. 2012. Checklist of the World Scarabaeoidea. Animma X supplement 5: 1-278.

LUEDERWALDT, H. 1925. Novas especies do gênero Pinotus (Coleoptera-Lamellicornidae- Coprinae). Revista do Museo Paulista 2 (1): 67-69.

MARTÍNEZ, A.; HALFFTER, G. 1986. Situacion del género Canthidium. Acta Zoológica Mexicana 18: 19-40.
MEDINA, C. A.; LOPERA-TORO, A.; VITOLO, A.; GILL, B. D. 2001. Escarabajos coprófagos de Colombia. Biota Colombiana 2 (2): 131-144.

MINISTERIO DEL AMBIENTE DEL ECUADOR. 2013. Sistema de clasificación de los ecosistemas del Ecuador continental. Subsecretaria de patrimonio natural, Quito, Ecuador. $232 \mathrm{p}$.

OCAMPO, F. C. 2010. A revision of the Argentinean endemic genus Eucranium Brullé with description of one new species and new synonymies. Journal of Insect Science 10 (205): 1-25.

PAULIAN, R. 1939. Contribution à l'étude des Canthonides américains (Coleopt. Lamellic.) Annales de la Société de France 108: 1-48.

PECK, S. B. 2005. The beetles of the Galápagos Islands, Ecuador; evolution, ecology, and diversity (Insecta: Coleoptera). NRC Research Press, Ottawa, Ontario, Canadá. 302 p.

PEREIRA, F. S. 1942. Pinotus da secção semiaeneus. Arquivos do Museu Paranaense 2: 35-60.

PEREIRA, F. S.; D'ANDRETTA, M. A. V. 1955. The species of Deltochilum of the subgenus Calhyboma Kolbe. Revista Brasiliera Entomologica 4: 7-50.

PUKER, A.; CORREA, C. M. A.; KORASAKI, V. 2014. Deltochilini and Phanaeini dung beetles (Coleoptera: Scarabaeidae: Scarabaeinae) in introduced and native ecosystems of Brazil. Journal of Natural History 48 (35-46): 2105-2116. http://dx.doi. org/10.1080/00222933.2014.908969.

PULIDO-HERRERA, L. A.; ZUNINO, M. 2007. Catálogo preliminar de los Onthophagini de America. pp. 93-129. En: Zunino, M.; Melic, A. (Eds.). Escarabajos, diversidad y conservación biológica. Ensayos en homenaje a Gonzalo Halffter. Volumen 7. Monografías Tercer Milenio $\mathrm{m} 3 \mathrm{~m}$. Sociedad Entomológica Aragonesa. Zaragoza. España. 210 p.

RATCLIFFE, B. C. 2002. A checklist of the Scarabaeoidea of Panama. Zootaxa 32: 1-48.

RATCLIFFE, B. C.; SMITH, A. B. 1999. New species of Canthonella Chapin (Scarabaeidae: Scarabaeinae) from Amazonian Brazil. Coleopterists Bulletin 53: 1-7.

SCHMIDT, A. 1922. Bestimungstabelle der mir bekannten Canthon-Arten. 2: Verbretungsgebiete de Canthon-arten. 3: Neubeschreibungen von Canthon), Saprosites, Mendidius, Euparia und Ataenius. Archiv für Naturgeschichte. 88: 61-103.

SILVA, F.; LOUZADA, J.; VAZ-DE-MELLO, F. Z. 2015. A revision of the Deltochilum subgenus Aganhyboma Kolbe, 1893 (Coleoptera: Scarabaeidae: Scarabaeinae). Zootaxa 3925 (4): 451-504. http://dx.doi.org/10.11646/zootaxa.3925.4.1

VAZ-DE-MELLO, F. Z. 2008. Synopsis of the new subtribe Scatimina (Coleoptera: Scarabaeidae: Ateuchini), with descriptions of twelve new genera and review of Genieridium, new genus. Zootaxa 1955: 1-75.

SOLÍS, Á.; KOHLMANN, B. 2012. Checklist and distribution atlas of the Scarabaeinae of Costa Rica. Zootaxa 3482: 1-32.

VAZ-DE-MELLO, F. Z. 2000. Estado atual de conhecimentos dos Scarabaeidae s. str. (Coleoptera: Scarabaeoidea) do Brasil. pp. 183-195. En: Martín-P., F.; Morrone, J. J.; Melic, A. (Eds.). Hacia un proyecto CYTED para el inventario y estimación de la diversidad entomológica en Iberoamérica: PRIBES-2000. Volumen 1. Monografías Tercer Milenio m3m. Sociedad Entomológica Aragonesa. Zaragoza. España. 326 p.

VAZ-DE-MELLO, F. Z.; EDMONDS, W. D.; OCAMPO, F. C.; SCHOOLMEESTERS, P. 2011. A multilingual key to the genera and subgenera of the subfamily Scarabaeinae of the New World (Coleoptera: Scarabaeidae). Zootaxa 2854: 1-73.

Recibido: 2-nov-2016 • Aceptado: 9-nov-2017

Citación sugerida:

CHAMORRO, W.; MARÍN-ARMIJOS, D.; GRANDA, V.; VAZDE-MELLO, F. Z. 2018. Listado de especies y clave de géneros y subgéneros de escarabajos estercoleros (Coleoptera: Scarabaeidae: Scarabaeinae) presentes y presuntos para Ecuador. Revista Colombiana de Entomología 44 (1): 72-100. Enero - Junio 2018. 